\title{
Application and validation of near infrared- spectroscopy to monitor cerebral oxygenation, perfusion and metabolism in the rat
}

Citation for published version (APA):

de Visscher, G. (2002). Application and validation of near infrared-spectroscopy to monitor cerebral oxygenation, perfusion and metabolism in the rat. [Doctoral Thesis, Maastricht University]. Universiteit Maastricht. https://doi.org/10.26481/dis.20020627gv

Document status and date:

Published: 01/01/2002

DOI:

10.26481/dis.20020627gv

Document Version:

Publisher's PDF, also known as Version of record

\section{Please check the document version of this publication:}

- A submitted manuscript is the version of the article upon submission and before peer-review. There can be important differences between the submitted version and the official published version of record.

People interested in the research are advised to contact the author for the final version of the publication, or visit the DOI to the publisher's website.

- The final author version and the galley proof are versions of the publication after peer review.

- The final published version features the final layout of the paper including the volume, issue and page numbers.

Link to publication

\footnotetext{
General rights rights.

- You may freely distribute the URL identifying the publication in the public portal. please follow below link for the End User Agreement:

www.umlib.nl/taverne-license

Take down policy

If you believe that this document breaches copyright please contact us at:

repository@maastrichtuniversity.nl

providing details and we will investigate your claim.
}

Copyright and moral rights for the publications made accessible in the public portal are retained by the authors and/or other copyright owners and it is a condition of accessing publications that users recognise and abide by the legal requirements associated with these

- Users may download and print one copy of any publication from the public portal for the purpose of private study or research.

- You may not further distribute the material or use it for any profit-making activity or commercial gain

If the publication is distributed under the terms of Article $25 \mathrm{fa}$ of the Dutch Copyright Act, indicated by the "Taverne" license above, 


\section{Application and validation of near infrared-spectroscopy to monitor cerebral oxygenation, perfusion and metabolism in the rat.}

\section{Proefschrift}

ter verkrijging van de graad van doctor aan de Universiteit Maastricht,

op gezag van de Rector Magnificus,

Prof. dr. A. C. Nieuwenhuijzen Kruseman,

volgens het besluit van het College van Decanen,

in het openbaar te verdedigen op donderdag 27 juni 2002 om 12u

door

Geofrey De Visscher 


\section{Promotores}

Prof. dr. M. Borgers

Prof. dr. R. S. Reneman

\section{Co-promotor}

Dr. K. A. van Rossem (Janssen Pharmaceutica, Beerse, België)

\section{Beoordelingscommissie}

Prof. dr. F.C.S. Ramaekers (Voorzitter)

Dr. C.E. Elwell (University College London)

Prof. dr. C. Ince (Universiteit van Amsterdam)

Dr. F. Prinzen

Prof. dr. D. Slaaf

The investigations described in this thesis were carried out at the department of Life Science, Janssen Research Foundation, Beerse, Belgium.

This study was financially supported by the Janssen Research Foundation. 
Voor Nérée 
(C) 2002 Geofrey De Visscher

Vormgeving: www.nuleen.be

ISBN 90-9015949-5

D/2002/Geofrey De Visscher, uitgever 
Chapter 1

Introduction

\section{Chapter 2}

Nitric oxide does not inhibit cerebral cytochrome oxidase 'in vivo' or in the reactive hyperaemic phase post brief anoxia in the adult rat

\section{Chapter 3}

Cerebral blood flow assessment with indocyanine green bolus transit detection by near-infrared spectroscopy in the rat

\section{Chapter 4}

Assessment of regional cerebral blood flow at various time points in the same rat by means of fluorescent microspheres

\section{Chapter 5}

Validation of CBF assessment by means of indocyanine green bolus transit detection with NIRS: a comparison with coloured microsphere flowmetry

\section{Chapter 6}

Comparison between intracranial pressure measured in the cerebral cortex and the cerebellum of the rat

\section{Chapter 7}

Assessment of saturation with oxygen of cerebral venous blood and estimation of the cerebral metabolic rate of oxygen in rats using near infrared spectroscopy

\section{Chapter 8}

Discussion and future prospects

\section{Summary}

Samenvatting

Dankwoord 

Chapter 1

Introduction 


\section{Basic aspects of near infra-red spectroscopy}

Jöbsis (1977) first made use of the relative transparency of brain tissue to the wavelengths of light ranging from 700 to $1000 \mathrm{~nm}$ to measure tissue oxygenation and circulatory parameters non-invasively. Since then this technique, known as near-infrared spectroscopy (NIRS), has been further developed for use in both experimental and clinical conditions to monitor oxygenation of blood and tissue. Related applications in brain include the measurement of cerebral blood flow in adults (Olsen et al., 1996) and preterm infants (Edwards et al., 1988), detection of intracranial haematomas after head injury (Robertson et al., 1995), functional imaging in adults (Villringer et al., 1993; Tamura et al., 1997), quantitation of cerebral blood volume in infants (Wyatt et al., 1990) and measurement of mitochondrial dysfunction via the cytochrome oxidase signal (Cooper et al., 1999).

Different NIRS systems exist, but they are all based on the same physical principles. The most important one is the general principle of absorption, stating that the intensity of light passing through a solution containing a chromophore becomes reduced. The relationship between the variables contributing to this reduction is given in the Beer-Lambert equation:

$$
\log \left[\frac{I_{0}}{I}\right]=\alpha . c . d
$$

Where $\mathrm{I}_{0} / \mathrm{I}$ is the ratio of the light intensity entering to emerging from the solution, $\alpha$ is the extinction coefficient, $\mathrm{c}$ is the chromophore concentration and $\mathrm{d}$ the thickness of the solution as illustrated in figure 1 .

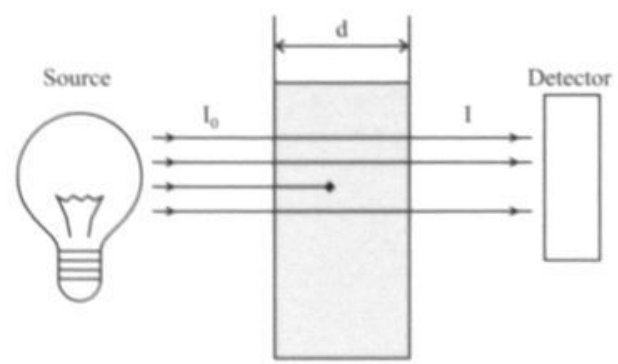

Figure 1. Light absorption as it occurs in a non scattering solution. The difference between the inciding $\left(\mathrm{I}_{0}\right)$ and emerging (I) light intensity is measured by the detector. When the thickness of the solution (d) is known the Beer-Lambert law allows calculation of the chromophore concentration. - represents a light absorbing compound. (adapted from: OwenReece et al., 1999) 
This equation introduces us into the simplest form of spectroscopy, often used in research laboratories as colorimetric spectrophotometry for the direct or indirect determination of proteins, RNA, and many more. The use of this form of spectrometry in tissue is impossible because tissue is a highly light scattering medium. Scattering occurs at the boundary of two media with different diffraction coefficients and causes the light to bend away from its linear path. Such boundaries are present in the brain at both macroscopic and microscopic level; ventricle-brain tissue and cytoplasm-cell membrane boundary, respectively (Elwell, 1995). As illustrated in figure 2, scattering causes two major deviations from the Beer-Lambert law. The first is that reduction of the light is not entirely caused by absorption but that an unknown amount is lost by scattering. The second scattering effect is an unknown increase in the pathlength of the light travelling through the tissue. Looking back at the Beer-Lambert equation it becomes eminent that both $\mathrm{I}_{0} / 1$ and $\mathrm{d}$ are disturbed by the scattering phenomenon.

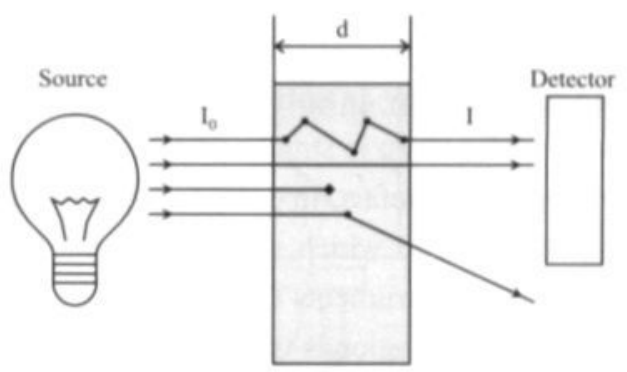

Figure 2. Light loss and absorption as it occurs in a scattering solution. The difference between the inciding $\left(\mathrm{I}_{0}\right)$ and emerging (I) light intensity is measured by the detector, but loss of light is caused by either a light absorbing compound $(\bullet)$ or scattering out of the detectors range (lower line). Besides loss of light scattering can also cause an increase of the light pathway (upper line). (adapted from: Owen-Reece et al., 1999)

The ratio of the actual distance the light travels through the medium to the thickness is expressed as the differential pathlength factor (DPF). Different methods for the assessment of this factor exist. Time of flight experiments use the delay of detection caused by such a medium to calculate DPF and optical pathlength (Delpy et al., 1988). Another method which will be extensively discussed below is the use of the absorption of water in the tissue to asses the DPF. The equation looks as follows:

$$
\mathrm{DPF}=\frac{\mathrm{d}_{\mathrm{r}}}{\mathrm{d}}
$$


where $d_{r}$ is the real distance and $d$ the thickness of the solution. In the human head the DF is accepted to be 6.3 (Duncan et al., 1995), whereas in the rat brain it is somewhat smaler, approximately 4.4 (Cope et al., 1989). Knowing the DPF and assuming that the contributionof scattering to the light intensity decrease remains the same it is possible to calculate the chanes in concentration of the chromophores in micromolar.

The chromophores generally studied in NIRS are oxyhaemoglobin, deoxyhaemoglobin ad oxidised $\mathrm{Cu}_{A}$ (cytochrome oxidase redox state), which all have a characteristic absorpton spectrum in the near infrared range (Wray et al., 1988). Changes in the concentration of oxyhaemoglobin and deoxyhaemoglobin can then be used for the calculation of the changesn the concentration of total haemoglobin. These variables are indicators for the blood and oxygn supply to the brain and can be used to assess cerebral blood volume (Wyatt et al., 1990). The $\mathrm{A}_{\text {A }}$ group is the prosthetic $\mathrm{Cu}$-Cu-group (Tsukihara et al., 1995) within cytochrome oxidase that hs an absorption band in the NIR-spectrum when oxidised and so changes in its oxidation state cn be measured by near-infrared spectroscopy. In normal brain tissue the cytochrome componentof the attenuation spectrum in the NIR region is small compared to that from haemoglobin and so the cytochrome signal is vulnerable to artefact. In order to measure changes in the $\mathrm{Cu}_{\mathrm{A}}$ oxidation state, a full spectral NIR system is used which is more robust in separating the cytochrome oxidase signal than four-wavelength instruments (Matcher et al., 1995). Another chromophore showing a strong absorption within this region is water, which has an absorption peak at $975 \mathrm{~nm}$ (Cope et al., 1989). Combined with the assumption of an $85 \%$ water content, this feature can then be used to calculate the actual pathlength.

Different algorithms have been developed for deconvolution of the chromophores. In 1995 Matcher and co-workers described a performance comparison of some of these algorithms. The algorithms compared used a different number of wavelength, 3, 4, 6 and 112, to calculate the changes in the concentration of oxyhaemoglobin, deoxyhaemoglobin and $\mathrm{Cu}_{A}$. From this study it was concluded that substantial differences can arise when different algorithms were used in deconvoluting the same in vivo data set and that this was particularly the case for the $\mathrm{Cu}_{\mathrm{A}}$ signal. They also state, based on the route mean square of the $\mathrm{Cu}_{A}$ signal, that the use of a multi wavelength system may be useful to decrease the distortions on the signal caused by tissue scattering.

For further information the reader is referred to the review by Owen-Reece et al., 1999. 


\section{The actual NIRS system as used in our studies}

The multi wavelength NIRS system and algorithms used were all developed at the Department of Medical Physics and Bioengineering, University College London. A clear description of the CCD based spectrophotometer (figure 3 ) has been provided by Cope and co-workers (1989). In short the transmitted light is collected in a grid-based spectrograph that disperses the light in order to obtain a spectrum. This spectrum is then projected onto a cooled CCD camera, detecting the intensity for each wavelength. These data are then transferred to a computer for the deconvolution.

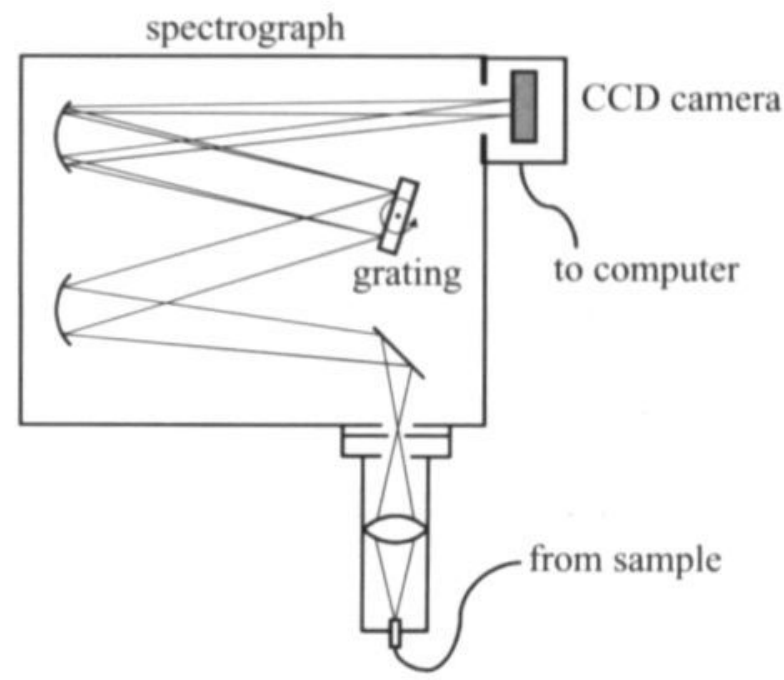

Figure 3. Schematic diagram of the CCD spectroscopy system for tissue oxygenation measurements (adapted from Cope et al., 1989)

Since the publication of the systems set up some additions and further developments have been made. Figure 4 is a schematic representation of our current system. A $100 \mathrm{~W}$ halogen lamp is used as a light source and a cut off filter is used to reduce heat transduction along the emitting fibre or optode. The emitting optode is placed on one side of the head and the receiving one on the other side. This configuration allows us to measure the whole brain in transmission mode. The light from the receiving optode is converted to an electric signal using the same setup as described above. The current software then allows on line deconvolution of the spectra, thus allowing immediate NIRS monitoring. One of the additions in our system is the computer controlled breathing gas blender, based on the one described by Elwell and co-workers (1994). This system allows rapid and accurate breathing gas mixture switching and is programmable in advance, thus following the same protocol for each individual animal. As marked on the diagram, in general isoflurane was used as an anaesthetic but the system is easily adaptable to other anaesthetics. 
The chromophores listed next to the controlling computer include indocyanine green (ICG). The detection of this chromophore is a further development which will be described below. Te system time resolution depends on the controlling computer and our system allowed to measure at $10 \mathrm{~Hz}$ or lower. To achieve better time resolution NIR spectra were collected contiguously ad averaged. All electronically recorded physiological data were transferred online to the controlling computers and stored in the same data file, thus yielding a time related recording of all data.

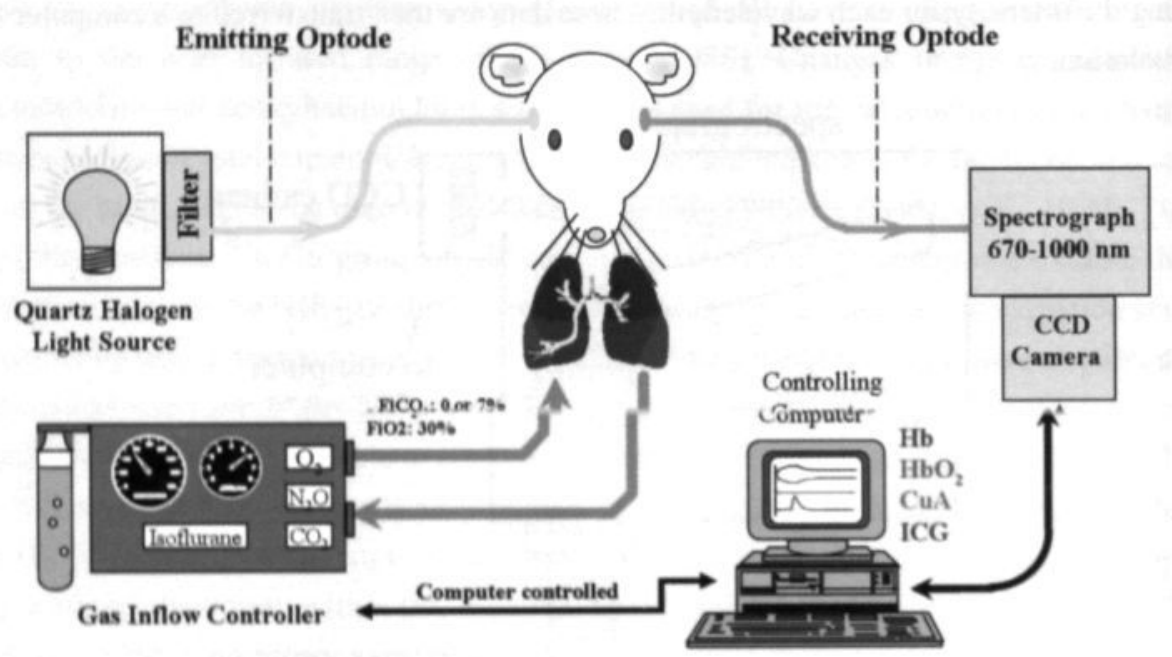

Figure 4. Schematic diagram of the equipment used for inhalation gas mixture regulation and NIRS monitoring.

The pathlength and actual area of measurement have been modelled using a Monte Carlo simulation, as shown in figure 5 (Prof. Dr. Delpy D.T., personal communication). This simulation clearly showed that the method of transillumination used, is actually measuring the region of interest. the brain, with only small proportions of the skull. This simulation, starting from an interoptode spacing of $13.8 \mathrm{~mm}$, resulted in an average pathlength of $56.5 \mathrm{~mm}$. Yielding a differential pathlength factor of 4.1, this result is in good agreement with those found in in vivo (Cope et al., 1989).
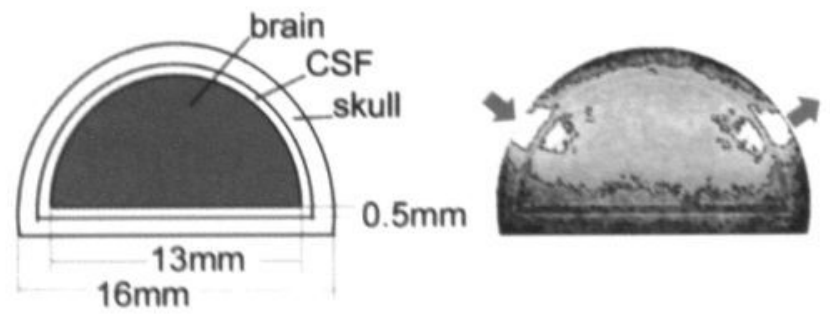

$16 \mathrm{~mm}$
Figure 5. Monte Carlo simulation of the rat head transillumination at $800 \mathrm{~nm}$ wavelength. The arrows indicate the optodes. (Prof. Dr. Delpy D.T., personal communication) 
Absolute changes in the concentration of oxyhaemoglobin $\left(\left[\mathrm{HbO}_{2}\right]\right)$, deoxyhaemoglobin $([\mathrm{Hb}])$ and oxidised $\mathrm{Cu}_{A}\left(\left[\mathrm{Cu}_{A}\right]\right)$ were calculated from the change in attenuation between 780 and $900 \mathrm{~nm}$ (Cope et al., 1989; Matcher et al., 1995) and normalised to the baseline optical pathlength measured from the $840 \mathrm{~nm}$ water feature using $2^{\text {nd }}$ differential analysis (Matcher and Cooper, 1994). Assuming an $85 \%$ water content the absolute concentration of $\mathrm{Hb}$ was obtained from $2^{\text {nd }}$ differential analysis and normalised to the pathlength obtained from the 740 $\mathrm{nm}$ water feature. The absolute $[\mathrm{Hb}]$ and absolute changes in $\left[\mathrm{HbO}_{2}\right]$ and $\left[\mathrm{Cu}_{\mathrm{A}}\right]$ were monitored on-line. Absolute $\left[\mathrm{HbO}_{2}\right]$ was back-calculated taking the value after terminal anoxia as zero. Total haemoglobin $([\mathrm{HbT}])$ was calculated as the sum of $\left[\mathrm{HbO}_{2}\right]$ and $[\mathrm{Hb}]$, and mean cerebral saturation of haemoglobin with oxygen $\left(\mathrm{SmcO}_{2}\right)$ by the following formula: $\left(\left[\mathrm{HbO}_{2}\right] /[\mathrm{HbT}]\right) \mathrm{x}$ 100.

As described above the $\mathrm{Cu}_{\mathrm{A}}$ signal could also be measured by our system and this oxidised cytochrome oxidase signal was validated with cyanide (Cooper et al., 1999) and correlates with the decline in phosphocreatine during the onset of anoxia in the new-born piglet as measured by ${ }^{31}$ P NMR spectroscopy (Springett et al., 2000). This technique has already been used to study cerebral energy failure in different experimental conditions (Cooper and Springett, 1997; van Rossem et al., 1999).

Part of the work presented in this thesis was performed with indocyanine green (ICG), a nontoxic dye with a specific absorption spectrum in the near infrared range. Since its development in the Kodak Research Laboratories (Brooker, 1955; Fox and Wood, 1960) and introduction in the clinical research in 1956 (Fox et al.), many clinical applications have been described for ICG. After i.v. injection the dye is almost entirely confined to the blood compartment and it has been used to measure plasma volume (Haller et al., 1993) and blood flow in humans (Carski et al., 1978; Speich et al., 1988). In rats, plasma and red blood cell transit through a region of the cortex was assessed simultaneously by dual wavelength NIRS and single bolus injection of ICG (Eke et al., 1997). ICG bolus transit detection with NIRS has been used to measure CBF quantitatively in newborn piglets by simultaneous monitoring of the concentration of ICG in the brain and the arterial blood by multi wavelength NIRS and ICG pulse oxymetry, respectively (Springett et al., 2000). The latter technique can not be applied in small laboratory animals since the heart rate exceeds the frequency limit of the existing pulse oxymeter. Qualitative measurements of CBF in pigs were performed by Kuebler et al. (1998) who calculated a blood flow index from the ICG bolus transit curve according to a derivative of the Sapirstein bolus fraction principle (Perbeck et al., 1985). 
Figure 6 summarises the NIR absorption spectra from the four chromophores routinely stuced within this thesis.

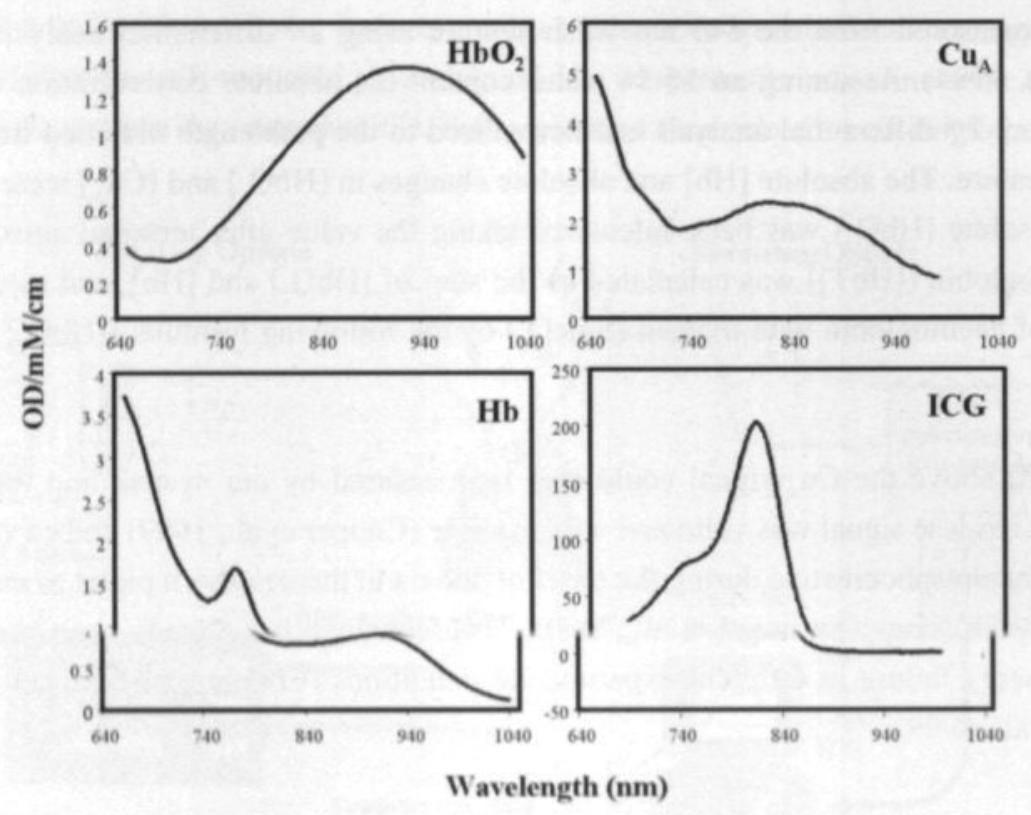

Figure 6. Absorption spectra of oxyhaemoglobin $\left(\mathrm{HbO}_{2}\right)$, deoxyhaemoglobin $(\mathrm{Hb})$, oxidised cytochrome oxidase ( $\left.\mathrm{Cu}_{\mathrm{A}}\right)$ and indocyanine green (ICG). 


\section{The microsphere technique as a reference for cerebral blood flow measurements}

Since validation of an application needs the comparison with an established technique measuring the same variable, we chose to compare our ICG-bolus derived blood flow index with microsphere blood flow measurement. This technique was first introduced by Rudolph and Heymann in 1967. They used radionuclide labelled microspheres for organ perfusion in sheep foetuses. The use of different isotopes allowed multiple flow assessments. An important improvement to the technique was the use of an arterial reference sample enabling the calculation of absolute blood flow in the region of interest (Makowski et al., 1968). Application of this technique in rats followed soon thereafter (Mendell and Hollenberg, 1971; Rakusan and Blahitka, 1974, McDevitt and Nies, 1976). Early studies again using radioactive microspheres have then investigated the minimum requirements for the microsphere blood flow techniques (Buckberg et al., 1971; Reneman et al., 1975; Flameng et al., 1977). Novel techniques derived from the radioactive microsphere flow assessment have been described (for review: Prinzen and Bassingthwaighte, 2000). Instead of using radiolabeled microspheres, dye filled microspheres were introduced. Different methods using fluorescent (Glenny et al., 1993; Austin et al., 1993; Mori et al., 1992; Morita et al., 1990) or non-fluorescent dye (Kowallik et al., 1991; Hale et al., 1988) labelled microspheres have been developed. The approach first published for coloured microspheres by Kowallik and co-workers (1991) has become widely used even for fluorescent dyes (Abel et al., 1993; Glenny et al., 1993). It consists of detecting the concentration of one or more dyes with a spectrophotometer after recovery of the microspheres from the tissue of interest and extraction of the dye. This methodology using coloured microspheres has among others, been used for the study of CBF before and after balloon-dilatation induced brain death in rats (Herijgers et al., 1996).

Although yielding a relatively good measurement and spatial resolution of blood flow in the region of interest, the tissue from the region of interest is destroyed by the digestion step necessary for the retrieval of the microspheres, thus preventing further examination of the tissue. Since we were interested in both $\mathrm{rCBF}$ and the histology in certain pathophysiological conditions we developed a fluorescent microsphere rCBF measurement that also allowed histological examination of the tissue. 


\section{Adjuvant physiological parameters to assess ceretra perfusion and metabolism}

Since therapeutic regimen are often instituted on the basis of ICP values, it is of interest to conbin the NIRS technique with the assessment of intracranial pressure (ICP) and cerebral metaoli rate of oxygen $\left(\mathrm{CmrO}_{2}\right)$. ICP is a very relevant factor when studying certain pathophysiolgica situations such as closed head injury. ICP can be measured using an accurate ICP snsol (Codmann ICP Neuro microsensor) with a diameter of $1.2 \mathrm{~mm}$. However, implantation $\hat{c}$ the ICP probe in the cerebral cortex may induce unwanted changes in NIR light scattering and elicit cortical spreading depressions with consequent unwanted haemodynamic and metaolic alterations. Therefore, the sensor should be implanted preferably in other structures. The accuracy of ICP measurements in normal and pathological conditions and possible interfeence with NIRS measurements are to be evaluated and the most appropriate implantation techique and location selected.

The second parameter, $\mathrm{CmrO}_{2}$, can be calculated from arterial and venous oxygen saturation of the blood and cerebral blood flow using the following formulas:

$$
\begin{aligned}
& \operatorname{avDO}_{2}=1.34 \times[\mathrm{Hb}]_{\text {blood }} \times\left(\mathrm{SaO}_{2}-\mathrm{SvO}_{2}\right) \\
& \mathrm{CmrO}_{2}=\mathrm{avDO}_{2} \times \mathrm{CBF}
\end{aligned}
$$

In the clinic avDO, in brain is assessed from the calculated oxygen content of an arterial and a jugular bulb venous blood sample. Due to the anatomy of the rat jugular vein it is difficult to take venous blood samples at this site. Our attempts for cannulation of the maxillary vein failed. In this type of preparation the ear bars of the stereotaxic apparatus hindered the outflow of the cannula. Finally a sagital sinus cannulation was achieved and allowed venous blood sampling from the rat brain. 


\section{Aim of this thesis}

The aim of this thesis was to develop a cost-effective method for the simultaneous monitoring of cerebral oxygenation, perfusion, intracranial pressure and metabolism in small experimental animals by means of near-infrared spectroscopy

\section{State of the art of NIRS: evaluation and shortcomings}

In a first study 'state of the art' NIRS equipment was used to study the effect of nitric oxide synthase inhibition on cytochrome oxidase (Chapter 2). As this initial study, the opportunity was created to define the shortcomings of the technique. Major shortcomings were the lack of validation of cerebral blood flow assessment by the NIRS technique and of the measurement of metabolic rate of oxygen. Another shortcoming was the lack of simultaneous measurement of intracranial pressure together with NIRS-analysis of cerebral blood flow. Intracortical pressure measurements in combination with NIRS-studies are not possible for technical reasons, and alternative pressure monitoring positions in the brain have to be determined. At last, the degree of cerebral damage by itself will limit the accuracy of the determination of cerebral metabolic rate by NIRS measurement.

It can be expected that a high proportion of irreversible cell death, edema associated with no flow conditions and low metabolic rate in the area of interest will influence the accuracy of the NIRS measurement. Therefore, early and easy assessable factors such as arterial and venous blood gasses, $\mathrm{pH}$, haemoglobin concentration, brain temperature and mean arterial blood pressure can be assessed on their predictive value for the determination of the critical threshold for accurate metabolic rate estimation with NIRS.

\section{Reliability: validation of the NIRS technique for CBF assessment in the rat}

'State of the art' NIRS equipment and injections of a non-toxic, spectroscopically detectable tracer (ICG) has not been extensively used and validated in small laboratory animals. This made this technique cost ineffective and not readily applicable in larger preclinical pharmacological studies. Injections of indocyanine green (ICG) in order to obtain a cerebral blood flow measurement with the multi wavelength NIRS was incompletely studied and needed further development. A major draw back of this technique in contrast to its use in piglets is the fact that no absolute flow data could be derived from the ICG bolus in small animals, because of heart 
rate induced limitations of the currently available ICG detecting pulse oxymeters. A qualitative measure of cerebral blood flow can be achieved by the use of a cerebral blood flow index (BFI $\left.{ }_{w}\right)$ which, however, had not been used nor validated in the rat (Chapter 3). BFI is calculated by deviding the amplitude of the bolus passage curve by the rise time, both obtained with NIRS, combined with body weight. Therefore, in the rat we compared body weight corrected BFI with absolute flow data obtained by means of an established microsphere flow measurement technique in a wide range of cerebral blood flow values (Chapter 5).

An important draw back of the currently available microsphere techniques is their incompatibility with histological assessment of cerebral structure in the areas of interest. Indeed, tissue digestion is a fundamental step in microsphere retrieval. Therefore, we implemented the use of a fluorescent microsphere based flow technique to study microsphere distribution in histological sections of the rat brain (Chapter 4 ).

\section{Simultaneous monitoring of cerebral pressure and perfusion}

Besides cerebral blood flow, intracranial pressure (ICP) is an essential parameter in the assessment of severe head injured patients and as such this clinically relevant variable should be readily applicable in a rat model. However, introduction of the ICP probe often induces bleeding and NIRS requires a preparation completely devoid of any massive intracranial bleeding or haematoma in the cerebrum. In order to avoid this bleeding in the area of NIRS measurement another approach for ICP assessment was studied: the intracerebellar pressure measurement. This alternative ICP measurement, not causing any problems for NIRS measurements in the cerebrum, was compared to the standard cerebral measurement (Chapter 6).

\section{Cerebral oxygen metabolic rate measurement by NIRS: feasibility and limitations}

Besides the previously discussed clinically relevant variables, study of the cerebral metabolic rate of oxygen is also a necessity. Because arterio-venous oxygen saturation difference is an essential factor to calculate metabolic rate of oxygen, a venous blood sample from the cerebrum is a prerequisite in those experiments. The technique of a bleeding free sagital sinus cannulation combined with ICG flow assessment has been worked out for the study of cerebral metabolic rate of oxygen (Chapter 7). In a first approach we evaluated the influence of pentobarbital and closed head injury (Engelborghs et al., 1997 and 2000: De Mulder et al., 2000) on the general physiological variables as well as on more important cerebral variables such as $\mathrm{BFI}_{\mathrm{w}}$. avDO, and 
$\mathrm{CmrO}_{2}$. Furthermore the correlation between venous blood oxygen saturation $\left(\mathrm{SvO}_{2}\right)$ and the NIRS derived cerebral blood oxygen saturation $\left(\mathrm{SmcO}_{2}\right)$ was studied to verify the assumption that NIRS is measuring a mixture of minor proportion arterial and large proportion venous blood (Watzman et al., 2000). 


\section{References}

Abel FL, Cooper RH, Beck RR (1993) Use of fluorescent latex microspheres to measure coronary blood flow distributit. Circ. Shock 41(3): 156-161.

Austin GE, Tuvlin MB, Martino-Salzman D, Hunter RL, Justicz AG, Thompson NK, Brooks AC (1993) Determinationf regional myocardial blood flow using fluorescent microspheres. Am. J. Cardiovasc. Pathol. 4(4): 352-357.

Brooker LGS (1955) Some recent developments in the chemistry of photographic sensitizing dyes. Experientia (suppl): 229-257.

Buckberg GD, Luck JC, Payne DB, Hoffman JI, Archie JP, Fixler DE (1971) Some sources of error in measuring regiorl blood flow with radioactive microspheres. J. Applied. Physiol. 31 (4): 598-604.

Carski TR, Staller BJ, Hepner G, Banka VS, Finney RA (1978) Adverse reactions after administration of indocyanine gret. JAMA 240 (7): 635.

Cooper CE, Cope M, Springett R, Amess PN, Penrice J, Tyszcuk L, Punwani S, Ordidge R, Wyatt J, Delpy DT (1999) Usef mitochondrial inhibitors to demonstrate that cytochrome oxidase near-infrared spectroscopy can measure mitochond $\mathrm{l}$ dysfunction noninvasively in the brain. J. Cereb. Blood Flow Metab. 19: 27-38.

Cooper CE, Springett R (1997) Measurements of cytochrome oxidase and mitochondrial energetics by near-infrar spectroscopy. Phil. Trans. Royal Soc. London B 352: 669-676.

Cope M, Delpy DT, Wray S, Wyatt JS, Reynolds EOR (1989) A CCD spectrophotometer to quantitate the concentrationf

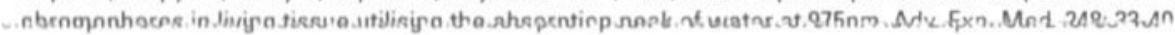

De Mulder G, van Rossem K, Van Reempts J, Borgers M, Verlooy J (2000) Validation of a closed head injury model for use in long-term studie. Acta neurochir. (suppl) 76: 409-413.

Delpy DT, Cope M, van der Zee P, Arridge SR, Wray S, Wyatt JS (1988) Estimation of optical pathlength through tissue from direct time of flight measurement. Phys. Med. Biol. 33: 1433-1442.

Duncan A, Meek JH, Clemence M, Elwell CE, Tyszczuk L, Cope M, Delpy DT (1995) Optical pathlength measurements on adult head, calf and forearm and the head of the newborn infant using phase resolved optical spectroscopy. Phys. Med. Biol. 40(2): 295-304.

Edwards AD, Wyatt JS, Richardson C, Delpy DT, Cope M, Reynolds EOR (1988) Cotside measurement of cerebral blood flow in ill newborn infants by near infrared spectroscopy. The lancet 2: 770-771.

Eke A, Herman P, Balla I, Ikrenyi C (1997) NIRS assessment of regional red blood cell and plasma transit by a single bolus of indocyanine green in the brain cortex. Abstract presented at the $25^{\mathrm{m}}$ annual meeting of the International Society of Oxygen Transport to Tissue 1997: www.elet2.sote.hu/eke/publications/abstracts.html

Elwell CE, Cope M, Kirkby D, Owen-Reece H, Cooper CE, Reynolds EOR, Delpy DT (1994) An automated system for the measurement of the response of cerebral blood volume and cerebral blood flow to changes in arterial carbon dioxide tension using near infrared spectroscopy. in: Hogan M.C. et al., Oxygen transport to tissue XVI, Plenum Press, New York.: $143-155$.

Elwell CE (1995) A practical users guide to near infrared spectroscopy. Hamamatsu Photonics KK.

Engelborghs K, Verlooy J, Van Deuren B, Van Reempts J, Borgers M (1997) Intracranial pressure in a modified experimental model of closed head injury. Acta Neurochir. suppl. 70: 123-125.

Engelborghs K, Haseldonckx M, Van Reempts J, van Rossem K, Wouters L, Borgers M, Verlooy J (2000) Impaired autoregulation of cerebral blood flow in an experimental model of traumatic brain injury. J. Neurotrauma 17(8): 667-677.

Flameng W, Winkler B, Wusten B, Schaper W (1977) Minimum requirements for the measurement of regional myocardial flow using tracer microspheres. Bibl. Anat. (15 Pt 1): 24-29. 
Fox IJ, Brooker LGS, Heseltine DW, Wood EH (1956) A new dye for continuous recording of dilution curves in whole blood independent of variations in blood oxygen saturation. Circ. 24: 937-938.

Fox IJ, Wood EH (1960) Indocyanine green: physical and physiologic properties. Proc. Staff Meet. Mayo Clinic, 35 (25): 732-744.

Glenny RW, Bernard S, Brinkley M (1993) Validation of fluorescent-labeled microspheres for measurement of regional organ perfusion. J. Appl. Physiol. 74(5): 2585-2597.

Hale SL, Alker KJ, Kloner RA (1988) Evaluation of nonradioactive, colored microspheres for measurement of regional myocardial blood flow in dogs. Circ. 78(2): 428-434.

Haller M, Akbulut C, Brechtelbauer H, Fett W, Briegel J, Finsterer U, Peter K (1993) Determination of plasma volume with indocyanine green in man. Life Sci. 53: 1597-1604.

Herijgers P, Leunens V, Tjandra-Maga TB, Mubagwa K, Flameng W (1996) Changes in organ perfusion after brain death in the rat and its relation to circulating catecholamines. Transplant. 62: 330-335.

Jobsis FF (1977) Noninvasive, infrared monitoring of cerebral and myocardial oxygen sufficiency and circulatory parameters. Science 198 (4323): 1264-1267.

Kowallik P, Schulz R, Guth BD, Schade A, Paffhausen W, Gross R, Heusch G (1991) Measurement of regional myocardial blood flow with multiple colored microspheres. Circ. 83(3): 974-982.

Kuebler WM, Sckell A, Habler O, Kleen M, Kuhnle GEH, Welte M, Messmer K, Goetz AE (1998) Noninvasive measurement of regional cerebral blood flow by near-infrared spectroscopy and indocyanine green. J. Cereb. Blood Flow Metab. 18: 445-456.

Makowski EL, Meschia G, Droegemueller W, Battaglia FC (1968) Measurement of umbilical arterial blood flow to the sheep placenta and fetus in utero: Distribution of cotyledons and the intercotyledonary chorion. Circ. Res. 32: 623-631.

Matcher SJ, Cooper CE (1994) Absolute quantification of deoxyhaemoglobin concentration in tissue near infrared spectroscopy. Phys. Med. Biol. 39: 1295-1312.

Matcher SJ, Elwell CE, Cooper CE, Cope M, Delpy DT (1995) Performance comparison of several published tissue nearinfrared spectroscopy algorithms. Anal. Biochem. 227: 54-68.

McDevitt DG, Nies AS (1976) Simultaneous measurement of cardiac output and its distribution with microspheres in the rat. Cardiovasc. Res. 10(4): 494-498.

Mendell PL, Hollenberg NK (1971) Cardiac output distribution in the rat: comparison of rubidium and microsphere methods. Am. J. Physiol. 221(6): 1617-1620.

Mori H, Haruyama S, Shinozaki Y, Okino H, lida A, Takanashi R, Sakuma I, Husseini WK, Payne BD, Hoffman JI (1992) New nonradioactive microspheres and more sensitive $\mathrm{X}$-ray fluorescence to measure regional blood flow. Am. J. Physiol. 263(6 Pt 2): H1946-1957.

Morita Y, Payne BD, Aldea GS, McWatters C, Husseini W, Mori H, Hoffman JI, Kaufman L (1990) Local blood flow measured by fluorescence excitation of nonradioactive microspheres. Am. J. Physiol. 258(5 Pt 2): H1573-1584.

Olsen KS, Svendsen LB, Larsen FS (1996) Validation of transcranial near infrared spectroscopy for evaluation of cerebral blood flow autoregulation. J. Neurosurg. Anesth. 8 (4): 280-285.

Owen-Reece H, Smith M, Elwell CE, Goldstone JC (1999) Near infrared spectroscopy. Brit. J. Anaesth. 82(3): 418-426.

Perbeck L, Lund F, Svensson L, Thulin L (1985) Fluorescein flowmetry: a method for measuring relative capillary blood flow in the intestine. Clin. Physiol. 5 (3): 281-292.

Prinzen FW, Bassingthwaighte JB (2000) Blood flow distributions by microsphere deposition methods. Cardiovasc. Res. 45(1): 13-21.

Prinzen FW, Glenny RW (1994) Developments in non-radioactive microsphere techniques for blood flow measurement. Cardiovasc. Res. 28(10): 1467-1475. 
Rakusan K, Blahitka J (1974) Cardiac output distribution in rats measured by injection of radioactive microspheres via cardiac puncture. Can. J. Physiol. Pharmacol. 52(2): 230-235.

Reneman RS, Jageneau AH, van Gerven W, Dony J, Beirnaert P (1975) The radioactive microsphere method for the assessment of regional myocardial blood flow after coronary artery occlusion. Inaccuracies due to variations in the diameter distribution of the spheres. Pflugers Arch. 353(4): 337-47.

Robertson CS, Gopinath SP, Chance B (1995) A new application for near-infrared spectroscopy: detection of delayed intracranial hematomas after head injury. J. Neurotrauma. 12 (4): 591-600.

Rudolph AM, Heymann MA (1967) The circulation of the fetus in utero. Methods for studying distribution of blood flow, cardiac output and organ blood flow. Circ. Res. 21(2): 163-184.

Speich R, Saesseli B, Hoffmann U, Neftel KA, Reichen J (1988) Anaphylactoid reactions after indocyanine-green administration. Ann. Internal. Med. 109 (4): 345-346.

Springett R, Newman J, Cope M, Delpy DT (2000) Oxygen dependency and precision of cytochrome oxidase signal from full spectral NIRS of the piglet brain. Am. J. Physiol.: Heart Circ. Phys. 279: H2202-H2209.

Springett R, Wylezinska M, Cady EB, Cope M, Delpy DT (2000) Oxygen dependency of cerebral oxidative phosphorylation in newborn piglets. J. Cereb. Blood Flow Metab. 20: 280-289.

Tamura M, Hoshi Y, Okada F (1997) Localized near-infrared spectroscopy and functional optical imaging of brain activity. Phil. Trans. Royal Soc. London B 352: 737-742.

Tsukihara T, Aoyama H, Yamashita E, Tomizaki T, Yamaguchi H, Shinzawa-Itoh K, Nakashima R, Yaono R, Yoshikawa S (1995) Structures of metal sites of oxidized bovine heart cytochrome $c$ oxidase at 2.8 A. Science 269(5227): 1069-1074.

van Rossem K, Garcia-Martinez S, De Mulder G, Van Deuren B, Engelborghs K, Van Reempts J, Borgers M (1999) Brain oxygenation after experimental closed head injury. Adv. Exp. Med. Biol. 471: 209-215.

Villringer A, Planck J, Hock C, Schleinkofer L, Dirnagl U (1993) Near infrared spectroscopy (NIRS): a new tool to study hemodynamic changes during activation of brain function in human adults. Neurosci. Lett. 154: 101-104.

Watzman HM, Kurth CD, Montenegro LM, Rome J, Steven JM, Nicolson SC (2000) Arterial and venous contributions to near-infrared cerebral oximetry. Anesthesiol. 93(4): 947-953.

Wyatt JS, Cope M, Delpy DT, Richardson CE, Edwards AD, Wray S, Reynolds EOR (1990) Quantitation of cerebral blood volume in human infants by near-infrared spectroscopy. J. Appl. Physiol. 68 (3): 1086-1091. 
Chapter 2

Nitric oxide does not inhibit cerebral cytochrome oxidase 'in vivo' or in the reactive hyperaemic phase post brief anoxia in the adult rat

Geofrey De Visscher, Roger Springett, David T. Delpy, Jos Van Reempts,

Marcel Borgers \& Koen van Rossem 


\section{Abstract}

In this study, near infrared spectroscopy was applied to examine whether cytochrome oxidase in the rat brain is inhibited by nitric oxide 'in vivo'. During normoxia, intravenous 1-NAME administration significantly decreased the cerebral saturation of haemoglobin with oxygen but did not alter the cytochrome oxidase redox state. Anoxia significantly reduced the cytochrome oxidase. The time course of the recovery of the redox state during reoxygenation was not altered by I-NAME. Our results suggest that in adult rats cytochrome oxidase is not inhibited by NO, neither in physiological conditions nor during reoxygenation after a brief anoxic period. 


\section{Introduction}

Nitric oxide (NO) is a competitive inhibitor of cytochrome oxidase, the terminal enzyme of the electron transport chain. In cultured synaptosomes, oxygen consumption can be inhibited by NO at physiological concentrations particularly at low oxygen tensions (Brown and Cooper, 1994). For this reason it has been proposed that nitric oxide could be a physiological modulator of the oxygen affinity of cytochrome oxidase 'in vivo' (Clementi et al., 1999). This has been supported by the apparent decrease in the oxygen affinity of cytochrome oxidase 'in vivo' compared to mitochondrial suspensions (Kreisman et al., 1981; Hempel et al., 1977) and the increase in whole body oxygen consumption during systemic inhibition of NO synthase (NOS) (Shen et al., 1994).

Measurements of $\mathrm{CBF}$ and $\mathrm{CMRO}_{2}$ during NOS inhibition in the rat (Horvath et al., 1994) and piglet (Greenberg et al., 1994) have shown decreases in CBF but no change in oxygen consumption at normocapnia. A more sensitive technique would be to measure the redox centres of cytochrome oxidase or the redox state of cytochrome $\mathrm{c}$, which have been shown to become more reduced during inhibition in mitochondrial suspensions (Cassina and Radi, 1996) and isolated cardiomyocytes (Stumpe et al., 2001).

Using full spectral near infrared spectroscopy (NIRS), we observed in preliminary experiments that in the brain of adult rats the copper $\mathrm{A}$ centre $\left(\mathrm{Cu}_{\mathrm{A}}\right)$ of the cytochrome oxidase is reduced during the reactive hyperaemia after a brief period of anoxia (unpublished results). Previously it was shown that during reperfusion after ischaemic hypoxia, NO tension increases to levels shown to inhibit oxygen consumption 'in vitro' and that this release can be inhibited by I-NAME (Malinski et al., 1993).

The aim of this study is to determine 'in vivo' whether NO inhibits cytochrome oxidase in the brain under normal physiological conditions and during the reactive hyperaemia after a brief period of anoxia. 


\section{Materials and methods}

Animal housing and treatment conditions complied with European Union directive \# 86/609 on animal welfare.

Twelve male Sprague-Dawley rats (360-460 g) were anaesthetised with isoflurane $(1.5 \%)$. intubated and ventilated with a 30:70 oxygen: nitrogen gas mixture. The left femoral artery was cannulated for arterial blood sampling and monitoring of the MABP and heart rate, and the lefi femoral vein for injection of l-NAME solution (Sigma Pool, Dorset, UK). The rats were fixed in a stereotaxic apparatus, the parietal and temporal bones exposed for application of the optodes as described previously (van Rossem et al., 1999a). After surgery, the animals were allowed to stabilise for at least 1 hour and then the rats were subjected to a $70 \mathrm{~s}$ period of anoxia. After 40 min of recovery, a second anoxic period of $70 \mathrm{~s}$ was performed followed by a $10 \mathrm{~min}$ period of recovery. Then, a terminal anoxia was applied. Six rats received a $30 \mathrm{mg} / \mathrm{kg}$ bolus (i.v.) of I-NAME $30 \mathrm{~min}$ before the second anoxia. Six control animals obtained an equal quantity of saline. Blood samples for blood gas analvsis (ABL505. Radiometer Copenhagen . Denmark) were collected $1 \mathrm{~min}$ before each period of anoxia.

The NIRS system and algorithms have been described previously (Springett et al., 2000). NIR spectra were collected contiguously with a period of $50 \mathrm{~ms}$ and twenty spectra were averaged to give a time resolution of 1 second. Absolute changes in the concentration of oxyhaemoglobin $\left(\left[\mathrm{HbO}_{2}\right]\right)$, deoxyhaemoglobin $([\mathrm{Hb}])$ and oxidised $\mathrm{Cu}_{\mathrm{A}}\left(\left[\mathrm{Cu}_{\mathrm{A}}\right]\right)$ were calculated from the change in attenuation between 780 and $900 \mathrm{~nm}$ (Cope et al., 1989; Matcher et al., 1995) and normalised to the baseline optical pathlength measured from the $840 \mathrm{~nm}$ water feature using $2^{\text {nd }}$ differential analysis (Matcher and Cooper, 1994). Assuming a $85 \%$ water content the absolute concentration of $\mathrm{Hb}$ was obtained from $2^{\text {nd }}$ differential analysis and normalised to the pathlength obtained from the $740 \mathrm{~nm}$ water feature. The absolute $[\mathrm{Hb}]$ and absolute changes in $\left[\mathrm{HbO}_{2}\right]$ and $\left[\mathrm{Cu}_{\mathrm{A}}\right]$ were monitored on-line. Absolute $\left[\mathrm{HbO}_{2}\right]$ was back-calculated taking the value after terminal anoxia as zero. Total haemoglobin $([\mathrm{HbT}])$ was calculated as the sum of $\left[\mathrm{HbO}_{2}\right]$ and $[\mathrm{Hb}]$, and mean cerebral saturation of haemoglobin with oxygen $\left(\mathrm{SmcO}_{2}\right)$ by the following formula: $\left(\left[\mathrm{HbO}_{2}\right]\right.$ [HbT]) x 100.

Differences between groups were evaluated using the Wilcoxon-Mann-Whitney midrank sum test. Differences within groups were evaluated using the Wilcoxon matched-pairs signed-ranks test. 


\section{Results}

Table 1 shows the physiological data obtained before the pretreatment and posttreatment anoxic periods. No significant differences were found between groups at the onset of the experiment. Pre-treatment NIRS parameters were also comparable between groups (Table 2) except for $[\mathrm{HbT}]$ which was on average $10 \mu \mathrm{M}$ lower in the l-NAME group $(\mathrm{p}=0.041)$.

Table 1. Physiological variables before the first (Pretreatment) and second (Posttreatment) anoxia.

\begin{tabular}{|c|c|c|c|c|}
\hline & \multicolumn{2}{|l|}{ Control $(n-6)$} & \multicolumn{2}{|c|}{ I-NAME $(n-6)$} \\
\hline & Pretreatment & Posttreatment & Pretreatment & Posttreatment \\
\hline Weight (g) & $424+23$ & & $399 \times 25$ & \\
\hline MABP $(\mathrm{mm} \mathrm{Hg})$ & $93+9$ & $100 \pm 15$ & $83 \neq 8$ & $115+5^{\circ}$ \\
\hline Anterial pH & $7.43 \pm 0.03$ & $7.43 \pm 0.02$ & $7.42 \pm 0.01$ & $7.41+0.02$ \\
\hline $\mathrm{PaCO}_{2}(\mathrm{~mm} \mathrm{Hg})$ & $44.5=3.9$ & $43.2=3.1$ & $44.8+1.1$ & $44.8+3.1$ \\
\hline $\mathrm{PaO}_{2}(\mathrm{~mm} \mathrm{Hg})$ & $118.3 \pm 10.3$ & $119.3 \pm 13.6$ & $109.9 \times 17.3$ & $110.5 \pm 13.4$ \\
\hline
\end{tabular}

Data are represented as mean $=$ SD. Blood pressure and blood gases were measured I min before onset of anoxia. "significantly different $(\mathrm{p}<0.05)$ from pre-treatment in the same group.

Table 2. NIRS parameters $1 \mathrm{~min}$ before and 3 and $10 \mathrm{~min}$ after onset of a 70 s period of anoxia

\begin{tabular}{|c|c|c|c|c|c|c|c|}
\hline & & $T=-1 \min$ & & $\mathrm{T}-3 \mathrm{~min}$ & & $\mathrm{~T}-10 \mathrm{~min}$ & \\
\hline & & Pretreatment & Pout treatment & Pretreatinent & Poutreatiment & Pretreatment & Rutirasinemt \\
\hline \multirow[t]{2}{*}[\mathrm{Hb}]{$(\mu \mathrm{M})$} & Control & $27.8 \pm 2.7$ & $25.6 \div 2.6$ & $19.1+2.6$ & $19.0 * 2.7$ & $28.9 \div 2.2$ & $2 \times 7+4.3$ \\
\hline & I-NAME & $25.0=2.8$ & $27.7 \times 3.2$ & $15.5=2.1+$ & $21.9+26^{\circ}$ & $26.1+2.04$ & $33.0+3.9^{*}$ \\
\hline \multirow[t]{2}{*}[\mathrm{HbO}_{2}]{$(\mu \mathrm{M})$} & Control & $82.5+7.1$ & $79.0 \pm 7.5$ & $115.6=9.3$ & $113.6=8.5$ & $75.2+8.6$ & $72.1=11.3$ \\
\hline & I-NAME & $75.3 \times 3.6$ & $64.4=4.6^{\circ}$ & $109.2+6.8$ & $106.4 \times 4.3$ & $69.2 \times 2.9$ & $65.4 \div 6.3$ \\
\hline \multirow[t]{2}{*}[\mathrm{HbT}]{$(\mu \mathrm{M})$} & Control & $110.3 \times 9.5$ & $104.6 \times 8.7$ & $134.7+10.9$ & $132.6 * 9.3$ & $104.1+9.6$ & $100 x+10.4$ \\
\hline & I-NAME & $99.6=3.24$ & $92.1=6.6$ & $124.7=6.6$ & $12 \times .2=5.6$ & $95.2+3.5$ & $98.4+91$ \\
\hline \multirow[t]{2}{*}{$\mathrm{SmcO}_{2}\left({ }^{\circ} *\right)$} & Control & $74 x+10$ & $75.4=2.1$ & $85.8=1.3$ & $85.7=1.8$ & $72.1+2.5$ & $71.3+5.1$ \\
\hline & I-NAME & $756 \div 2.3$ & $69.9 \neq 2.3^{*}$ & $875=1.8$ & $830=16^{\circ}$ & $72.6 \div 1.8$ & $66.5 \pm 22^{\circ}$ \\
\hline
\end{tabular}

Data are represented as means $\pm \mathrm{SD}$. [Hb]: deoxyhacmoglobin concentration: [HbO$]$ oxyhaemoglobin concentration; $[\mathrm{HbT}]$ : total hacmoglobin concentration; $\mathrm{SmcO}_{2}$; the derived saturation of haemoglobin with oxygen. $\mathrm{T}$ : time relative to the onset of anoxia. - significantly different $(\mathrm{p}<0.05$ ) from pre-treatment in the same group, + significantly different from pretreatment control group. 

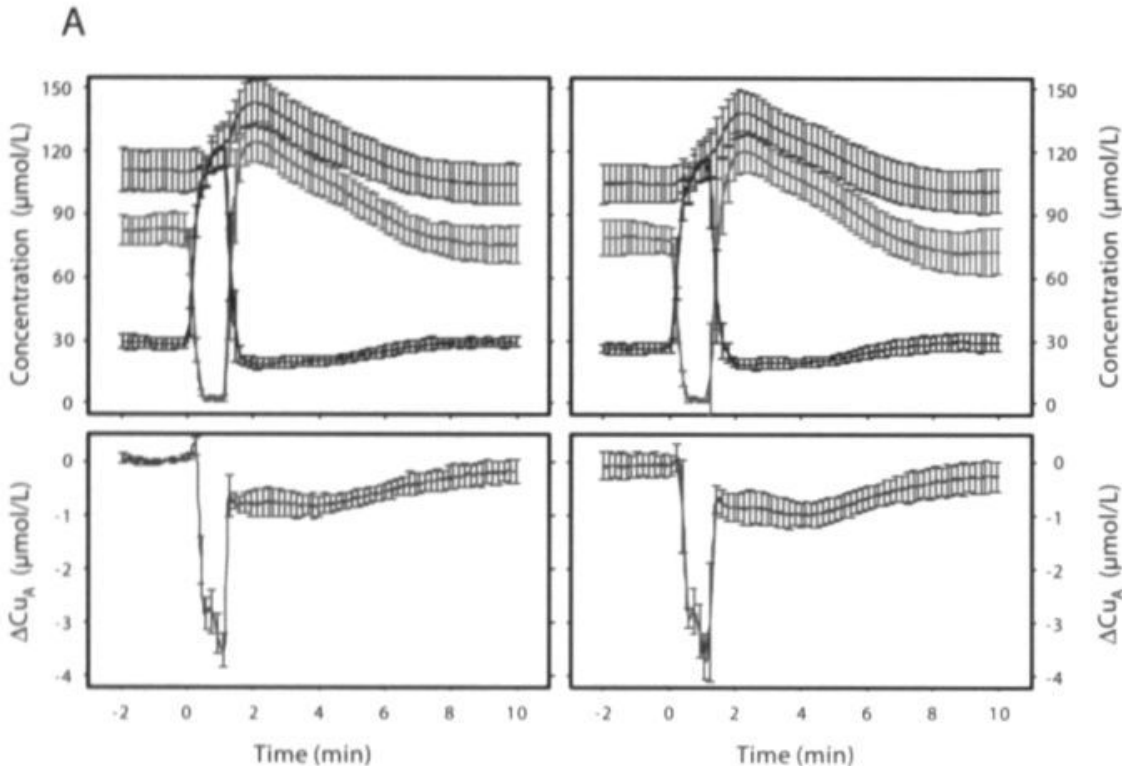

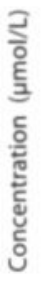

\section{B}
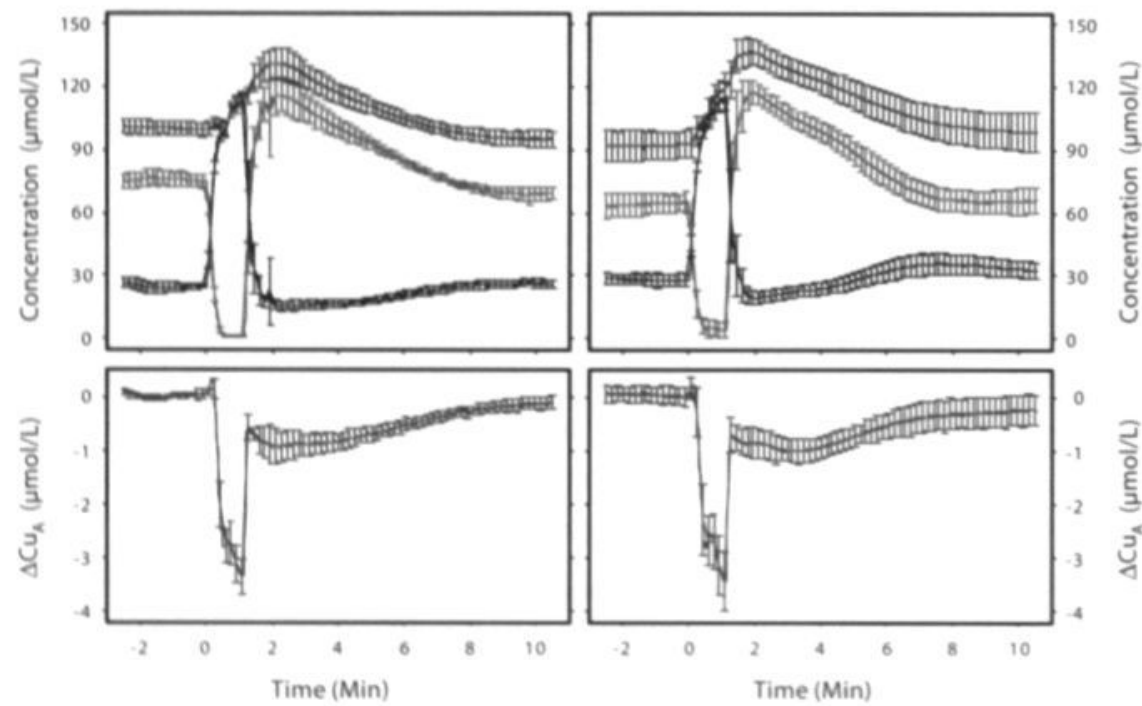

Figure 1. Mean time course (mean $\pm \mathrm{SD}$ ) of NIRS variables during and after a $70 \mathrm{~s}$ period of anoxia for the control $(\mathrm{A})$ and I-NAME (B) treated group. The left panels are before and the right after administration of saline and I-NAME respectively. In part $A$ as well as part $B$ upper panels show oxyhaemoglobin ([HbO,]), deoxyhaemoglobin ([Hb]) and total haemoglobin $([\mathrm{HbT})$ concentrations in red, blue and purple respectively. Lower panels show changes in cytochrome oxidase redox state $\left(\Delta\left[\mathrm{Cu}_{A}\right)\right)$ in time. Time zero indicates the onset of anoxia. 
During anoxia and reoxygenation, the changes in haemoglobin parameters and $\left[\mathrm{Cu}_{\mathrm{A}}\right]$ showed a similar pattern in all animals. Figure 1 shows the mean time course of these changes for the control and 1-NAME treated group, both pretreatment and posttreatment. No significant differences were noticed between the control and l-NAME group. Immediately after onset of anoxia, $\left[\mathrm{HbO}_{2}\right]$ dropped to zero whereas $[\mathrm{Hb}]$ increased. $[\mathrm{HbT}]$ gradually increased during anoxia. After reoxygenation $\left[\mathrm{HbO}_{2}\right]$ rapidly increased to levels more than $40 \mu \mathrm{M}$ above baseline level whereas $[\mathrm{Hb}]$ decreased to approximately $10 \mu \mathrm{M}$ below baseline, resulting in a further increase in $[\mathrm{HbT}]$. All haemoglobin parameters gradually recovered. $\left[\mathrm{Cu}_{\mathrm{A}}\right]$ significantly changed during anoxia and reoxygenation. After the onset of the anoxia $\left[\mathrm{Cu}_{\mathrm{A}}\right]$ rapidly decreased down to approximately $3 \mu \mathrm{M}$ below baseline level. Immediately after the onset of reoxygenation $\left[\mathrm{Cu}_{\mathrm{A}}\right]$ increased to approximately $1 \mu \mathrm{M}$ below baseline level. The complete recovery of $\left[\mathrm{Cu}_{\mathrm{A}}\right]$ took about as long as the recovery of the haemoglobin parameters.

In the control group pretreatment and posttreatment values of arterial blood pressure, blood gases, $\left[\mathrm{Cu}_{\mathrm{A}}\right]$ and brain haemoglobin parameters were comparable. Administration of I-NAME induced a significant increase in MABP $(\mathrm{p}=0.028)$ and a significant decrease in $\left[\mathrm{HbO}_{2}\right](\mathrm{p}=$ $0.031)$ and $\mathrm{SmcO}_{2}(\mathrm{p}=0.031)$ (Table 1 and Table 2$)$. No changes in $\left[\mathrm{Cu}_{\mathrm{A}}\right]$ were noticed. I-NAME did not alter the changes in NIRS parameters during anoxia but induced a small but significant increase in $[\mathrm{Hb}]$ during the hyperaemic phase following reoxygenation (Table 2 ). The decrease in $\mathrm{SmcO}_{2}$ induced by I-NAME before anoxia was maintained during the hyperaemic phase.

Table 3 shows the changes in $\left[\mathrm{Cu}_{\mathrm{A}}\right]$ during and after anoxia. No significant differences within or between groups were observed. The decline in $\left[\mathrm{Cu}_{A}\right]$ during anoxia, plotted as a function of the $\mathrm{SmcO}_{2}$, was comparable before and after treatment with either saline (control) or I-NAME (Figure 2). As interference with other chromophores might influence the $\left[\mathrm{Cu}_{\wedge}\right]$ signal (Cooper et al., 1994), a decrease was regarded significant when it was more negative than $-0.5 \mu \mathrm{M}$. The critical saturation level at which the decline became significant was comparable between the first and second anoxic period in both the control group $(9.69 \pm 2.05 \%$ and $11.61 \pm 2.11 \%$ respectively) and the $1-\mathrm{NAME}$ group $(10.80 \pm 1.92 \%$ and $14.09 \pm 7.88 \%$ respectively). A marked increase in the critical saturation was noticed in only one animal of the I-NAME group. The statistical analysis showed no significant differences between groups. 
Table 3. Changes in concentration of oxidised $\mathrm{Cu}_{\wedge}(\mu \mathrm{M})$ before, during and after a $70 \mathrm{~s}$ periods of anoxia.

\begin{tabular}{ll|ll}
\hline & & Pretreatment & Posttreatment \\
\hline $\mathrm{T}=-1 \mathrm{~min}$ & Control & $-0.02 \pm 0.06$ & $-0.07 \pm 0.20$ \\
& I-NAME & $0.02 \pm 0.03$ & $0.04 \pm 0.18$ \\
& & \\
$\mathrm{~T}=3 \mathrm{~min}$ & Control & $-0.78 \pm 0.22$ & $-0.89 \pm 0.30$ \\
& I-NAME & $-0.88 \pm 0.23$ & $-1.02 \pm 0.23$ \\
& & $-0.17 \pm 0.23$ & $-0.27 \pm 0.29$ \\
$\mathrm{~T}=10$ min & Control & $-0.15 \pm 0.13$ & $-0.27 \pm 0.27$ \\
& I-NAME & $-3.60 \pm 0.35$ & $-3.80 \pm 0.41$ \\
& & $-3.40 \pm 0.33$ & $-3.45 \pm 0.58$ \\
Max. change & Control & & \\
during anoxia & I-NAME & &
\end{tabular}

Data are represented as mean $\neq$ SD. Changes are relative to baseline level at onset of the experiment. Negative values express the reduction of $\mathrm{Cu}_{*}, \mathrm{~T}$ : time relative to the onset of anoxia. No significant differences could be observed between groups and between pre and post-treatment
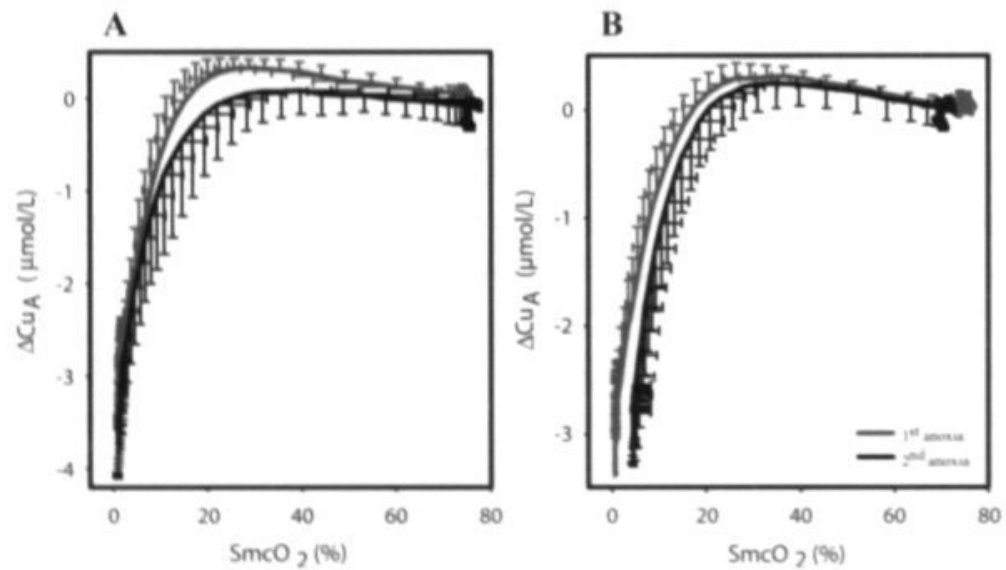

Figure 2. Changes in cytochrome oxidase redox state $\left(\Delta\left[\mathrm{Cu}_{A}\right]\right)$ observed during anoxia and expressed as a function of cerebral haemoglobin saturation $\left(\mathrm{SmcO}_{2}\right)$ for the control (A) and I-NAME (B) treated group. The red and blue curves were obtained respectively before and after administration of saline (A) and I-NAME (B). Bars indicate mean \pm SD. 


\section{Discussion}

1-NAME is a non-specific inhibitor of nitric oxide synthase (Hobbs and Gibson, 1990; Rees et al., 1990). Intravenous infusion at a dose of $30 \mathrm{mg} / \mathrm{kg}$ produced a significant increase in MAPB consistent with previous reports (Buchanan and Phillis, 1993; Prado et al., 1993). In the brain I-NAME causes vasoconstriction, increased vascular resistance and decreased CBF (for review see: Iadecola et al., 1994). In the present study, a significant fall in $\left[\mathrm{HbO}_{2}\right]$ and $\mathrm{SmcO}_{2}$ was observed after infusion of I-NAME. This is consistent with a decrease in CBF as a result of the inhibition of cerebral NOS. Decreases in $\mathrm{SmcO}_{2}$ of this magnitude do not alter the $\mathrm{Cu}_{A}$ redox state (van Rossem et al., 1999b). Hence, any significant direct effect of l-NAME on the $\mathrm{Cu}_{\text {A }}$ redox status should be noticed as such. The absence of a change in the redox state of $\mathrm{Cu}_{\mathrm{A}}$ after injection of I-NAME indicates that in physiological conditions NO does not inhibit cytochrome oxidase.

In preliminary experiments we observed a partial reduction of $\mathrm{Cu}_{A}$ during the hyperaemic phase succeeding a brief period of anoxia (unpublished results). We postulated that during reoxygenation $\mathrm{NO}$ is synthesised by $\mathrm{cNOS}$ and contributes to the vasodilation and partial inhibition of cytochrome oxidase. Previously it was shown that NO is synthesised during the reperfusion after middle cerebral artery occlusion (Malinski et al., 1993; Sato et al., 1994) and after $60 \mathrm{~min}$ of hypoxia (Fujisawa et al, 1999). In addition, 'in vitro' experiments have shown that in isolated nerve terminals and mitochondria NO clearly inhibits the respiration by competing with oxygen at the oxygen binding site of cytochrome oxidase (Brown and Cooper, 1994, Brudvig et al., 1980; Cleeter et al., 1994). The present study shows that a reduction in oxidised $\mathrm{Cu}_{\mathrm{A}}$ occurs reproducibly during and after a $70 \mathrm{~s}$ period of anoxia and that brain haemoglobin oxygenation and $\mathrm{Cu}_{4}$ redox state completely recover within $15 \mathrm{~min}$ after reoxygenation. Pretreatment with I-NAME did not alter the time course of changes in the $\mathrm{Cu}_{A}$ redox state during and after anoxia and did not reduce the partial inhibition of $\mathrm{Cu}_{A}$ after reoxygenation. The time course and magnitude of changes in haemoglobin concentration and oxygenation were neither affected. This indicates that in adult rats NO does not play a major role in the vascular responses during anoxia and reoxygenation and that $\mathrm{NO}$ is not significantly involved in the inhibition of cytochrome oxidase in these conditions. In contrast to middle cerebral artery occlusion (Malinski et al., 1993: Sato et al., 1994) and 60 min. of hypoxia (Fujisawa et al, 1999), NO may not be increased after a brief period of anoxia, or the changes in concentration of NO in these conditions may not be sufficient to induce the same inhibitory effects as in 'in vitro' conditions.

From our data no conclusions can be drawn regarding the question whether NO derived from iNOS inhibits respiration 'in vivo'. The model we apply should be iNOS free as upregulation of 
this enzyme can only be found several hours after an insult (Chatzipanteli et al., 1999; Ikeno et al., 2000). Therefore, although NO may inhibit cytochrome oxidase 'in vivo' after prolonged insults such as hypoxia-ischemia, the data presented in this paper would suggest that NO derived from cNOS activation does not inhibit cytochrome oxidase under normal physiological conditions nor during the reactive hyperaemia after brief anoxia. Other factors that may affect the redox state of the cytochrome oxidase during reoxygenation include mitochondrial $\mathrm{Ca}^{++}$overload, $\mathrm{O}_{2}$-radicals, ionic shifts, acidosis, or simply an increased oxygen demand that is not matched by the oxygen delivery. Increased oxidative metabolism is likely to occur after a period of anoxia, as ionic shifts over the cell membrane have to be restored (for review: Siesjo, 1981).

We conclude that, in adult rats, inhibition of NOS by 1-NAME does not alter the vascular responses, nor the partial reduction of cytochrome oxidase during and after a $70 \mathrm{~s}$ period of anoxia. This indicates that NO is not a major determinant of the observed alterations in these conditions. 


\section{References}

Brown GC, Cooper CE (1994) Nanomolar concentrations of nitric oxide reversibly inhibit synaptosomal respiration by competing with oxygen at cytochrome oxidase. FEBS Lett. 356: 295-298.

Brudvig GW, Stevens TH, Chan SI (1980) Reactions of nitric oxide with cytochrome c oxidase. Biochem. 19: 5275-5285.

Buchanan JE, Phillis JW (1993) The role of nitric oxide in the regulation of cerebral blood flow. Brain Res. 610: 248-255.

Cassina A, Radi R (1996) Differential inhibitory action of nitric oxide and peroxynitrite on mitochondrial electron transport. Arch. Biochem. Biophys. 328(2): 309-316.

Chatzipanteli K, Wada K., Busto R, Dietrich WD (1999) Effects of moderate hypothermia on constitutive and inducible nitric oxide synthase activities after traumatic brain injury in the rat. J. Neurochem. 72(5): 2047-2052.

Cleeter MWJ, Cooper JM, Darley-Usmar VM, Moncada S, Schapira AHV (1994) Reversible inhibition of cytochrome c oxidase, the terminal enzyme of the mitochondrial respiratory chain, by nitric oxide. FEBS Lett. 345: 50-54.

Clementi E, Brown GC, Foxwell N., Moncada S (1999) On the mechanism by which vascular endothelial cells regulate their oxygen consumption. Proc. Natl. Acad. Sci. USA 96(4): 1559-1562.

Cooper CE, Matcher SJ, Wyatt JS, Cope M, Brown GC, Nemoto EM, Delpy DT (1994) Near-infrared spectroscopy of the brain: relevance to cytochrome oxidase bioenergetics. Biochem. Soc. Trans. 22: 974-980.

Cope M, Delpy DT, Wray S, Wyatt JS, Reynolds EOR (1989) A CCD spectrophotometer to quantitate the concentration of chromophores in living tissue utilising the absorption peak of water at $975 \mathrm{~nm}$. Adv. Exp. Med. Biol. 247: 33-40.

Fujisawa H, Koizumu H, Ito H, Yamashita K, Maekawa T (1999) Effects of mild hypothermia on the cortical release of excitatory amino acids and nitric oxide synthesis following hypoxia. J. Neurotrauma 16(11): 1083-1093.

Greenberg RS, Helfaer MA, Kirsch JR, Moore LE, Traystman RJ (1994) Nitric oxide synthase inhibition with NG-monomethyl-L-arginine reversibly decreases cerebral blood flow in piglet. Crit. Care Med. 22(3): 385-392.

Hempel FG, Jobsis FF, LaManna JL, Rosenthal MR, Saltzman HA (1977) Oxidation of cerebral cytochrome aa, by oxygen plus carbon dioxide at hyperbaric pressures. J. Appl. Physiol. 43: 873-879.

Hobbs AJ, Gibson A (1990) L-N-nitro-arginine and its methyl ester are potent inhibitors of non-adrenergic, non-cholinergic transmission in the rat anococcygeus. Brit. J. Pharmacol. 100: 749-752.

Horvath I, Sandor NT, Ruttner Z, McLaughlin AC (1994) Role of nitric oxide in regulating cerebrocortical oxygen consumption and blood flow during hypercapnia. J. Cereb. Blood Flow Metab. 14(3): 503-509.

ladecola C, Pelligrino DA, Moskowitz MA, Lassen NA (1994) Nitric oxide synthase inhibition and cerebrovascular regulation. J. Cereb. Blood Flow Metab. 14: 175-192.

Ikeno S, Nagata N, Yoshida S, Takahashi H, Kigawa, Terakawa N (2000) Immature brain injury via peroxynitrite production induced by inducible nitric oxide synthase after hypoxia-ischemia in rats. J. Obstet. Gynaecol. Res. 26(3): 227-234.

Kreisman NR, Sick TJ, LaManna JC, Rosenthal M (1981) Local tissue oxygen tension-cytochrome a,a3 redox relationships in rat cerebral cortex in vivo. Brain Res. 218(1-2): 161-174.

Malinski T, Bailey F, Zhang ZG, Chopp M (1993) Nitric oxide measured by a porphyrinic microsensor in rat brain after transient middle cerebral artery occlusion. J. Cereb. Blood Flow Metab. 13(3): 355-358.

Matcher SJ, Cooper CE (1994) Absolute quantification of deoxyhaemoglobin concentration in tissue near infrared spectroscopy. Phys. Med. Biol. 39: 1295-1312.

Matcher SJ, Elwell CE, Cooper CE, Cope M, Delpy DT (1995) Performance comparison of several published tissue nearinfrared spectroscopy algorithms. Anal. Biochem. 227: 54-68. 
Prado R, Watson BD, Wester P (1993) Effects of nitric oxide synthase inhibition on cerebral blood flow following bilateral carotid artery occlusion and recirculation in the rat. J. Cereb. Blood Flow Metab. 13(4): 720-723.

Rees DD, Palmer RMJ, Schulz R, Hodson HR, Moncada S (1990) Characterization of three inhibitors of endothelial nitric oxide synthase in vitro and in vivo. Brit. J. Pharmacol. 101: 746-752.

Sato S, Tominaga T, Ohnishi T, Ohnishi ST (1994) Role of nitric oxide in brain ischemia. Ann. NY Acad. Sci. 738: 369-373.

Shen W, Xu X, Ochoa M, Zhao G, Wolin MS, Hintze TH (1994) Role of nitric oxide in the regulation of oxygen consumption in conscious dogs. Circ. Res. 75(6): 1086-1095.

Siesjo BK (1981) Cell damage in the brain: a speculative synthesis. J. Cereb. Blood Flow Metab. 1: 155-185.

Springett R, Newman J, Cope M, Delpy DT (2000) Oxygen dependency and precision of cytochrome oxidase signal from full spectral NIRS of the piglet brain. Am. J. Physiol. Heart Circ. Physiol. 279: H2202-H2209.

Stumpe T, Decking UK, Schrader J (2001) Nitric oxide reduces energy supply by direct action on the respiratory chain in isolated cardiomyocytes. Am J Physiol Heart Circ Physiol 280(5): H2350---H2356.

van Rossem K, Garcia-Martinez S, De Mulder G, Van Deuren B, Engelborghs K, Van Reempts J, Borgers M (1999a) Brain oxygenation after experimental closed head injury. Adv. Exp. Med. Biol. 471: 209-215.

van Rossem K, Garcia-Martinez S, Wouters L, De Mulder G, Van Deuren B, Van Reempts J, Borgers M (1999b) Cytochrome oxidase redox state in brain is more sensitive to hypoxia after closed head injury: a near-infrared spectroscopy (NIRS) study [abstract]. J. Cereb. Blood Flow Metab. 19 (Suppl 1): S391. 
Chapter 3

\section{Cerebral blood flow assessment with indocyanine green bolus transit detection by near-infrared spectroscopy in the rat}

Geofrey De Visscher, Koen van Rossem, Jos Van Reempts, Marcel Borgers, Willem Flameng \& Robert S. Reneman 


\section{Abstract}

In this study we evaluated the feasibility of measuring cerebral blood flow in rats by monitoring the transit of an indocyanine green bolus through the brain with multi wavelength near-infrared spectroscopy. Different volumes of a $1 \mathrm{mg} / \mathrm{ml}$ indocyanine green solution $(5 \mu \mathrm{l}, 15 \mu \mathrm{l}, 25 \mu \mathrm{l}, 50 \mu \mathrm{l})$ were injected intravenously in the search for an optimal dose. Clear transit curves were obtained with all doses and a blood flow index could easily be determined. The indocyanine green signal obtained with the bolus of $5 \mu \mathrm{l}$ rapidly returned to baseline and interfered minimally with the haemoglobin and cytochrome oxidase signals. This dose was used in a second study to evaluate the reproducibility of the signal and the effect of hypercapnia. Two groups of rats received 7 repetitive boli of indocyanine green. In one group, $7 \% \mathrm{CO}_{2}$ was added to the gas mixture before the second, fourth, and sixth indocyanine green injection. Hypercapnia consistently caused a significant increase in blood flow index, cerebral haemoglobin concentration and $\mathrm{O}_{2}$-saturation. In the control group these variables remained stable in time. We conclude that monitoring of the transit of an indocyanine green bolus with multi wavelength near-infrared spectroscopy can be used to assess cerebral blood flow qualitatively in rats in combination with continuous monitoring of brain oxygenation. 


\section{Introduction}

In 1977 Jöbsis first used the relative transparency of brain tissue to the wavelengths ranging from $700-1000 \mathrm{~nm}$ to measure tissue oxygenation and circulatory parameters non-invasively. Since then this technique, known as near-infrared spectroscopy (NIRS), has been further developed and used in experimental and clinical conditions to monitor oxygenation of blood and tissue. Related applications in brain include the measurement of cerebral blood flow in adults (Olsen et al., 1996) and preterm infants (Edwards et al., 1988), detection of intracranial haematomas after head injury (Robertson et al., 1995), functional imaging in adults (Villringer et al., 1993; Tamura et al., 1997), quantitation of cerebral blood volume in infants (Wyatt et al., 1990) and measurement of mitochondrial dysfunction via the cytochrome oxidase signal (Cooper et al., 1999).

In our laboratory, NIRS has been used to investigate brain oxygenation after closed head injury in an experimental rat model (van Rossem et al., 1999a+b) using a multiwavelength NIRS system developed at the University College London (Cope et al., 1989; Matcher et al., 1995). In transmission mode, this system allows monitoring of the oxygenation of the whole brain of the rat. Our aim was to use this system to assess cerebral blood flow (CBF) in rats. CBF has been measured by NIRS from acutely induced changes in haemoglobin oxygenation (Elwell et al., 1994 ) but this requires equipment and procedures not readily applicable in rats. An alternative is to measure the transit of a bolus of a suitable chromophore.

Indocyanine green (ICG) is a non-toxic dye with a specific absorption spectrum in the nearinfrared range. Since its development in the Kodak Research Laboratories (Brooker, 1955; Fox and Wood, 1960) and introduction in the clinical research in 1956 (Fox et al., 1956), many clinical applications have been described for ICG. After i.v. injection, the dye is almost entirely confined to the blood compartment and it has been used to measure plasma volume (Haller et al., 1993) and blood flow in humans (Roberts et al., 1993; Ruokonen et al., 1993; Burggraaf et al., 1998; Roberts et al., 1998). In rats, plasma and red blood cell transit through a region of the cortex was assessed simultaneously by dual wavelength NIRS and single bolus injection of ICG (Eke et al., 1997). ICG bolus transit detection with NIRS has been used to measure CBF quantitatively in newborn piglets by simultaneous monitoring of the concentration of ICG in the brain and the arterial blood by multiwavelength NIRS and ICG pulse oximetry, respectively (Springett et al., personal communication). The latter technique can not be applied in small laboratory animals since the heart rate exceeds the frequency limit of the existing apparatus. Qualitative measurements of CBF in pigs were performed by Kuebler et al. (1998) who calculated a blood 
flow index from the ICG bolus transit curve according to a derivative of the Sapirstein bolus fraction principle (Perbeck et al., 1985).

The aim of the present study was to evaluate the applicability of ICG bolus transit detection by means of multi wavelength NIRS to assess changes in CBF in rats. Hypercapnia was applied to induce these changes and the approach of Kuebler et al. (1998) was employed. Prior to this evaluation, we determined the dose of ICG providing a sufficiently large signal in the brain without inducing unwanted cross-talk effects. 


\section{Materials and methods}

\section{Animal treatment and preparation}

Animal housing and treatment conditions complied with the European Union directive \# 86/ 609 on animal welfare. Thirty male Sprague-Dawley rats (Charles River, Sulzfeld, Germany) weighing $380-430 \mathrm{~g}$ were used, ten in the first and twenty in the second series of experiments. Anaesthesia was induced with $5 \%$ isoflurane in $30 \% \mathrm{O}_{2}$ and $70 \% \mathrm{~N}_{2} \mathrm{O}$ during $5 \mathrm{~min}$. After endotracheal intubation, the isoflurane concentration was switched to $2 \%$ and the animals were surgically prepared. A silicon-tipped PE50 cannula was inserted into the right external jugular vein towards the vena cava for indocyanine green (ICG) bolus injection. To monitor mean arterial blood pressure (MABP) and heart rate (HR), the left femoral artery was cannulated.

The rats were fixed in a stereotaxic apparatus (Model 900, David Kopf, Tujunga, CA, USA). A thermistor inserted into the tip of an ear bar was used to measure the tympanic temperature, providing an accurate measurement of brain temperature (Brambink et al., 1999; Haseldonckx et al., unpublished results). A rectal thermistor probe was inserted to monitor body temperature, which was controlled with a heating pad connected to a homemade temperature control unit. The end tidal $\mathrm{CO}_{2}\left(\mathrm{EtCO}_{2}\right)$ and breathing rate were continuously monitored with an $\mathrm{EtCO}_{2}$-monitor (Capnogard, Novametrix, Wallingford, CT, USA).

The parietal and temporal bones were exposed by removing the scalp, periosteum and parts of the temporal muscles. Sites of possible bleeding were cauterised. Emitting and receiving optical fibres ( $3 \mathrm{~mm}$ diameter) were placed onto the right and left temporal bones, respectively (frontal pole of the fibres at the level of the bregma, angle of $\pm 10^{\circ}$ relative to both the coronal and sagittal plane). To prevent blood entering the space between the skull and the optical fibre, optical gel (Optical Gel code 0608, R.P. Cargille Laboratories Inc., Cedar Grove, New Jersey, USA) was used to fill in this space. The skull was covered with black clay (Modelling clay No 8401, Eberhard Faber GmbH, Neumarkt, Germany).

The isoflurane concentration was then switched to $1.5 \%$ and this level was maintained till the end of the experiment. Measurements were started $60 \mathrm{~min}$ after the induction of anaesthesia and a stabilisation period of $10 \mathrm{~min}$ was allowed to obtain stable measurements. The NIRS measurements were then started for $80 \mathrm{~min}$. At the end of the experiment the animals were killed by terminal anoxia. 


\section{Dose-finding study}

Ten rats were used in this study. The aim was to find an accurate ICG bolus yielding a good balance between signal/noise and cross-talk between ICG and $\mathrm{Hb}$ signals. In each animal, subsequent boli of $5 \mu \mathrm{l}, 15 \mu \mathrm{l}, 25 \mu \mathrm{l}$ and $50 \mu \mathrm{l}$ were given at respectively $10 \mathrm{~min}, 30 \mathrm{~min}, 50 \mathrm{~min}$ and $70 \mathrm{~min}$ after the onset of the NIRS measurements.

\section{Cerebral blood flow responsiveness study}

In this second study hypercapnia was induced by adding $7 \% \mathrm{CO}_{2}$ to the breathing gas mixture (final mixture: $30 \% \mathrm{O}_{2}, 63 \% \mathrm{~N}_{2} \mathrm{O}$, and $7 \% \mathrm{CO}_{2}$ ). This results in an increased $\mathrm{CBF}$ in isoflurane anaesthetised rats (Lee et al., 1995). A total of 20 rats were assigned to either a control group or a $\mathrm{CO}_{2}$ stimulated group of 10 animals each. Starting at $10 \mathrm{~min}$. after onset of the measurements, all rats received 7 repetitive ICG boli of $5 \mu \mathrm{l}$ with a $10 \mathrm{~min}$ time interval. In the $\mathrm{CO}_{2}$ group, $7 \%$ $\mathrm{CO}_{2}$ was added to the normal gas mixture from $5 \mathrm{~min}$ before until $1 \mathrm{~min}$ after the second, fourth, and sixth ICG injection.

\section{NIRS equipment}

The NIRS equipment consisted of a CCD spectrophotometer, NIRS software and algorithms, all developed at the University College London (Cope et al., 1989; Matcher et al., 1995). The absolute concentration of deoxyhaemoglobin $([\mathrm{Hb}])$ and the changes in the concentration of oxyhaemoglobin $\left(\left[\mathrm{HbO}_{2}\right]\right)$ and the redox status of the copper $\mathrm{A}\left(\mathrm{Cu}_{\mathrm{A}}\right)$ centre of cytochrome oxidase were monitored by application of multi wavelength spectroscopy (670-1000 nm) and second differential NIRS (Matcher and Cooper, 1994). Taking the minimum value obtained by the terminal anoxia as zero, absolute $\left[\mathrm{HbO}_{2}\right]$ was calculated. The total concentration of haemoglobin $[\mathrm{HbT}]$ in the brain was calculated as the sum of $[\mathrm{Hb}]$ and $\left[\mathrm{HbO}_{2}\right]$. ICG has an absorption peak at $805 \mathrm{~nm}$ (Landsman et al., 1976) and can be measured by the same set up as the ICG absorption spectrum is included in the algorithm. During ICG bolus transit detection the sampling frequency was switched from $0.1 \mathrm{~Hz}$ to $10 \mathrm{~Hz}$.

\section{Indocyanine green solution}

A $1 \mathrm{ml} / \mathrm{mg}$ ICG (IR-125, laser grade; Acros, Geel, Belgium) solution was used in these studies. The solution also contained $5 \%$ bovine serum albumin (BSA fraction V: Sigma, Bornem, 
Belgium) to bind the ICG. The solution was then sterilised by filtration with a $0.22 \mu \mathrm{m}$ filter unit. If BSA is added ICG will not bind to the endothelium of the vascular wall and a clear passage of the bolus can be detected. The ICG solution is also stable when BSA is added, otherwise selfaggregation of the dye may occur (Cherrick et al., 1960; Gentile et al., 1985).

\section{Data analysis}

\section{Blood flow index calculation}

$\triangle \mathrm{ICG}$ was calculated from the ICG bolus transit curve by subtraction of the baseline value before injection (mean value of 20 measurements) from the peak value after injection. The rise time ( $\Delta t)$ was measured from the first value where the ICG signal deviates from the baseline towards the peak value. A blood flow index (BFI) was then calculated by dividing $\Delta \mathrm{ICG}$ by $\Delta \mathrm{t}$ (Kuebler et al., 1998).

\section{Calculation of $t_{90}$}

An important part of the dose-finding study was to evaluate cross-talk between the ICG signal and other NIRS signals during and after the ICG bolus transit. To have a measure of the duration of these disturbances the time-interval between the peak of the disturbance and the point of return to $10 \%$ of its amplitude $\left(\mathrm{t}_{90}\right)$ was calculated for $[\mathrm{Hb}],\left[\mathrm{HbO}_{2}\right], \mathrm{CuA}$ and ICG.

EtCO, data analysis

$\mathrm{EtCO}_{2}$ was monitored throughout the experiment. The mean $\mathrm{EtCO}_{2}$ value of the last minute before ICG injection was used as the value at ICG boli time points.

\section{Statistical analysis}

All the results are expressed as medians and $95 \%$ confidence intervals [CI]

Differences between groups were evaluated using the Wilcoxon-Mann-Whitney midrank sum test. Differences within groups were evaluated using the Wilcoxon matched-pairs signed-ranks test. 


\section{Results}

Table 1 summarises the physiological data at the onset of the measurements from both studies. All these parameters remained stable during the experiments, except for $\mathrm{EtCO}_{2}$ in the $\mathrm{CO}_{2}$ group of the second study.

Table 1: Baseline values of physiological parameters at the onset of the NIRS measurement

\begin{tabular}{lccc}
\hline & Dose-finding study & \multicolumn{2}{c}{ Cerebral blood flow responsiveness study } \\
& & Control group & $\mathrm{CO}_{2}$ group \\
\hline Weight $(\mathrm{g})$ & $412[394-426]$ & $396[374-411]$ & $407[399-432]$ \\
MABP $(\mathrm{mm} \mathrm{Hg})$ & $83.9[68.9-96.5]$ & $87.1[80.9-96.2]$ & $90.1[81.4-98.2]$ \\
$\mathrm{HR}(\mathrm{BPM})$ & $338[317-380]$ & $358[328-380]$ & $370[340-401]$ \\
EtCO $(\mathrm{mm} \mathrm{Hg})$ & $43.5[39.4-45.6]$ & $44.0[41.8-48.7]$ & $46.0[43.9-52.2]$ \\
T-brain $\left({ }^{\circ} \mathrm{C}\right)$ & $36.1[35.9-36.4]$ & $36.5[36.3-37.1]$ & $36.5[36.1-36.8]$
\end{tabular}

Values are expressed as medians [95\% CI]. MABP: mean arterial blood pressure; HR: heart rate: $\mathrm{E}_{\mathrm{COO}}$ : end tidal $\mathrm{CO}_{2}$; T-brain: brain temperature.

In the $\mathrm{CO}_{2}$ group one animal was eliminated due to breathing problems after the fourth ICG bolus.

\section{Dose-finding study}

Figure IA shows the ICG transit curves obtained from the four consecutive injections in a representative animal. A clear dose-dependent increase in the amplitude of the ICG signal was seen in all subjects. $\Delta t$ did not change significantly with increasing doses. Figure $1 \mathrm{~B}$ shows in detail the curve obtained with the bolus of $5 \mu \mathrm{l}$. Note that the signal is 10 times smaller than the one obtained with the bolus of $50 \mu \mathrm{l}$ (Figure 1A). The BFI could easily be derived from each transit curve (see Materials and methods). 


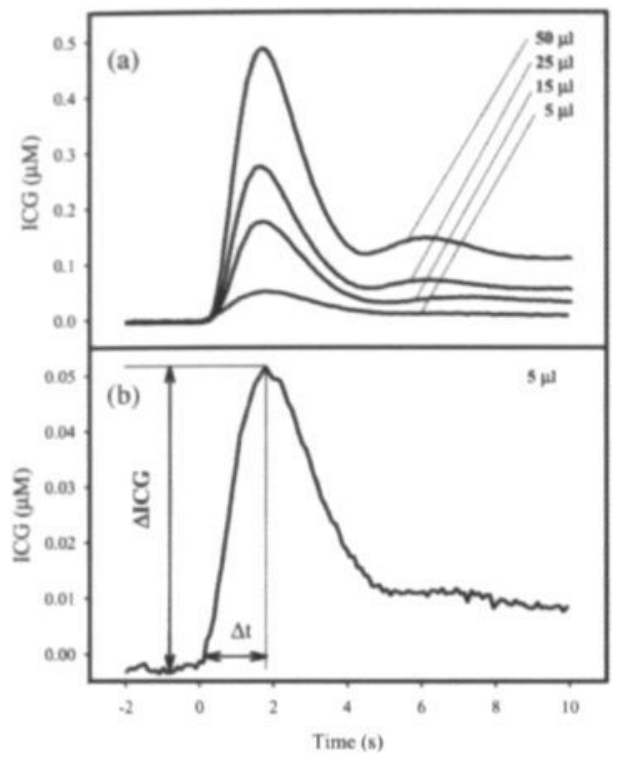

Figure 1. Transit curves obtained with multi wavelength near-infrared spectroscopy after i.v. injection of ICG boli. Four increasing volumes of indocyanine green (ICG) were injected subsequently: $5 \mu \mathrm{l}, 15 \mu \mathrm{l}, 25 \mu \mathrm{l}$ and $50 \mu \mathrm{l}$. A. The transit curves from 1 animal are shown superimposed on one another, taking the time point of the initial deflection as zero. B. The ICG bolus transit curve from the $5 \mu$ dose. The signal-to-noise ratio is excellent. Two basic parameters that can be derived, ICG and rise time ( $t$ ), are indicated by arrows.

As a consequence of the observed dose-dependent increase in $\triangle \mathrm{ICG}$, the calculated BFI also increased dose-dependently, as is shown in Figure 2.

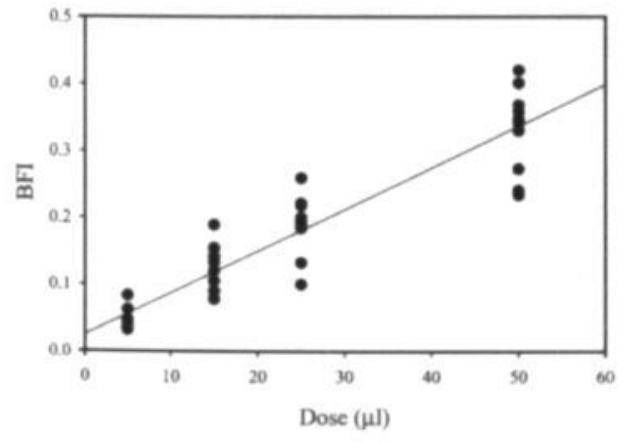

Figure 2. Blood flow index (BFI) data derived from the indocyanine green bolus transit curves obtained with different volumes of ICG injected $(5 \mu \mathrm{l}, 15 \mu \mathrm{l}, 25 \mu \mathrm{l}$ and 50 $\mu$ l). The BFl increases dose-dependently (linear regression: $\mathrm{BFI}=6,239 \cdot 10^{-3}$.Dose $\left.+0.025(\mathrm{R}=0.9284)\right)$.

Figure 3 shows changes in the NIRS variables during the injection of an ICG bolus with a volume of $5 \mu \mathrm{l}$. The detected changes in the $\left[\mathrm{Cu}_{A}\right],\left[\mathrm{HbO}_{2}\right]$ and $[\mathrm{Hb}]$ are immediate and last shorter than the ICG bolus passage. Table 2 presents a summary of the $t_{90}$ data. When $5 \mu$ l of ICG solution was injected, the $t_{90}$ for both $[\mathrm{Hb}]$ and $\mathrm{Cu}_{\mathrm{A}}$ was much smaller than the $\mathrm{t}_{90}$ for ICG. The $\mathrm{t}_{90}$ for $\left[\mathrm{HbO}_{2}\right]$ could not be determined accurately as the change in this signal was too small to have 
a sufficient signal-to-noise ratio. When larger volumes were injected, the $\mathrm{t}_{90}$ for $\left[\mathrm{HbO}_{2}\right]$ lasted maximally 3.67 seconds whereas the $t_{90}$ for the other variables increased dose-dependently up to several minutes. The largest $\mathrm{t}_{90}$ was observed for the $\mathrm{Cu}_{\mathrm{A}}$ signal.

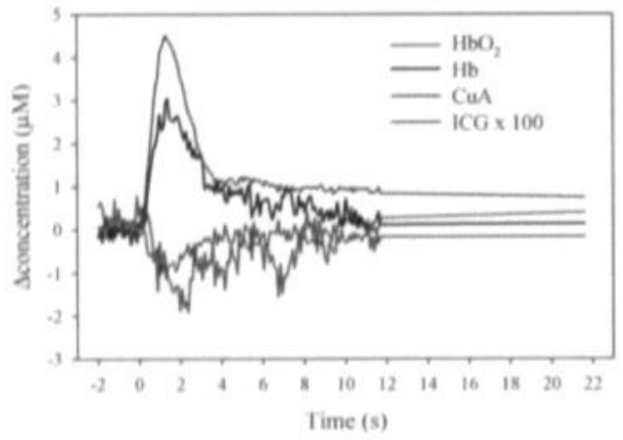

Figure 3. Changes in chromophores during the transit of a bolus of indocyanine green (ICG) through the brain after injection of $5 \mu \mathrm{l}$ of indocyanine green solution. Deflection from the baseline levels can be observed in all the signals. Due to the low signal-to-noise ratio the $\mathrm{t}_{s \mathrm{x}}$ for $\mathrm{HbO}_{2}$ can not be determined accurately.

Table 2: $t_{90}(\mathrm{~s})$ of NIRS signals after i.v, boli of different ICG dosages

\begin{tabular}{lcccc}
\hline & ICG $5 \mu \mathrm{I}$ & ICG $15 \mu \mathrm{I}$ & ICG $25 \mu \mathrm{I}$ & ICG $50 \mu \mathrm{I}$ \\
\hline $\mathrm{Hb}$ & $3.67[2.18-7.67]$ & $52.6[17.8-98.5]$ & $92.7[23.7-123.0]$ & $113.6[74.0-164.7]$ \\
$\mathrm{HbO}_{2}$ & $\mathrm{ND}$ & $1.83[1.50-1.98]$ & $2.28[1.78-2.77]$ & $2.83[2.38-3.27]$ \\
$\mathrm{Cu}_{A}$ & $2.69[1.98-6.14]$ & $121.8[71.8-180.0]$ & $152.4[120.9-232.1]$ & $346.7[297.2-387.4]$ \\
$\mathrm{ICG}$ & $61.2[50.6-70.9]$ & $96.7[77.2-103.4]$ & $95.5[83.4-131.5]$ & $122.6[113.0-141.8]$ \\
\hline
\end{tabular}

Values are expressed as medians [95\% CI]. ND: not detectable; $\mathrm{Hb}$ : deoxyhaemoglobin; $\mathrm{HbO}_{2}$ : oxyhaemoglobin; $\mathrm{Cu}_{\mathrm{A}}$ : the redox state of the copper $\mathrm{A}$ centre of cytochrome oxidase; ICG: indocyanine green.

\section{Cerebral blood flow responsiveness study}

No significant differences in the baseline values of the physiological parameters were found between both groups (Table 1). Table 3 shows the $\mathrm{EtCO}_{2}$ data from both groups. Seven percent $\mathrm{CO}_{2}$ breathing (hypercapnia) consistently caused a significant rise in $\mathrm{EtCO}_{2}(\mathrm{p}<0.005)$. 
Table 3: End tidal $\mathrm{CO}_{2}$ at every $1 \mathrm{CG}$ injection in the cerebral blood flow responsiveness study

\begin{tabular}{|c|c|c|c|c|c|c|c|}
\hline ICG bolus & $1^{\alpha}$ & $2^{\text {nd }}$ & $3^{\text {nd }}$ & $4^{\text {th }}$ & $5^{\text {th }}$ & $6^{\text {th }}$ & $7^{\text {th }}$ \\
\hline \multicolumn{8}{|c|}{ Control Group } \\
\hline Median & 44.0 & 44.1 & 44.3 & 44.7 & 44.9 & 46.1 & 44.0 \\
\hline $95 \% \mathrm{Cl}$ & {$[41.8-48.7]$} & {$[42.4-47.3]$} & {$[41.8-46.5]$} & {$[42.8-47.9]$} & [42.4-48.9] & [42.5-53.9] & [41.0.55.2] \\
\hline \multicolumn{8}{|l|}{$\mathrm{CO}_{2}$ group } \\
\hline Median & 46.0 & $70.6^{*}$ & 49.0 & $72.7^{*}$ & 49.4 & $73.9^{*}$ & 47.9 \\
\hline $95 \% \mathrm{Cl}$ & {$[43.9-52.2]$} & {$[67,0-73.0]$} & {$[44,9-55.0]$} & {$[69.9-77.0]$} & {$[46.3 .57 .1]$} & {$[70.0-76.6]$} & {$[46.9 .58 .4]$} \\
\hline
\end{tabular}

Values are expressed as $\mathrm{mmHg}$.

- significantly different from the value at the previous time point $(p<0.005)$.

Figure 4 shows the seven ICG curves from one randomly chosen animal. The measurements during $\mathrm{CO}_{2}$ challenges can clearly be distinguished from the measurements during normocapnia. The curves obtained during $\mathrm{CO}_{2}$ breathing have a higher amplitude of the ICG signal and a smaller $\Delta$ t. Both effects contribute to an increased BFI.

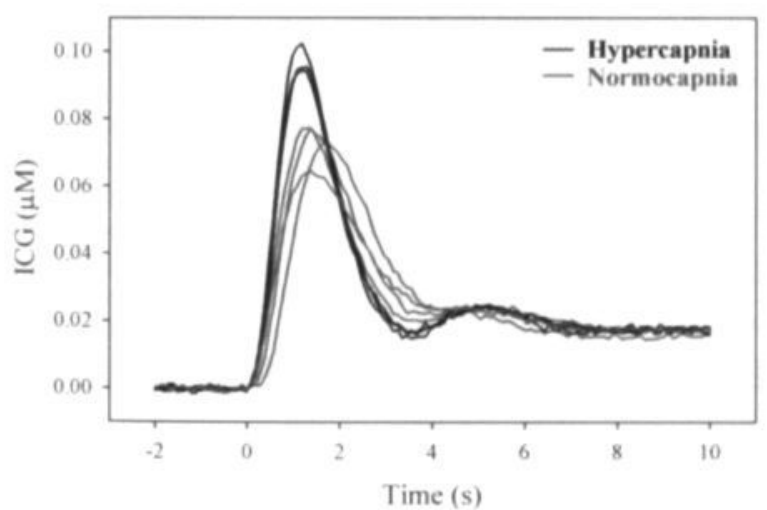

Figure $5 \mathrm{~A}$ shows the BFI values obtained in both groups. A significant increase was observed during $7 \% \mathrm{CO}_{2}$ breathing $(\mathrm{p}<0.01$ ). The control values of both groups during normocapnia (first, third, fifth and seventh ICG bolus) were not significantly different. Figures $5 \mathrm{~B}$ and $\mathrm{C}$ show the effects of $\mathrm{CO}_{2}$ breathing on $\left[\mathrm{HbO}_{2}\right]$ and $[\mathrm{HbT}]$. During the $\mathrm{CO}_{2}$ challenges an increase in both oxy- and total haemoglobin was observed $(\mathrm{p}<0.005$ ). During hypercapnia deoxyhaemoglobin consistently decreased, but this decrease was always smaller than the concurrent increase in oxyhaemoglobin (data not shown).
Figure 4. Indocyanine green (ICG) bolus transit curves obtained during normocapnia and hypercapnia. Seven ICG bolus transit curves from one randomly chosen animal from the $\mathrm{CO}_{2}$ group are shown. Red curves are the control curves for this animal and blue curves were obtained during $7 \% \mathrm{CO}_{2}$ breathing. 


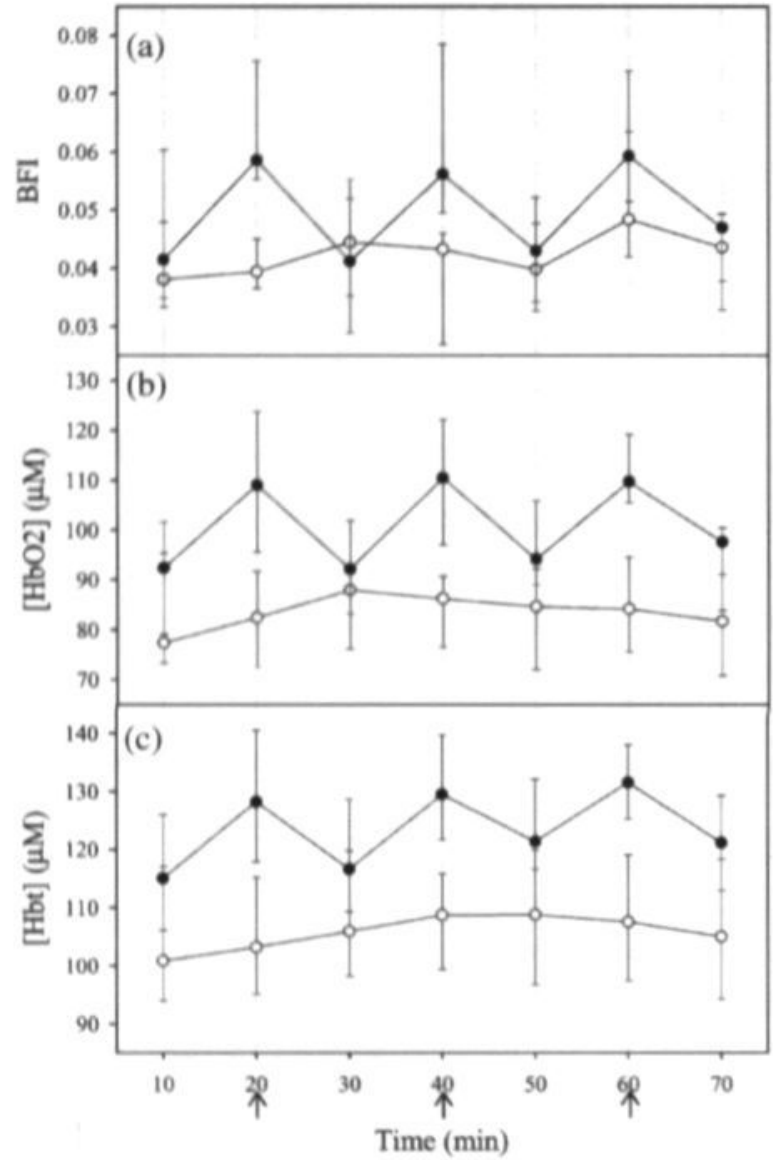

Figure 5. Near-infrared spectroscopy data from the cerebral blood flow responsiveness study. A. The blood flow indices (BFI). B. The oxyhaemoglobin concentrations $([\mathrm{HbO}])$. C The total haemoglobin concentrations ([Hbt]) from both groups. Open and black dots represent the medians of the control group and the $\mathrm{CO}_{2}$ group respectively. Bars represent the $95 \%$ confidence interval. The arrows indicate the time points when $7 \% \mathrm{CO}_{2}$ was added to the breathing gas mixture in the $\mathrm{CO}_{2}$ group. Hypercapnia induces a significant increase in all variables.

A last parameter calculated from the data was the percentage of increase in BFI per $\mathrm{mmHg}$ of increase in EtCO. This value amounted to 1.831 [1.393-3.236], 2.461 [0.992-3.487] and $1.576[0.476-3.570] \% / \mathrm{mmHg}$ for the first, second and third $\mathrm{CO}_{2}$ response, respectively. No significant differences were found between these values. 


\section{Discussion}

In the present study we evaluated the feasibility of the transit detection of an i.v. ICG bolus with multi wavelength NIRS in order to measure CBF in rats. Kuebler and co-workers (1998) applied four-wavelength NIRS to monitor regional CBF in a frontal area of the brain cortex of pigs and calculated a relevant blood flow index from the ICG transit curve by dividing the amplitude of the deflection by the rise time. We adopted this approach but used a slightly different measurement of the rise time. Kuebler et al. (1998) took the time between 10 and $90 \%$ of the peak value, whereas we measured the time from the onset to the peak of the deflection. This can be done accurately in our setting as application of a high sampling speed provides a clear onset and peak of the transit curve.

\section{Dose-finding study}

This study shows that incrementing the bolus volume consistently results in a dose-dependent increase in the amplitude of the ICG signal in each individual animal. The lowest dose administered still provides a clear transit curve with a good signal-to-noise ratio allowing accurate assessment of the BFI.

The rise time $(\Delta \mathrm{t})$ was not significantly influenced by the dosage, indicating that a given flow the BFI is only $\triangle \mathrm{ICG}$ dependent. This implies that the amount of ICG injected has to be accurate in order to enable comparison between different BFIs. In this respect, the reproducibility of repetitive BFI measurements in the control group of the second study is reassuring.

An important part of this study was the evaluation of the effect of the ICG bolus transit on the other chromophore signals. In order to assess the ICG-BFI simultaneously with [Hb], $\left[\mathrm{HbO}_{2}\right]$ and the redox state of the $\mathrm{Cu}_{\mathrm{A}}$ centre of cytochrome oxidase, the ICG bolus transits should be clearly visible and cause only minor disturbances of limited duration in the other NIRS signals. We used the $t_{90}$ to evaluate this effect. Because the bolus with a volume of $5 \mu \mathrm{l}$ induces only short-lasting effects on the other chromophore signals and provides a good signal-to-noise ratio for the ICG signal, we opted to use this dose for further studies. Due to interference with the other chromophore signals, doses of $15 \mu \mathrm{l}$ and higher should be discarded in studies where continuous monitoring of the other chromophores is important. 


\section{Cerebral blood flow responsiveness study}

The $\mathrm{EtCO}_{2}$ increased significantly after adding $7 \% \mathrm{CO}_{2}$ to the breathing gas mixture. Significant increases in BFI ranging from 16 to $98 \%$ were found during hypercapnia. Using $7.5 \% \mathrm{CO}_{2}$ breathing in rats, Estevez and Phillis (1997) found a similar range of rCBF increase (20 to $100 \%$ ) with Laser-Doppler probes. In order to evaluate the BFI response to hypercapnia in a semi-quantitative way, we calculated its relative increase per $\mathrm{mmHg}$ of increase in $\mathrm{EtCO}_{2}$. The values obtained at the three subsequent $\mathrm{CO}_{2}$ responses were reproducible and in concordance with those found in cat and rat by other authors (von Kummer, 1984; Lee et al., 1995), suggesting that the measurement of relative CBF changes by our method is accurate.

During hypercapnia, other NIRS parameters also changed as compared to their control values. The clear increases in $\left[\mathrm{HbO}_{2}\right]$ and $[\mathrm{HbT}]$ are in accordance with a vasodilation found in the cerebral vasculature of rats, rabbits, cats, dogs (Raper et al., 1971, For review see: ladecola et al., 1994) and neonatal piglets (Springett et al., 2000a+b) in response to the hypercapnic periods. The changes in end tidal $\mathrm{CO}_{2}, \mathrm{BFI}$ and NIRS chromophores during repetitive $\mathrm{CO}_{2}$ responses were all reproducible.

It is clear that this technique is suitable for the performance of repetitive measurements of CBF. In case repetitive measurements are done, a proper time interval should be considered in order to prevent accumulation of ICG in the blood (see table 2). If long inter-bolus periods are applied the number of ICG boli is probably not limited. Other factors, for example the anaesthesia, may then determine the duration of the measurements. We assume that it should also be possible to inject a few small ICG boli in a very short time period without significant accumulation of ICG in the plasma. Probably, several repetitive CBF measurements with short intervals are feasible when cross-talk with other NIRS signals is not a matter of concern.

\section{Conclusion}

We conclude that multi wavelength NIRS monitoring of the transit of an indocyanine green bolus can be used to assess cerebral blood flow qualitatively in rats. A bolus with a volume of $5 \mu \mathrm{l}$ of a $1 \mathrm{mg} / \mathrm{ml}$ ICG solution gives a good signal-to-noise ratio with only very small disturbances of the other NIRS measurements. This bolus can be used to perform repetitive qualitative measurements of $\mathrm{CBF}$ and also to measure changes in blood flow in a semi-quantitative way. Validation of the technique is the subject of further investigation. 


\section{Acknowledgements}

We would like to thank Dr. Roger Springett and Prof. Dr. David T. Delpy of the department of Medical Physics at the University College London for providing the NIRS equipment and software. We would also like to thank Mr. Marc Haseldonckx and Mr. Bruno Van Deuren from the department of Neuropathology at Janssen Research Foundation (Beerse, Belgium) for technical support and advice. 


\section{References}

Brambink AM, Kopacz L, Astheimer A, Noga H, Heimann A, Kempski 0 (1999) Control of brain temperature during experimental global ischemia in rats. J. Neurosci. Meth. 92: 111-122.

Brooker LGS (1955) Some recent developments in the chemistry of photographic sensitizing dyes. Experientia suppl. 2 : 229-257.

Burggraaf J, Schoemaker RC, Kroon JM, Cohen AF (1998) The influence of nifedipine and captopril on liver blood flow in healthy subjects. Br. J. Clin. Phermacol. 45: 447-451.

Cherrick GR, Stein WS, Levy CM, Davidson CS (1960) Indo-cyanine green: observations on its physical properties, plasma decay and hepatic excretion. J. Clin. Invest. 39: 592-600.

Cooper CE, Cope M, Springett R, Amess PN, Penrice J, Tyszcuk L, Punwani S, Ordidge R, Wyatt J, Delpy DT (1999) Use of mitochondrial inhibitors to demonstrate that cytochrome oxidase near-infrared spectroscopy can measure mitochondrial dysfunction noninvasively in the brain. J. Cereb. Blood Flow Metab. 19(1) : 27-38.

Cope M, Delpy DT, Wray S, Wyatt JS, Reynolds EOR (1989) A CCD spectrophotometer to quantitate the concentration of chromophores in living tissue utilising the absorption peak of water at $975 \mathrm{~nm}$. Adv. Exp. Med. Biol. 248: 33-40.

Edwards AD, Wyatt JS, Richardson C, Delpy DT, Cope M, Reynolds EOR (1988) Cotside measurement of cerebral blood flow in ill newborn infants by near-infrared spectroscopy. Lancet 2: 770-771.

Eke A, Herman P, Balla I, Ikrenyi C (1997) NIRS assessment of regional red blood cell and plasma transit by a single bolus of indocyanine green in the brain cortex. Abstract presented at the $25^{\mathrm{m}}$ annual meeting of the International Society of 0xygen Transport to Tissue : www.elet2. sote.hu/eke/publications/abstracts.html.

Elwell CE, Cope M, Edwards AD, Wyatt JS, Delpy DT, Reynolds EOR (1994) Quantification of adult cerebral hemodynamics by near-infrared spectroscopy. J. Appl. Physiol. 77(6): 2753-2760.

Estevez AY, Phillis JW (1997) Hypercapnia-induced increases in cerebral blood flow: roles of adenosine, nitric oxide and cortical arousal. Brain Res. 758: 1-8.

Fox IJ, Brooker LGS, Heseltine DW, Wood EH (1956) A new dye for continuous recording of dilution curves in whole blood independent of variations in blood oxygen saturation. Circ. 24: 937-938.

Fox IJ, Wood EH (1960) Indocyanine green: physical and physiologic properties. Proc. Staff Meet. Mayo Clin. 35(25): $732-744$.

Gentile S, Bajema BL, Baldini G, Lunazzi G, Groothuis GMM, Tribelli C, Meijer DKF, Sottocasa GL (1985) Measurement of the association of cholephylic organic anions with different binding proteins. Biochem. Pharmacol. 34(14): 2439-2444.

Haller M, Akbulut C, Brechtelbauer H, Fett W, Briegel J, Finsterer U, Peter K (1993) Determination of plasma volume with indocyanine green in man. Life Sci. 53: 1597-1604.

ladecola C, Pelligrino DA. Moskowitz MA, Lassen NA (1994) Nitric oxide synthase inhibition and cerebrovascular regulation. J. Cereb. Blood Flow Metab. 14: 175-192.

Jobsis FF (1977) Noninvasive, infrared monitoring of cerebral and myocardial oxygen sufficiency and circulatory parameters. Science 198(4323): 1264-1267.

Kuebler WM, Sckell A. Habler 0, Kleen M, Kuhnle GEH, Welte M, Messmer K, Goetz AE (1998). Noninvasive measurement of regional cerebral blood flow by near-infrared spectroscopy and indocyanine green. J. Cereb. Blood Flow Metab. 18. 445-456.

Landsman MLJ, Kwant G, Mook GA, Zillstra WG (1976). Light-absorbing properties, stability, and spectral stabilization of indocyanine green. J. Appl. Physiol. 40 (4): 575-583.

Lee JG, Smith JJ, Hudetz AG, Hillard CJ, Bosnjak ZJ, Kampine JP (1995) Laser-doppler measurement of the effects of halothane and isoflurane on the cerebrovascular $\mathrm{CO}$, response in the rat. Anesth. Anal. 80: 696-702 
Matcher SJ, Cooper CE (1994) Absolute quantification of deoxyhaemoglobin concentration in tissue near-infrared spectroscopy. Phys. Med. Biol. 39: 1295-1312.

Matcher SJ, Elwell CE, Cooper CE, Cope M, Delpy DT (1995) Performance comparison of several published tissue nearinfrared spectroscopy algorithms. Anal. Biochem. 227: 54-68.

Olsen KS, Svendsen LB, Larsen FS (1996) Validation of transcranial near-infrared spectroscopy for evaluation of cerebral blood flow autoregulation. J. Neurosurg. Anesthesiol. 8(4): 280-285.

Perbeck L, Lund F, Svensson L, Thulin L (1985) Fluorescein flowmetry: a method for measuring relative capillary blood flow in the intestine. Clin. Physiol. 5(3): 281-292.

Raper AJ, Kontos HA, Patterson JL (1971) Response of pial precapillary vessels to changes in arterial carbon dioxide tension. Circ. Res. 28: 518-523.

Roberts I, Fallon P, Kirkham FJ, Lloyd-Thomas A, Cooper C, Maynard R, Elliot M, Edwards AD (1993) Estimation of cerebral flow with near-infrared spectroscopy and indocyanine green. The Lancet 342: 1425.

Roberts IG, Fallon P, Kirkham FJ, Kirshbom PM, Cooper CE, Elliott MJ, Edwards AD (1998) Measurement of cerebral blood flow during cardiopulmonary bypass with near-infrared spectroscopy. J. Thor. Cardiovasc. Surg. 115: 94-102.

Robertson CS, Gopinath SP, Chance B (1995) A new application for near-infrared spectroscopy: detection of delayed intracranial hematomas after head injury. J. Neurotrauma 12 (4): 591-600.

Ruokonen E, Takala J, Kari A, Saxén H, Mertsola J, Hansen EJ (1993) Regional blood flow and oxygen transport in septic shock. Crit. Care Med. 21(9): 1296-1303.

Tamura M, Hoshi Y, Okada F (1997) Localized near-infrared spectroscopy and functional optical imaging of brain activity. Phil. Trans. R. Soc. Lond. B 352: 737-742.

Springett R, Newman J, Cope M, Delpy DT (2000a) Oxygen dependency and precision of cytochrome oxidase signal from full spectral NIRS of the piglet brain. Am. J. Physiol. Heart. Circ. Physiol. 279: H2202-H2209.

Springett R, Wylezinska M, Cady EB, Cope M, Delpy DT (2000b) Oxygen dependency of cerebral oxidative phosphorylation in newborn piglets. J. Cereb. Blood Flow Metab. 20: 280-289.

van Rossem K, Garcia-Martinez S, De Mulder G, Van Deuren B, Engelborghs K, Van Reempts J, Borgers M (1999a) Brain oxygenation after experimental closed head injury. Adv. Exp. Med. Biol. 471: 209-215.

van Rossem K, Garcia-Martinez S, Wouters L, De Mulder G, Van Deuren B, Van Reempts J, Borgers M (1999b) Cytochrome oxidase redox state in brain is more sensitive to hypoxia after closed head injury: a near-infrared spectroscopy (NIRS) study. J. Cereb. Blood Flow Metab. 19 Suppl 1: S391.

Villringer A, Planck J, Hock C, Schleinkofer L, Dirnagl U (1993) Near-infrared spectroscopy (NIRS): a new tool to study hemodynamic changes during activation of brain function in human adults. Neurosci. Lett. 154: 101-104.

von Kummer $R$ (1984) Local vascular response to changes in carbon dioxide tension. Long term observations in the cat's brain by means of hydrogen clearance technique. Stroke 15 (1): 108-114.

Wyatt JS, Cope M, Delpy DT, Richardson CE, Edwards AD, Wray S, Reynolds EOR (1990) Quantitation of cerebral blood volume in human infants by near-infrared spectroscopy. J. Appl. Physiol 68 (3): 1086-1091. 
Chapter 4

\section{Assessment of regional cerebral blood flow at various time points in the same rat by means of fluorescent microspheres}

Geofrey De Visscher, Marc Haseldonckx, Willem Flameng, Marcel Borgers, Robert S. Reneman \& Koen van Rossem 


\section{Abstract}

The aim of the study was to evaluate the microsphere technique for the quantitative assessment of regional cerebral blood flow (rCBF) at different time points in the same animal. Yellow-green and red fluorescent microspheres with a diameter of $15 \mu \mathrm{m}$ were injected into the rat at two different time points via a cannula inserted into the left ventricle of the heart. The reproducibility of the rCBF measurements in normocapnic conditions $(n=7)$ and the responsiveness of the flow to hypercapnia induced by $7 \% \mathrm{CO}_{2}(\mathrm{n}=7)$ was examined. The fluorescent spheres were counted on $100 \mu \mathrm{m}$ vibratome sections of perfusion-fixed brains and $\mathrm{rCBF}$ was calculated. The median total CBF in normocapnic rats was $224 \mathrm{ml} / \mathrm{min} / 100 \mathrm{~g}$ for the first microsphere injection and 216 $\mathrm{ml} / \mathrm{min} / 100 \mathrm{~g}$ for the second one. In the hypercapnic group CBF amounted to $400 \mathrm{ml} / \mathrm{min} / 100 \mathrm{~g}$ and after $30 \mathrm{~min}$ of normocapnia decreased to $178 \mathrm{ml} / \mathrm{min} / 100 \mathrm{~g}$. No differences between the left and right hemisphere were found and there was no indication that the first injection might have influenced the second one. The described approach allows combining the assessment of rCBF at different time points in physiological or pathological conditions with histological evaluation of related morphological alterations in the same brain region of the same animal. 


\section{Introduction}

Since the outcome of neurological damage after stroke is generally determined by the residual regional cerebral blood flow (rCBF) (for review: Demchuk and Buchan, 2000), accurate assessment of $\mathrm{rCBF}$ is needed for adequate interpretation and explanation of the neurological sequelae in experimental conditions.

Novel techniques have been derived from the radioactive microsphere method as introduced by Rudolph and Heymann (1967). Instead of radiolabeled microspheres, microspheres labelled with fluorescent (Glenny et al., 1993; Austin et al., 1993; Mori et al., 1992; Morita et al., 1990) or non-fluorescent dyes (Kowallik et al., 1991; Hale et al., 1988) are used. Another improvement was the introduction of an arterial reference sample enabling the calculation of absolute blood flow in the region of interest (Makowski et al., 1968).

Since its introduction, this technique has been further developed (for review: Prinzen and Glenny, 1994). The approach first published for coloured microspheres by Kowallik and co-workers (1991) has been extended to fluorescent dyes (Abel et al., 1993; Glenny et al., 1993). The method is based upon detecting the concentration of one or more dyes with a spectrophotometer after recovery of the microspheres from the tissue of interest and extraction of the dye. Coloured microspheres, for example, have been used to study CBF before and after balloon-dilatation induced brain death in rats (Herijgers et al., 1996).

Although providing a relatively good estimate of blood flow in the region of interest with a good spatial resolution, the tissue from this region is destroyed by the digestion step necessary for the retrieval of the microspheres, thus preventing further examination of the tissue. Since it is of interest to relate $\mathrm{rCBF}$ to neurological damage in pathophysiological conditions, we developed a fluorescent microsphere method to assess $\mathrm{rCBF}$ that also allows histological examination of the tissue. 


\section{Material and methods}

The following protocol is the final protocol, achieved after several changes which will be described in the result section.

The study was performed on 14 male Sprague-Dawley rats weighing $360-430 \mathrm{~g}$. Anaesthesia was induced with $4 \%$ isoflurane in $30 \% \mathrm{O}_{2}$ and $70 \% \mathrm{~N}_{2} \mathrm{O}$ during $5 \mathrm{~min}$.. After endotracheal intubation the animals were kept on $2 \%$ isoflurane and immobilised on a home made heating pad. The left femoral artery was cannulated (PE50) for arterial blood sampling and monitoring of mean arterial blood pressure (MABP) and heart rate (HR). A PE10 cannula was inserted into the left ventricle via the right brachial artery (Nakai et al., 1990). After surgery the rats were maintained on $1.5 \%$ isoflurane until the end of the experiment.

$\mathrm{MABP}$ and $\mathrm{HR}$, end tidal $\mathrm{CO}_{2}\left(\mathrm{EtCO}_{2}\right)$, breathing rate, $\mathrm{O}_{2}$-saturation of arterial blood and both rectal and ear temperature were continuously monitored and recorded

A thermistor inserted into the ear was used to measure the tympanic temperature, providing an accurate measurement of brain temperature (Brambink et al., 1999). A rectal thermistor

probe was inserted to monitor body temperature, which was maintained at $37{ }^{\circ} \mathrm{C}\left( \pm 0.5{ }^{\circ} \mathrm{C}\right)$, using a homemade temperature control unit connected with the heating pad. The end tidal $\mathrm{CO}_{2}$ $\left(\mathrm{EtCO}_{2}\right)$ and breathing rate were continuously monitored with an $\mathrm{EtCO}_{2}$-monitor (Capnogard, Novametrix, Wallingford, CT, USA). The $\mathrm{O}_{2}$ saturation of arterial blood was measured by a pulse oxymeter (Nonin, $8600 \mathrm{~V}$ ) suitable for rats. Together with MABP and HR the above described variables were continuously monitored and recorded.

The animals were randomly assigned to one of two groups. The control group received two microsphere injections. The first and the second injection were given 10 and $40 \mathrm{~min}$. after the start of the experiment, respectively. For the $\mathrm{CO}$, group the protocol was the same as in the control group except that the animals started breathing $7 \% \mathrm{CO}_{2}$ (final mixture: $30 \% \mathrm{O}_{2}, 63 \%$ $\left.\mathrm{N}_{2} \mathrm{O}, 7 \% \mathrm{CO}_{2}\right) 5 \mathrm{~min}$ before the first microsphere injection; $\mathrm{CO} 2$ breathing was continued during this injection and was stopped thereafter. The animals were normocapnic at the second microsphere injection. Three blood samples were taken for blood gas analysis. The first blood sample was taken one minute before the start of the experiment and the second and last one minute before the first and last microsphere injection, respectively. 
Two colours, yellow-green and red, of $15 \mu \mathrm{m}$ fluorescent microspheres (Molecular Probes) were used. The order of injection was randomised. Prior to injection the microspheres were sonicated for $5 \mathrm{~min}$. and vortexed for 30 seconds. A reference blood sample was withdrawn for $2 \mathrm{~min}$ from the left femoral artery, using a pump (Harvard apparatus, Infusion/Withdrawal pump, South Natick, Massachusetts, USA) at a flow rate of $0.566 \mathrm{~mL} / \mathrm{min}$. When the first blood entered the syringe, a $100 \mu \mathrm{l}$ bolus containing approximately 100.000 microspheres (Molecular Probes) was injected into the left ventricle over a $20 \mathrm{~s}$ period. The catheter was then flushed with $0.5 \mathrm{ml}$ saline for another $20 \mathrm{~s}$. The blood sample was transferred into a plastic test tube and the syringe was rinsed with saline. One $\mathrm{ml}$ of a $16 \mathrm{~N} \mathrm{KOH}$ solution was added and the blood samples were digested overnight. The next day the samples were filtered using $25 \mathrm{~mm}$ diameter polyester filter membranes with a $10 \mu \mathrm{m}$ pore size (Triton technology). The filtrate of the microsphere samples was filtered again twice, so 3 filters were obtained for each sample. These filters were mounted on microscopic slides with Aquamount (BDH Laboratory supplies) and a coverslip ( $24 \times 32$ $\mathrm{mm})$.

After the second microsphere injection the recording of all physiological parameters was ceased and the rat was killed by transcardial perfusion with a $4 \%$ formalin solution at room temperature. The animals were perfused for $10 \mathrm{~min}$. after which the brain and both kidneys were immersion fixated in $4 \%$ formalin. The brain and kidneys were cut into $100 \mu \mathrm{m}$ slices and each 4 subsequent slices were put on microscopic slides. Unmounted and uncoloured tissue sections were then analysed by visual counting. The number of yellow-green and red microspheres was counted and the slice surface measured with an image analysis system (Optimas 6.1, Optimas Corporation, Washington, USA). The left and right cerebral hemispheres were counted separately. The slice surfaces and the slice thickness then allowed calculation of the volume $\left(\mathrm{mm}^{3}\right)$ of the examined area. The filters were also counted by visual counting. The total amount of yellow-green and red microspheres was then calculated from the 3 filters for each colour per rat.

Cerebral and kidney blood flow were calculated with the following formula:

$$
\mathrm{Q}=((\mathrm{FR} \times \mathrm{CT}) /(\mathrm{CR} \times \mathrm{VT})) \times 10^{5}
$$

where

$\mathrm{Q}=$ flow in $\mathrm{ml} /\left(\min \times 100 \mathrm{~cm}^{3}\right)$

$\mathrm{FR}=$ flow rate reference sample $(\mathrm{ml} / \mathrm{min})$ 


\author{
$\mathrm{CR}=$ microsphere count in reference sample \\ $\mathrm{CT}=$ microsphere count in tissue \\ $\mathrm{VT}=$ tissue volume $\left(\mathrm{mm}^{3}\right)$
}

If left and right kidney flow differed more than $10 \%$ the rat was excluded because of inadequate microsphere mixing. Left and right cerebral hemispheric blood flows were calculated separately to detect possible left/right differences that may occur if the left ventricle canulla blocks the left common carotid artery. Total cerebral flow was calculated as the mean of both hemispheric flows.

\title{
Induction and evaluation of incomplete ischemia of the brain
}

This procedure has been described previously in detail by Haseldonckx and co-workers (1997). In short, fasted male Wistar rats of approximately $300 \mathrm{~g}$ were used. A catheter was inserted into the right jugular vein and both common carotid arteries were dissected free from the surrounding tissue. Incomplete ischemia could than be induced by clamping both common carotid arteries combined with simultaneous hypovolemia by rapid bleeding through the jugular vein until the MABP dropped to $35 \mathrm{mmHg}$. This blood pressure was maintained over 9 min and the ischemic period. When this protocol was used the first microsphere injection was performed at least 15 min after termination of the surgical procedure or $10 \mathrm{~min}$ after the first normal blood sample analysis. Induction of ischemia started $10 \mathrm{~min}$ after the first CBF assessment. The second microsphere injection was performed at $7 \mathrm{~min}$. of ischemia. The blood loss caused by reference blood sampling was counterbalanced by simultaneous saline infusion at the same rate. The ischemic period was ended by removal of the clamps and re-infusion of the blood. Sodium bicarbonate $(0.5 \mathrm{ml}, 0.6 \mathrm{M})$ was injected intravenously, and the animals were allowed to recover in an acclimatised room. Three days survival was allowed for ischemic damage maturation, after which the brains were fixed by transcardial perfusion with $4 \%$ formalin. After post fixation with $4 \%$ formalin, $100 \mu \mathrm{m}$ sections were cut as described above. 
Adjacent tissue samples from the hippocampal CAl region were dehydrated in graded series of alcohol and embedded in epoxy resin. For light microscopic evaluation, $2 \mu \mathrm{m}$ thick sections were stained with $0.1 \%$ toluidine blue for $45 \mathrm{~s}$ and mounted with pertex.

\section{Statistical analysis}

All the results are expressed as medians and $95 \%$ confidence intervals (CI). A two-sided Wilcoxon-Mann-Whitney rank-sum test was used for analysis between groups. Two-sided probability values of less than 0.05 were regarded as statistically significant. A Wilcoxon signed rank test was used to test whether the differences between measurements at different timepoints were significantly different from zero $(\mathrm{p}<0.05)$. 


\section{Results}

Table 1 shows the data from a preliminary experiment, in which the yield of subsequent filtrations was studied. Since the number of microspheres in the brain tissue was not subjected to possible microsphere loss occurring at the filtration, the reference sample filtration needed to be very accurate. The total number of five filtrations $(n=7)$ was considered as $100 \%$ and the yield of the fifth filtration was 4 [1-6] on a total of 275 [252-303] microspheres. As shown in the table a substantial loss of microspheres was observed when only 1 filtration was performed. Three subsequent filtrations are necessary to obtain an accurate microsphere count from the reference sample.

Table I. Median yield in percentage of the expected value after subsequent filtrations of both colours of microspheres used.

\begin{tabular}{lcc}
\hline Total amount of filtrations & Yellow-green microspheres & Red microspheres \\
\hline 1 & $89.59 \%$ & $85.10 \%$ \\
2 & $94.75 \%$ & $94.28 \%$ \\
3 & $97.33 \%$ & $97.32 \%$
\end{tabular}

The total yield obtained from 5 subsequent filtrations was set at $100 \%$. The maximum number of microspheres on the fifth filter was $6(<2 \%$ of total amount $)$.

The weights of the animals and the results of the blood gas analyses are shown in table 2. The weights were not different between both groups. During $\mathrm{CO}_{2}$ breathing arterial $\mathrm{CO}_{2}$ and $\mathrm{O}$, pressure were significantly different from the values before $\mathrm{CO}_{2}$ breathing and from values in the control group. Both groups showed a small significant decrease in $\mathrm{pH}$ at the third measurement. but the $\mathrm{pH}$ values were all within the physiological range. The $\mathrm{CO}_{2}$ group showed a larger significant decrease out of the physiological range during the addition of $7 \% \mathrm{CO}_{2}$ to the breathing gas. 
Table 2. Physiological data at 3 timepoints during the measurements $(n=7$ in each group).

\begin{tabular}{lccl}
\hline & Control group & $\mathrm{CO}_{2}$ group & p-value \\
\hline Weight $(\mathrm{g})$ & $388[362,418]$ & $401[377,424]$ & 0.3176 \\
$\mathrm{PaCO}_{2}$ before $\mathrm{CO}_{2}(\mathrm{mmHg})$ & $43.1[39.5,45.7]$ & $41.0[36.2,45.7]$ & 0.2686 \\
$\mathrm{PaCO}_{2}$ during $\mathrm{CO}_{2}(\mathrm{mmHg})$ & $41.6[37.7,46.2]$ & $57.0[47.4,64.9] \dagger$ & 0.0006 \\
$\mathrm{PaCO}_{2}$ after $\mathrm{CO}_{2}(\mathrm{mmHg})$ & $42.7[39.7,50.7]$ & $42.9[38.3,43.3]$ & 0.5350 \\
$\mathrm{PaO}_{2}$ before $\mathrm{CO}_{2}(\mathrm{mmHg})$ & $124[105,158]$ & $127[94.3,145]$ & 0.8788 \\
$\mathrm{PaO}_{2}$ during $\mathrm{CO}_{2}(\mathrm{mmHg})$ & $122[104,156]$ & $160[125,175] \dagger$ & 0.0122 \\
$\mathrm{PaO}_{2}$ affer $\mathrm{CO}_{2}(\mathrm{mmHg})$ & $126[102,146]$ & $135[109,151]$ & 0.5122 \\
$\mathrm{pH}_{\text {before } \mathrm{CO}_{2}}$ & $7.41[7.38,7.44]$ & $7.43[7.40,7.47] \dagger$ & 0.7786 \\
$\mathrm{pH}_{\text {during }} \mathrm{CO}_{2}$ & $7.41[7.38,7.45]$ & $7.32[7.29,7.34] \dagger$ & 0.0006 \\
$\mathrm{pH}_{\text {after }} \mathrm{CO}_{2}$ & $7.40[7.34,7.44] \dagger$ & $7.41[7.35,7.45] \dagger$ & 0.7104 \\
\hline
\end{tabular}

Values are expressed as median $[95 \% \mathrm{CI}] . \mathrm{PaCO}_{2}$ : partial pressure of $\mathrm{CO}_{2}$ in arterial blood; $\mathrm{PaO}_{2}$ : partial pressure of $\mathrm{O}_{2}$ in arterial blood. Indicated p-values from the Wilcoxon-MannWhitney comparison between the control and $\mathrm{CO}_{2}$ group, + indicates significant difference (Wilcoxon signed ranks test) from both other measurement of the same variable.

The 6 panels in figure 1 each show another physiological variable monitored throughout the entire duration of the experiment. Both heart rate and MABP tracing show perturbations at 10 and $40 \mathrm{~min}$. These decreases are artefacts caused by disconnecting the femoral artery catheter for reference blood sampling. During the addition of $7 \% \mathrm{CO}$, to the breathing gas mixture a clear increase in end tidal $\mathrm{CO}_{2}\left(\mathrm{EtCO}_{2}\right)$ can be observed in the $\mathrm{CO}_{2}$ group, this in contrast to the stable $\mathrm{EtCO}_{2}$ in the control group. At the time of the first microsphere injection $(10 \mathrm{~min})$ the $\mathrm{EtCO}_{2}$ level of the $\mathrm{CO}_{2}$ group has reached a stable plateau level. The sudden decrease in breathing rate observed in the $\mathrm{CO}_{2}$ group is an artefact caused by a temporary impossibility of the equipment to calculate the breathing rate during the increase in $\mathrm{EtCO}_{2}$. For both groups the $\mathrm{O}_{2}$-saturation of arterial blood and the rectal temperature tracings are comparable and well within normal physiological ranges. 

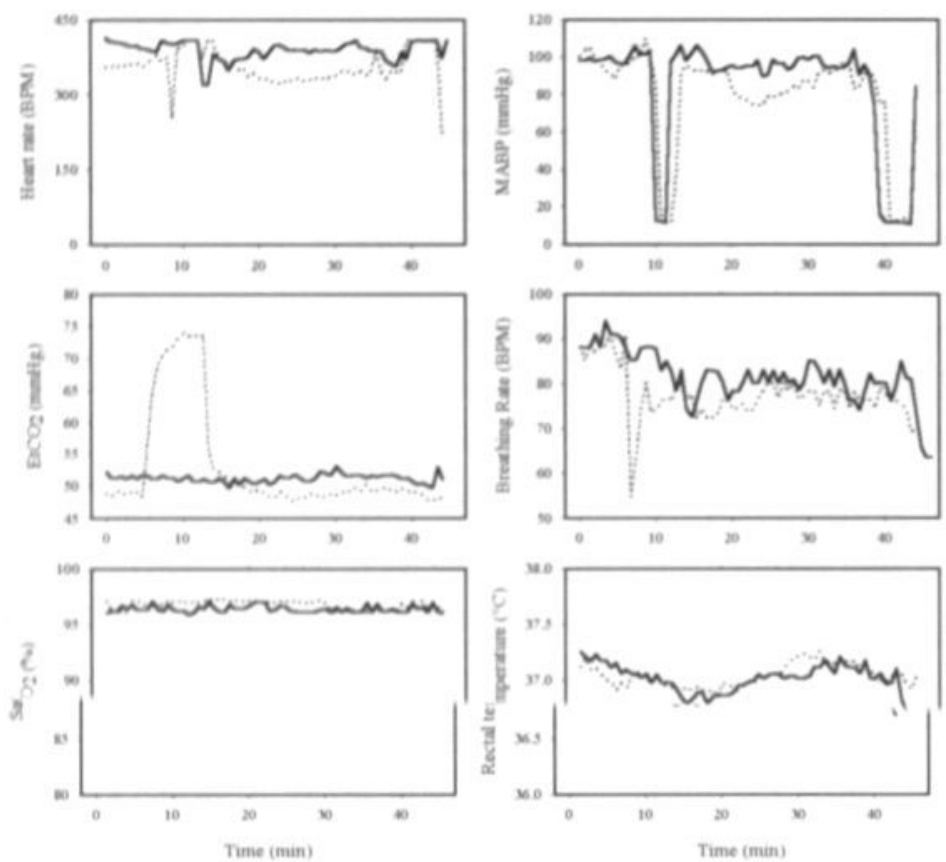

Figure 1. Every twentieth median value of the tracings from the different parameters from both groups $(n=7)$. The full line represents the median tracing of the control group and the dotted line the median tracing of the $\mathrm{CO}_{2}$ group. (MABP: mean arterial blood Nesseve, ifeCs? inortidalco $\mathrm{SaO}_{\gamma}$ : arterial saturation of haemoglobin with $0_{2}$ ).
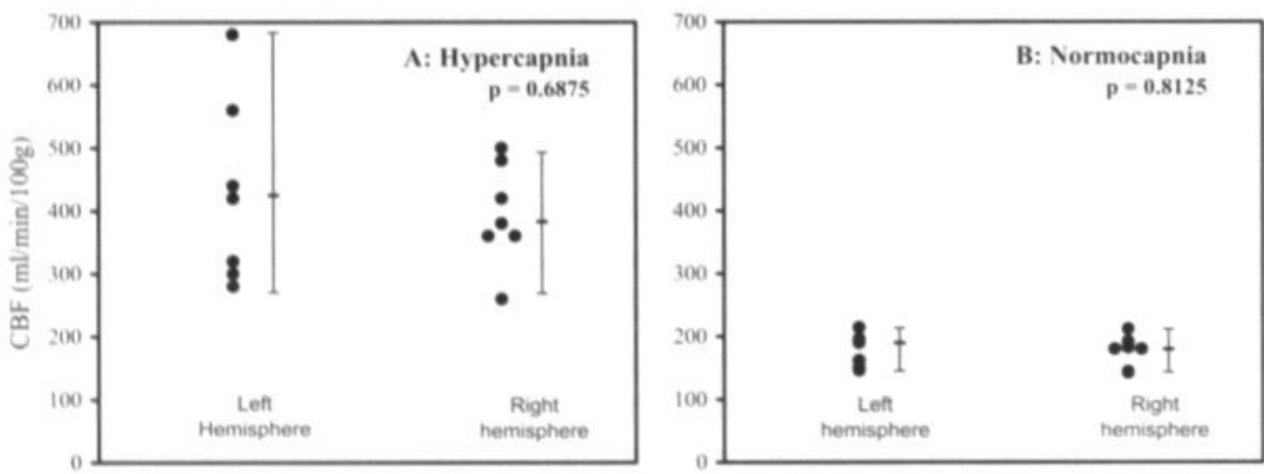

Figure 2. A. Median flow data $(\mathrm{n}=7)$ and $[95 \% \mathrm{CI}]$ as assessed in both hemispheres during hypercapnia induced by $7 \%$ $\mathrm{CO}$, breathing. B. Flow data from the same animals $30 \mathrm{~min}$. after termination of $7 \% \mathrm{CO}$, breathing.

The absence of differences between left and right hemispheric flow, a prerequisite for adequate $\mathrm{CBF}$ measurement, is illustrated in figure 2. All data in this figure are obtained from the $\mathrm{CO}_{2}$ group. Also in the control group there were no differences between both hemispheric CBF's (first CBF assessment: 209 [193-323] vs. $239[187-319] \mathrm{ml} / \mathrm{min} / 100 \mathrm{~g}$ ( $\mathrm{p}=0.6875)$ : second CBF assessment: $237[158-466]$ vs. $207[152-513] \mathrm{ml} / \mathrm{min} / 100 \mathrm{~g}(\mathrm{p}=0.6875))$. Panel A shows the flow data from both hemispheres during hypercapnia-induced flow increase. Panel B shows the flow 
data $30 \mathrm{~min}$. after this hypercapnia when the animals had returned to their initial $\mathrm{PaCO}_{2}$ levels. Paired testing of both data sets did not show any difference between hemispheric flows during either hypercapnia or normocapnia. The flow increases were similar in both hemispheres. Using the same data in regression analyses also yielded a good correlation between both hemispheric flows as illustrated in figure 3. The slope of the regression line did not differ from 1 (slope [95 \% $\mathrm{CI}]=1.31[0.89,1.74])$.

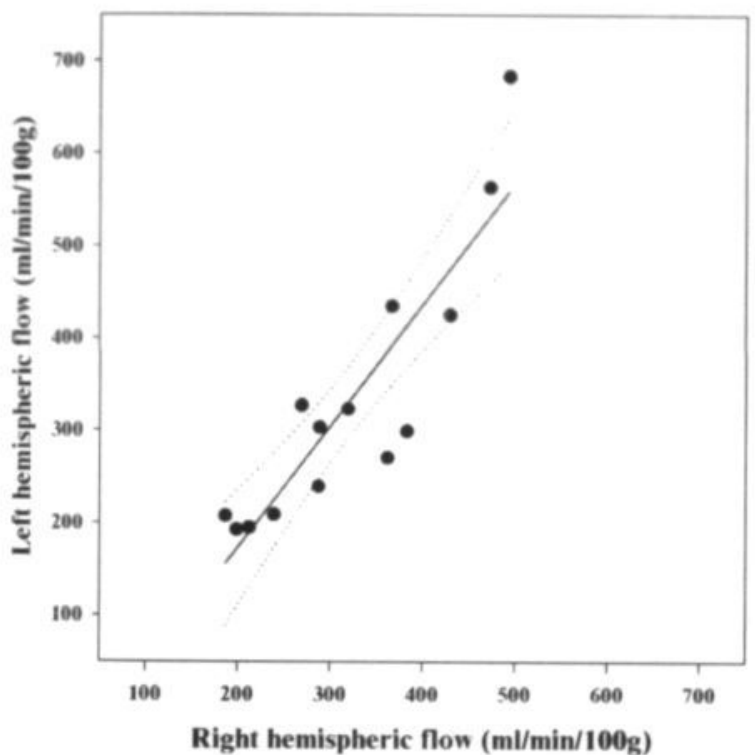

Figure 3. Comparison between both hemispheric flows using regression analysis and $95 \% \mathrm{Cl}$. Regression line: left hemispheric flow $=1.31 \times$ right hemispheric flow -89.68 and $R=0.89$.

Figure 4 shows the first ( $10 \mathrm{~min})$ and second $(40 \mathrm{~min})$ flow measurements in both groups. In the control group (panel A) the two measurements were comparable. The first and the second CBF measurement in the $\mathrm{CO}_{2}$ group were significantly different, indicating a marked increase of flow during hypercapnia (first measurement). During normocapnia, the $\mathrm{CBF}$ is decreased to values comparable with the control group $(\mathrm{p}=0.0728)$. 

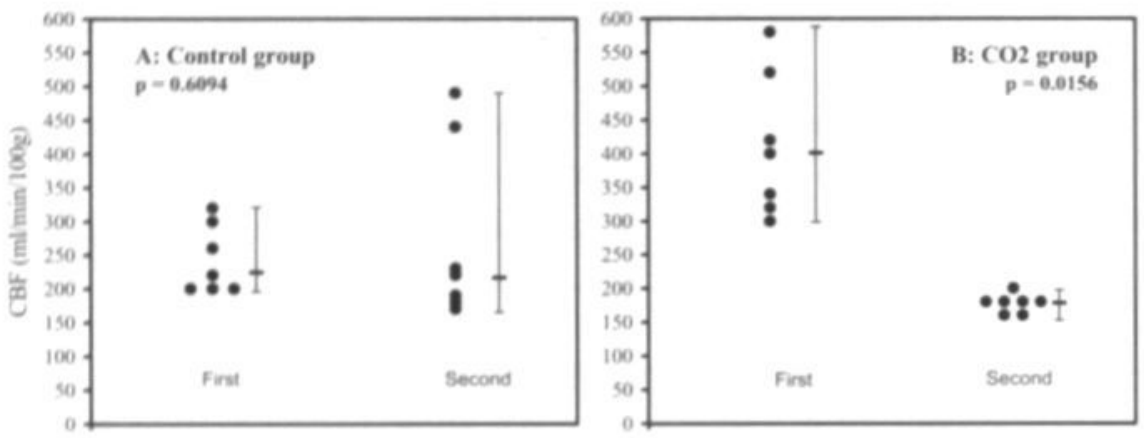

Figure 4. Median hemispheric flow data $[95 \% \mathrm{Cl}]$ at two time points in the normocapnic control group $(\mathbf{A})$ and during and 30 min. after $7 \% \mathrm{CO}_{2}$ breathing (B).

Figure 5 shows microscopic images of the brain tissue in normal conditions ( $\mathrm{A}$ and $\mathrm{C}$ ) and 3 days after induction of $9 \mathrm{~min}$ incomplete ischemia. The induction of incomplete ischemia has been described earlier (Smith et al., 1984) and is one of the models used in our lab (Haseldonckx et al., 1997). Two microsphere flow measurements were performed before and during incomplete ischemia, respectively. Panel A clearly shows the presence of both the yellow-green and red microspheres on a $100 \mu \mathrm{m}$ slice from the brain of a control animal. In the other animals the presence of microspheres injected during the incomplete ischemia is low. In 7 animals we counted a total of $31[28,32]$ sections and $1395[855,1546]$ and $228[148,581]$ microspheres were found during baseline and ischemia respectively, thus resulting in a maximum residual flow of $18.8 \%[13.4,38.5]$. The real flow is probably less then the calculated figures, since the reference samples contained an increased amount of microspheres due to the induced hypovolemia. In the measurements during ischemia one higher count (581) was found for which 482 were found in the right hemisphere, clearly indicating an incomplete clamping of the ipsilateral carotid artery or of a inhomogeneous mixing of the microspheres Panel B shows a 100 $\mu \mathrm{m}$ slice from a comparable area of the brain from a rat which underwent $9 \mathrm{~min}$ of incomplete ischemia and survived for 3 days. The azure-eosin stain contains organic solvents that dissolve the present microspheres. For this reason the microsphere counting has to be performed before this staining method. This picture clearly shows the pyramidal cell damage in the hippocampal CAI region after this insult. Panel $\mathrm{C}$ shows the normal aspect of the pyramidal cells on a $2 \mu \mathrm{m}$ slice of the CAI region. Panel D is a similar section after the incomplete ischemia showing clear evidence of both coagulative pyramidal cell change and microglial activation. 

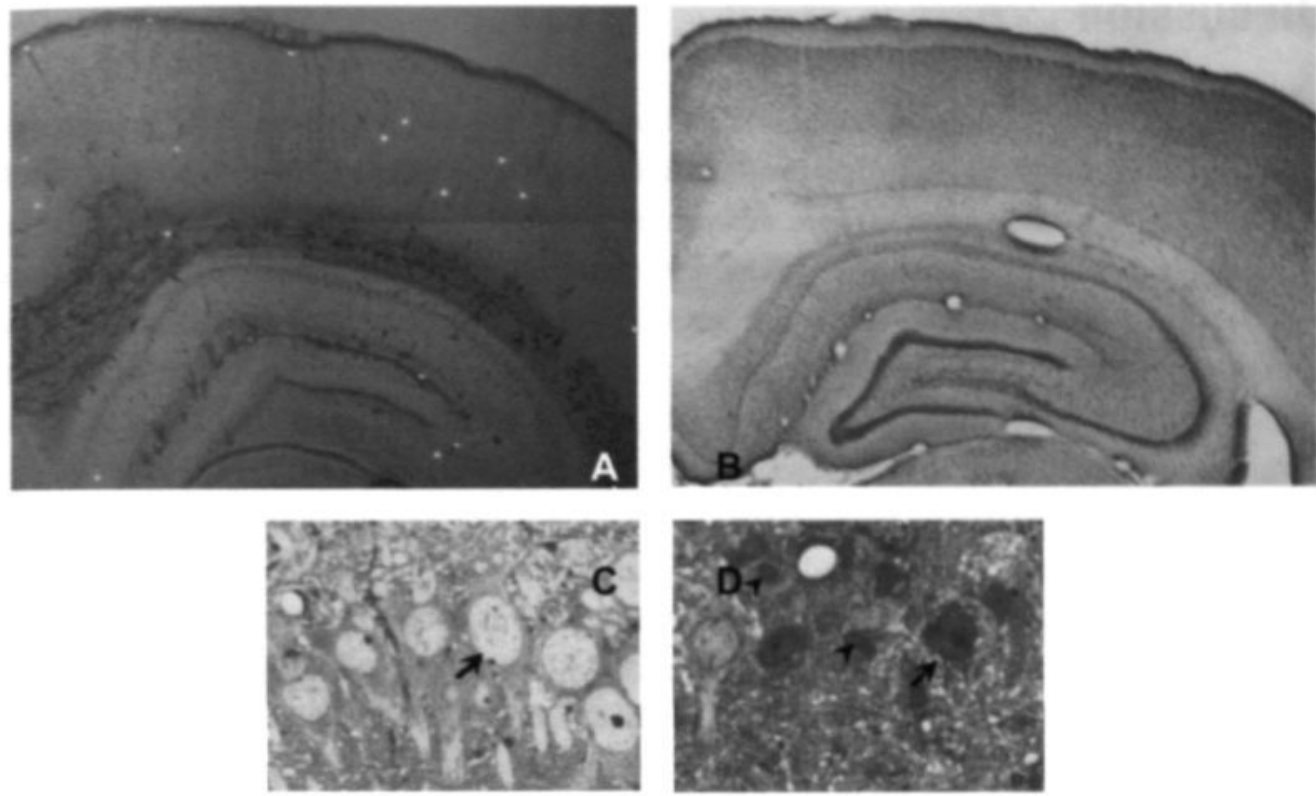

Figure 5. A. Mosaic picture of $100 \mu \mathrm{m}$ unstained vibratome section showing yellow-green and red fluorescent microspheres in cortical and hippocampal region. B. $100 \mu \mathrm{m}$ azure-eosin stained vibratome section showing pyramidal cell damage in the hippocampal CA1 region 5 days after $9 \mathrm{~min}$. incomplete ischemia. C. $2 \mu \mathrm{m}$ section adjacent to a vibratome section used for microsphere counting showing the normal aspect of the pyramidal cells (arrow) in a control rat. D. $2 \mu \mathrm{m}$ section of the CA1 region showing coagulative pyramidal cell change (arrow) and microglial activation (arrowhead) 5 days after ischemia. 


\section{Discussion}

In a first preliminary study we found a significant difference in left versus right hemispheric blood flow during hypercapnia when the fluorescent microspheres were injected via the external carotid artery (data not shown). These differences were not detectable in control animals. This experiment was terminated because in these conditions the rCBF measurement was not regarded accurate. Other groups had also shown differential flow distributions during hypercapnia when one carotid artery was occluded (De Ley et al., 1985). This problem was solved by placing the cannula for microsphere injection into the left ventricle via the brachial artery instead of the carotid artery, a procedure already described by Nakai and coworkers (1990).

The second problem we encountered was the loss of microspheres during the filtration of the reference blood sample. Since the microspheres trapped in the tissue and counted on the tissue slices gave us a number of microspheres without any loss, the CBF was largely overestimated. An analysis of subsequent filtrations indicated that three filtrations yielded a sufficient estimate ( $>97 \%$ ) of the real microsphere amount. Further addition of filtration is only time consuming and not extensively improving the CBF assessment.

As stated above our experiment also included a continuous monitoring of certain physiological variables in order to detect changes induced by the microsphere injections. Since no changes in either heart rate or MABP were found we are confident that the amount of microspheres injected did not alter general blood circulation and tissue perfusion. This is also concurrent with the findings of Kobayashi and co-workers (1994) that showed no haemodynamic disturbances after up to 4 subsequent injections of 500.000 microspheres. We remained well below this threshold with the injection of two boli of 100.000 microspheres each.

As figure clearly illustrates, the two subsequent microsphere cerebral blood flow assessments result in comparable cerebral blood flows, thus indicating that the second flow measurement is not influenced by the residing microspheres left in the tissue after the first flow measurement. From the same figure we can also conclude that this technique allows measurement of physiological cerebral blood flow alterations, which we studied with the use of induced hypercapnia and the return to the baseline values after hypercapnia. These facts lead us to conclude that it is certainly possible to perform two subsequent cerebral blood flow measurements. Furthermore it is our believe that additional measurement can be performed since the total amount of microspheres was far below the amount that was shown to cause blood flow alterations by Kobayashi and coworkers (1994). We also could not detect any morphological damage in normal and hypercapnic 
rats after microsphere injection, thus ensuring that the microspheres do not cause any damage by themselves.

Although we did not fully describe the cerebral blood flow during incomplete ischemia, we were still able to detect a small amount of microspheres in the rat brain. The number of microspheres counted during ischemia was well below the minimal 400 microspheres required to obtain an accurate microsphere blood flow assessment (Buckberg et al., 1971). This loss in accuracy could possible be solved by injection of a higher amount of microspheres.

The above described technique has two major advantages. The first is the possibility of animal survival for a long period of time after microsphere injection, after which the animals is sacrificed for the final microsphere count. This allows ischemic injury maturation in our experiments, but could also be useful in other experiments. More important is the unique possibility to obtain both cerebral blood flow data and histological examination results not only from the same animal but also from the same section, thus enabling a direct study of CBF combined pathophysiological morphology and histology.

We conclude that the fluorescent microsphere technique can be used to assess rCBF at two different time points in the same animal. This allows studying changes in rCBF during physiologic or pathologic conditions. The described approach allows combining the assessment of rCBF with detailed histological evaluation of the same brain region of the same animal. Histological evaluation of the brain several days after injection of the microspheres allows correlating the measured changes in flow with the neuropathological consequences. 


\section{References}

Abel FL, Cooper RH, Beck RR (1993) Use of fluorescent latex microspheres to measure coronary blood flow distribution. Circ. Shock 41: 156-161.

Austin GE, Tuvlin MB, Martino-Salzman D, Hunter RL, Justicz AG, Thompson NK, Brooks AC (1993) Determination of regional myocardial blood flow using fluorescent microspheres. Am. J. Cardiovasc. Pathol. 4: 352-357.

Buckberg GD, Luck JC, Payne DB, Hoffman JI, Archie JP, Fixler DE (1971) Some sources of error in measuring regional blood flow with radioactive microspheres. J. Appl. Physiol. 31(4): 598-604.

De Ley 6, Nshimyumuremyi J-B, Leusen I (1985) Hemispheric blood flow in the rat after unilateral common carotid occlusion: evolution with time. Stroke 16(1): 69-73.

Demchuk AM, Buchan AM (2000) Predictors of stroke outcome. Neurol. Clin. 18(2): 455-473.

Glenny RW, Bernard S, Brinkley M (1993) Validation of fluorescent-labeled microspheres for measurement of regional organ perfusion. J. Appl. Physiol. 74: 2585-2597.

Hale SL, Alker KJ, Kloner RA (1988) Evaluation of nonradioactive, colored microspheres for the measurement of regional myocardial blood flow in dogs. Circ. 78: 428-434

Haselonckx M, Van Reempts J, Van de Ven M, Wouters L, Borgers M (1997) Protection with lubeluzole against damage in rats. A quantitative histopathologic study. Stroke 28: 428-432.

Herijgers P, Leunens V, Tjandra-Maga TB, Mubagwa K, Flameng W (1996) Changes in organ perfusion after brain death in the rat and its relation to circulating catecholamines. Transplantation 62(3): 330-335.

Kobayashi N, Kobayashi K, Kouno K, Horinaka S, Yagi S (1994) Effects of intra-atrial injection of colored microspheres on systemic hemodynamics and regional blood flow in rats. Am. J. Physiol. 266: H1910-1917.

Kowallik P, Schulz R, Guth BD, Schade A, Paffhausen W, Gross R, Heusch G (1991) Measurement of regional blood flow with multiple colored microspheres. Circ. 83: 974-982.

Makowski EL, Meschia G, Droegemueller W, Battaglia FC (1968) Measurement of umbilical arterial blood flow to the sheep placenta and fetus in utero: Distribution of cotyledons and the intercotyledonary chorion. Circ. Res. 32: 623-631.

Mori H, Haruyama S, Shinozaki Y, Okino H, lida A, Takanashi R, Sakuma I, Husseini WK, Payne BD, Hoffman JI (1992) New nonradioactive microspheres and more sensitive $\mathrm{X}$-ray fluorescence to measure regional blood flow. Am. J. Physiol.263: H1946-1957.

Morita Y, Payne BD, Aldea GS, McWatters C. Husseini W, Mori H, Hoffman JI, Kaufman L (1990) Local blood flow measured by fluorescence excitation of nonradioactive microspheres. Am. J. Physiol. 258: H1573-1584.

Nakai M, Tamaki K, Yamamoto J, Shimouchi A, Maeda M (1990) A minimally invasive technique for multiple measurement of regional blood flow of the rat brain using radiolabeled microspheres. Brain Res. 507: 168-171.

Prinzen FZ, Glenny RW (1994) Developments in non-radioactive microsphere techniques for blood flow measurement. Cardiovasc. Res. 28: 1467-1475.

Rudolph AM, Heymann MA (1967) The circulation of the fetus in utero: Methods for studying distribution of blood flow, cardiac output and organ blood flow. Circ. Res. 21: 163-184.

Smith ML, Bendek G, Dahlgren N, Rosen I, Wieloch T, Siesjö BK (1984) Models for studying long-term recovery following forebrain ischemia in rat. Acta Neurol. Scand. 69: 385-401. 
Chapter 5

Validation of CBF assessment by means of indocyanine green bolus transit detection with NIRS: a comparison with coloured microsphere flowmetry

Geofrey De Visscher, Veerle Leunens, Marcel Borgers, Robert S. Reneman, Willem Flameng \& Koen van Rossem 


\section{Abstract}

The aim of this study was to validate the blood flow index (BFI), derived from the transit of an indocyanine green (ICG) bolus through the brain as monitored with near infra-red spectroscopy, for the measurement of cerebral blood flow in rats.

In a first part of the study, 72 male Sprague-Dawley rats received a $5 \mu \mathrm{I} \mathrm{ICG} \mathrm{bolus} \mathrm{either} \mathrm{after}$ i.v. administration of I-NAME ( 30 or $15 \mathrm{mg} / \mathrm{kg}$ ), or during $\mathrm{CO}_{2}$ breathing $(4$ or $7 \%$ ) or in control conditions. $\mathrm{CO}_{2}$ breathing and treatment with I-NAME respectively resulted in a dose dependent increase and decrease of the $\mathrm{BFI}$. Control animals with different body weight were used to evaluate the dependence of the BFI on blood volume. The observed volume effect could be eliminated by multiplication of the $\mathrm{BFI}$ with body weight $\left(\mathrm{BFI}_{w}\right)$.

In the second part, the $\mathrm{BFI}_{w}$ was compared with the $\mathrm{CBF}$ as measured with coloured microspheres (MS-flow). In order to increase the range over which the comparison was made, one group of rats was treated with I-NAME ( $30 \mathrm{mg} / \mathrm{kg}$ i.v.), a second with $7 \% \mathrm{CO}_{2}$ breathing, and a third group did not receive any treatment $\left(\mathrm{n}=12\right.$ in each group). The $\mathrm{BFI}_{w}$ as well as the MS-flow were significantly different in low, normal and high flow conditions. $\mathrm{BFI}_{w}$ showed to be a significant linear predictor of MS-flow. Linear regression analysis: $\mathrm{MS}$-flow $=62.4+7.06 \mathrm{BFI}_{w}$ $(\mathrm{R}=0.6466 ; \mathrm{p}<0.0001)$. We conclude that the $\mathrm{BFI}_{w}$ is an accurate predictor of global $\mathrm{CBF}$ as measured with coloured microspheres. 


\section{Introduction}

Jöbsis (1977) was the first to make use of the relative transparency of brain tissue to the wavelengths of light ranging from 700 to $1000 \mathrm{~nm}$ to measure tissue oxygenation and circulatory parameters non-invasively. Since then this technique, known as near-infrared spectroscopy (NIRS), has been further developed for use in both experimental and clinical conditions to monitor oxygenation of blood and tissue. Related applications in brain include the measurement of cerebral blood flow in adults (Olsen et al., 1996) and preterm infants (Edwards et al., 1988), detection of intracranial haematomas after head injury (Robertson et al., 1995), functional imaging in adults (Villringer et al., 1993; Tamura et al., 1997), quantitation of cerebral blood volume in infants (Wyatt et al., 1990) and measurement of mitochondrial dysfunction via the cytochrome oxidase signal (Cooper et al., 1999).

In our laboratory, NIRS has been used to investigate brain oxygenation after closed head injury in an experimental rat model (van Rossem et al., 1999a+b) and during transient anoxia (De Visscher et al., 2002a), using a multiwavelength NIRS system developed at the University College London (Cope et al., 1989; Matcher et al., 1995). In transmission mode, this system allows to monitor the oxygenation of the whole rat brain. We also have shown that the transit of a small bolus of indocyanine green (ICG) through the brain can be accurately monitored with NIRS in rats (De Visscher et al., 2002b).

ICG is a non-toxic dye with a specific absorption spectrum in the near-infrared range. Since its development in the Kodak Research Laboratories (Brooker, 1955; Fox and Wood, 1960) and introduction in clinical research in 1956 (Fox et al., 1956), many clinical applications have been described for ICG. After i.v. injection, the dye is almost entirely confined to the blood compartment and it has been used to measure plasma volume (Haller et al., 1993) and blood flow in humans (Roberts et al., 1993; Ruokonen et al., 1993; Burggraaf et al., 1998; Roberts et al., 1998). In rats, plasma and red blood cell transit through a region of the cortex was assessed simultaneously by dual wavelength NIRS and single bolus injection of ICG (Eke et al., 1997). ICG bolus transit detection with NIRS has been used to measure CBF quantitatively in newborn piglets by simultaneous monitoring of the concentration of ICG in the brain and the arterial blood by multiwavelength NIRS and ICG pulse oxymetry respectively (Springett R., personal communication). The latter technique can not be applied in small laboratory animals since heart rate exceeds the frequency limit of the existing pulse oxymeters. Qualitative measurements of CBF in pigs were performed by Kuebler et al. (1998) who calculated a blood flow index (BFI) from the ICG bolus transit curve according to a derivative of the Sapirstein bolus fraction principle (Perbeck et al., 1985b). We have adapted this method for use in the rat, a more 
commonly used laboratory animal. Injection of $5 \mu \mathrm{l}$ of ICG solution into the right atrium of the anaesthetised rat provides clear bolus transit curves, and repeated $\mathrm{CO}_{2}$ breathing $(7 \%)$ results in a reproducible increase of the BFI (De Visscher et al., 2002b).

The aim of the present study was to validate in rats the ICG bolus transit detection technique by comparing it to an established method for quantitative measurement of CBF using microspheres. Hypercapnia and I-NAME were applied to induce a wide range of CBF. In Sprague-Dawley rats $\mathrm{CO}_{2}$ is known to increase flow (Estevez et al., 1997) due to vasodilation while I-NAME decreases flow (Macrae et al., 1993) due to vasoconstriction. Different variants of the microsphere based flow technique exist (Prinzen and Glenny, 1994; Prinzen and Bassingthwaighte, 2000). The one we chose was a coloured microsphere method using the dye extraction technique first described by Kowallik et al. (1991) and routinely applied to measure organ perfusion, including brain perfusion, in rats (Herijgers et al., 1996). 


\section{Materials and Methods}

\section{Animal treatment and preparation}

Animal housing and treatment conditions complied with the European Union directive \# 86/609 on animal welfare. Ninety-six male Sprague-Dawley rats (Charles River, Sulzfeld, Germany) weighing 380-430 $\mathrm{g}$ and twelve rats between $280-330 \mathrm{~g}$ were used. Anaesthesia was induced with $5 \%$ isoflurane in $30 \% \mathrm{O}_{2}$ and $70 \% \mathrm{~N}_{2} \mathrm{O}$ during $5 \mathrm{~min}$. After endotracheal intubation, the animal was placed on a rectal temperature controlled heating pad. The left ventricle was cannulated for microsphere injection via the right brachial artery with a PE10 catheter threaded on a PE50 catheter (Nakai et al., 1990). For ICG bolus injection the right external jugular vein was cannulated with a silicon tipped PE50 catheter prefilled with albumin bound ICG solution. Both femoral arteries were cannulated with PE50 catheters for continuous monitoring of arterial pressure and arterial blood sampling. The left femoral vein was cannulated with a PE50 catheter for I-NAME administration.

The rats were fixed in a stereotaxic apparatus (Model 900, David Kopf, Tujunga, CA, USA). A thermistor inserted into the tip of an ear bar was used to measure the tympanic temperature, providing an accurate measurement of brain temperature (Brambink et al., 1999). A rectal thermistor probe was inserted to monitor body temperature, which was maintained at $37{ }^{\circ} \mathrm{C}$ $\left( \pm 0.5^{\circ} \mathrm{C}\right)$ using a homemade temperature control unit connected with the heating pad. The end tidal $\mathrm{CO}_{2}\left(\mathrm{EtCO}_{2}\right)$ and breathing rate were continuously monitored with an $\mathrm{EtCO}_{2}$-monitor (Capnogard, Novametrix, Wallingford, CT, USA).

The parietal and temporal bones were exposed by removing the scalp, periosteum and parts of the temporal muscles. Sites of possible bleeding were cauterised and the temporal bones were covered with cyano-acrylate glue. Emitting and receiving optical fibres ( $3 \mathrm{~mm}$ diameter) were placed onto the right and left temporal bones, respectively (frontal pole of the fibres at the level of the bregma, angle of $\pm 10^{\circ}$ relative to both the coronal and sagittal plane). To prevent blood entering the space between the skull and the optical fibre, optical gel (Optical Gel code 0608, R.P. Cargille Laboratories Inc., Cedar Grove, New Jersey, USA) was used to fill this space and to provide good optical coupling. The skull was covered with black clay (Modelling clay No 8401 , Eberhard Faber GmbH, Neumarkt, Germany).

The isoflurane concentration was then switched to $1.5 \%$ and this level was maintained till the end of the experiment. Five minutes prior to the start of the measurements a blood sample 
for blood gas analysis was taken. Measurements were started $90 \mathrm{~min}$ after the induction of anaesthesia and a stabilisation period of $15 \mathrm{~min}$ was allowed before the injection of the ICG bolus into the jugular vein.

In the first part of the study only the ICG bolus derived BFI was calculated. $\mathrm{CO}_{2}$ and I-NAME were used at different concentrations to increase or decrease flow, respectively. Sixty $(380-430 \mathrm{~g})$ animals where randomly assigned to five treatment groups ( $\mathrm{n}=12$ in each group): $30 \mathrm{mg} / \mathrm{kg}$ I-NAME, $15 \mathrm{mg} / \mathrm{kg}$ I-NAME, control, $4 \% \mathrm{CO}$ (final mixture: $30 \% \mathrm{O}_{2}, 66 \% \mathrm{~N}_{2} \mathrm{O}$, $4 \% \mathrm{CO}_{2}$ ) and $7 \% \mathrm{CO}_{2}$ (final mixture: $30 \% \mathrm{O}_{2}, 63 \% \mathrm{~N}_{2} \mathrm{O}, 7 \% \mathrm{CO}_{2}$ ). A sixth group $(\mathrm{n}=12)$ consisted of control animals with low body weight $(280-330 \mathrm{~g})$. The latter group was included to check possible influences of blood volume on BFI. I-NAME was dissolved in saline at a concentration of $24 \mathrm{mg} / \mathrm{ml}$ and injected i.v. as a bolus $5 \mathrm{~min}$ prior to the injection of ICG. $\mathrm{CO}_{2}$ breathing was started 5 min prior to the flow assessment and maintained until the end of the experiment. Immediately after monitoring of the ICG bolus transit through the brain the animals were killed by terminal anoxia.

Thirty-six rats were used in the second part of this study. The animals were randomly assigned to three treatment groups ( $\mathrm{n}=12$ in each group). The first group was treated with $30 \mathrm{mg} / \mathrm{kg}$ I-NAME (in saline) intravenously. The second was subjected to $7 \% \mathrm{CO}_{2}$ breathing (final mixture: $30 \% \mathrm{O}_{2}, 63 \% \mathrm{~N}_{2} \mathrm{O}, 7 \% \mathrm{CO}_{2}$ ) five min prior to flow assessment while the third group did not receive any treatment and served as control. Each rat received a $5 \mu$ l bolus injection of ICG into the right jugular vein followed by injection of 100,000 coloured microspheres into the left ventricle. A reference blood sample was taken over a period of $2 \mathrm{~min}$ from the left femoral artery starting before the onset of microsphere injection (flow rate: $0.566 \mathrm{ml} / \mathrm{min}$ ). Immediately after monitoring of the ICG bolus transit through the brain the animals were killed by terminal anoxia.

\section{NIRS equipment}

The NIRS system and algorithms have been described previously (Springett et al., 2000). NIR spectra were collected contiguously with a period of $100 \mathrm{~ms}$ and 100 spectra were averaged to give a time resolution of 10 seconds $(0.1 \mathrm{~Hz})$. Absolute changes in the concentration of oxyhaemoglobin $([\mathrm{HbO}]$,$) , deoxyhaemoglobin ([\mathrm{Hb}])$ and oxidised $\mathrm{Cu}_{A}\left(\left[\mathrm{Cu}_{A}\right]\right)$ were calculated from the change in attenuation between 780 and $900 \mathrm{~nm}$ (Cope et al., 1989; Matcher et al.. 1995) and normalised to the baseline optical pathlength measured from the $840 \mathrm{~nm}$ water feature using $2^{\text {nd }}$ differential analysis (Matcher and Cooper, 1994). Assuming an $85 \%$ water 
content of the brain, the absolute concentration of $\mathrm{Hb}$ was obtained from $2^{\text {nd }}$ differential analysis and normalised to the pathlength obtained from the $740 \mathrm{~nm}$ water feature. The absolute [Hb] and absolute changes in $\left[\mathrm{HbO}_{2}\right]$ and $\left[\mathrm{Cu}_{A}\right]$ were monitored on-line. Absolute $\left[\mathrm{HbO}_{2}\right]$ was back-calculated taking the value after terminal anoxia as zero. Total haemoglobin ([HbT]) was calculated as the sum of $\left[\mathrm{HbO}_{2}\right]$ and $[\mathrm{Hb}]$, and mean cerebral saturation of haemoglobin with oxygen $\left(\mathrm{SmcO}_{2}\right)$ by the following formula: $\mathrm{SmcO}_{2}=\left(\left[\mathrm{HbO}_{2}\right] /[\mathrm{HbT}]\right) \times 100$. ICG has an absorption peak at $805 \mathrm{~nm}$ (Landsman et al., 1976) and can be measured by the same set up as the ICG absorption spectrum is included in the algorithm. For ICG bolus transit detection the sampling frequency was switched from $0.1 \mathrm{~Hz}$ to $10 \mathrm{~Hz}$ (no averaging).

\section{Indocyanine green solution}

A $1 \mathrm{ml} / \mathrm{mg}$ ICG (IR-125, laser grade; Acros, Geel, Belgium) solution was used. Five percent bovine serum albumin (BSA fraction V; Sigma, Bornem, Belgium) was added to this solution to bind the ICG. The solution was then sterilised by filtration with a $0.22 \mu \mathrm{m}$ filter unit. If BSA is added, ICG will not bind to the endothelium of the vascular wall and a clear passage of the bolus can be detected. The ICG solution is also stable when BSA is added; otherwise self-aggregation of the dye may occur (Cherrick et al., 1960; Gentile et al., 1985).

\section{Coloured microsphere flow measurement}

After the ICG blood flow assessment, a reference blood sample was withdrawn for 2 min from the left femoral artery at a flow rate of $0.566 \mathrm{ml} / \mathrm{min}$, using a pump (Harvard apparatus, Infusion/ Withdrawal pump, South Natick, Massachusetts, USA). When the first blood entered the syringe, a $100 \mu \mathrm{l}$ bolus containing approximately 100.000 microspheres with a diameter of $15 \mu \mathrm{m}$ (DyeTrak, Triton, San Diego, CA, USA) was injected into the left ventricle over a $20 \mathrm{~s}$ period. The catheter was then flushed with $0.5 \mathrm{ml}$ saline for another $20 \mathrm{~s}$. At the end of the experiment the rat was killed and the brain and both kidneys were excised. The brain was further dissected into the following parts: the cerebellum and both cerebral hemispheres. All tissue samples were weighed and then digested in $4 \mathrm{M} \mathrm{KOH}$ in saline. The digested samples were negative pressure filtered using $10 \mu \mathrm{m}$ pore polyester filter membranes (Dye-Trak, Triton, San Diego, CA, USA). Dimethylformamide was used to extract the dye from the microspheres and the dye concentration was determined by automated spectrophotometry (Wieland et al., 1993). The following formula was used to calculate the organ blood flow: 


$$
\mathrm{C}_{\mathrm{b}} \times \mathrm{RBF} \times 100
$$

Organ blood flow $(\mathrm{ml} / \mathrm{min})=$

$$
\text { C, }
$$

Where $\mathrm{C}_{b}$ is counts in tissue sample, $\mathrm{C}_{r}$ is counts in reference sample and $\mathrm{RBF}$ is the reference withdrawal rate. The calculated organ blood flow was divided by the tissue weight resulting in the MS-flow expressed as $\mathrm{ml} / \mathrm{min} / 100 \mathrm{~g}$. Since the ICG flow assessment is a CBF measure of the total brain, the MS-flow used for comparison of both techniques was calculated as the weighed mean value from the three parts of the brain. If the difference between the flow of the left and the right kidney exceeded $10 \%$ the animal was excluded due to inhomogeneous mixing of the coloured microspheres in the circulation.

\section{Data analysis}

\section{Blood flow index calculation}

$\triangle \mathrm{ICG}$ was calculated from the ICG bolus transit curve by subtraction of the baseline value. taken immediately before injection (mean value of 20 measurements), from the peak value after injection. The rise time $(\Delta t)$ was measured as the time between the first value where the ICG signal deviates from the baseline and the peak value. The blood flow index (BFI) was then calculated by dividing $\Delta$ ICG by $\Delta t$ (Kuebler et al., 1998; De Visscher et al., 2002b). The index was then corrected for individual differences in blood volume by multiplying the BFI with the bodyweight expressed in grams $\left(\mathrm{BFI}_{w}=\mathrm{BFI} \times \mathrm{BW}\right)$. Since blood volume is linearly proportional to body weight, the latter can be used as a valid correction factor.

\section{Statistical analysis}

All the results are expressed as means \pm standard deviation (SD). Within each study the groups were first compared using a Kruskal-Wallis test. When a significant difference was found ( $p<$ 0.05 ) a two-sided Wilcoxon-Mann-Whitney rank-sum test was used for analysis between pairs of groups separately. Two-sided probability values of less than 0.05 were regarded as statistically significant. Linear regression and Bland and Altmann (1986) analyses were used to evaluate the correlation and agreement between both flow measurement techniques. A Wilcoxon signed rank 
test was used to test whether the differences between both methods were significantly different from zero ( $p<0.05$ ). The Shapiro-Wilk W test $(p<0.10)$, combined with a normal quantile plot was used to test the normality of the distribution of these differences. 


\section{Results}

\section{ICG cerebral blood flow study}

Table I summarises physiological data before the onset of the NIRS-measurement. The brain weight was obtained post mortem. An obvious significant difference in the body weight (BW) was found between the low weight (LW) control group and all other groups. The brain weight in the LW control groups was significantly different from all other groups except for the group treated with $4 \% \mathrm{CO}_{2}$. The baseline values of the pH-measurements showed statistically significant differences between groups, though all obtained values were within the normal physiological range.

\begin{tabular}{|c|c|c|c|c|c|c|c|}
\hline$(n=12)$ & I-NAME: $30 \mathrm{mg} / \mathrm{kg}$ & I.NAME: $15 \mathrm{mg} \mathrm{kg}$ & Control & $\mathrm{CO}_{2}: 4 \%$ & $\mathrm{CO}_{2}: 7 \%$ & Control L.W & p-value \\
\hline Weight (g) & $403 * 10$ & $402 \div 10$ & $407 \div 15$ & $398 \div 24$ & $404: 13$ & $329^{\circ}+33^{\circ}$ & -00001 \\
\hline Bnain weighe (g) & $2.11+0.07$ & $2.10 \div 0.07$ & $2.09=0.06$ & $2.06+0.06$ & $2.10+0.08$ & $202 \div 0.10^{\prime}$ & 0.0195 \\
\hline $\mathrm{Pa}(\mathrm{O})$ (mm) $\left.\mathrm{Ig}_{\mathrm{g}}\right)$ & $40.5 \times 42$ & $42.6 * 2.3$ & $39.9 \times 3.6$ & $41.6+5.1$ & $40.3 \times 2.8$ & $42.9+3.2$ & 0.1083 \\
\hline $\mathrm{PaO}_{3}(\mathrm{~mm} / \mathrm{lg})$ & $111+18$ & $107+10$ & $106+10$ & $105 \times 12$ & $114 * 13$ & $96.1+12$ & 0.0569 \\
\hline pH & $73 x+003$ & $7.37 \times 0.03$ & $7.38+0.02$ & $7.39 \times 0.02$ & $7.40 \div 0.024$ & $736+0.02$ & 0.0122 \\
\hline
\end{tabular}

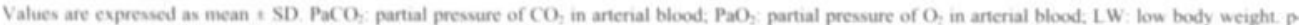
valuss lower than 005 indicate the existence of a difference between groups (Knuskal-Wallis comparison), a: significantly different from all other groups; b significantly different from all other groups except $\mathrm{CO}_{2} 4 \%, \mathrm{c}$ : significantly different from control and both $\mathrm{CO}$ groups; $d$ significantly different from control and I.NAMI (15 mg $\mathrm{kg}$ ) group (a, b, $c$ and $\mathrm{d}$ were obtained with Wilcoxon-Mann-Whitney comparison).

Figure 1 shows the effect of correction of the BFI for body weight $\left(B F I_{w}=B F I x B W\right)$. In figure IA the BFI's are shown for both the control and the LW control group. The BFI in the LW control group was significantly higher than in the control group ( $p=0.0045)$, whereas the $\mathrm{BFI}_{w}$ was comparable between both groups $(\mathrm{p}=0.4428$; Figure $1 \mathrm{~B})$. The $\Delta \mathrm{t}$ was comparable between control and LW control groups: $1.47 \pm 0.22 \mathrm{~s}$ for the control group and $1.44 \pm 0.14 \mathrm{~s}$ for LW control group ( $p=0.8091)$. However, the $\triangle \mathrm{ICG}$ was significantly lower in the control group than in the LW control group: $0.062 \pm 0.009 \mu \mathrm{M}$ versus $0.083 \pm 0.131 \mu \mathrm{M}$ respectively $(p=0.0005)$. 

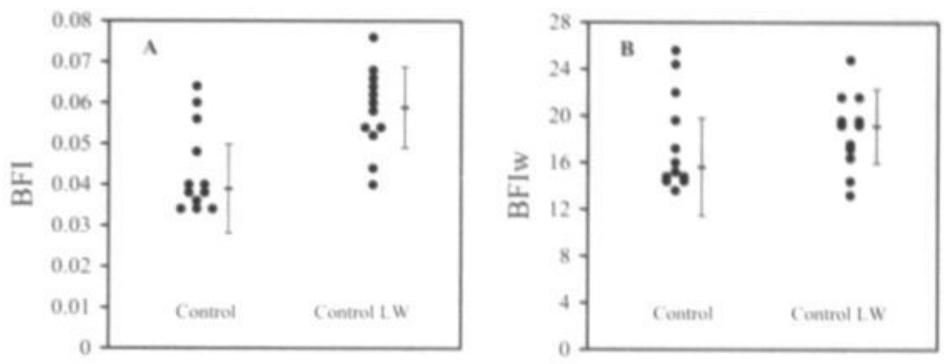

Figure 1. $\mathrm{BFI}$ and $\mathrm{BFI}$ corrected for blood volume $(\mathrm{BFI}=\mathrm{BFI} \times \mathrm{BW})$ in groups with different body weight. Dots represented individual data. Bars indicate mean \pm SD. Figure $1 A$ represents the $B F I$ data from both the normal and low body weight $(\mathrm{LW})$ control groups. BFI is significantly different between both control groups $(p=0.0045)$. The BFI data are represented in figure $1 . \mathrm{BFI}_{\mathrm{w}}$ is comparable between both groups $(\mathrm{p}=0.4428)$.

The $\mathrm{BFI}_{w}$ data from the control group and the groups treated with either I-NAME or $\mathrm{CO}_{2}$ are represented in figure 2 . The groups could be ranked according to increasing $\mathrm{BFI}_{w}$ as follows: INAME $(30 \mathrm{mg} / \mathrm{kg})<1$-NAME $(15 \mathrm{mg} / \mathrm{kg})<$ control $<\mathrm{CO}_{2} 4 \%<\mathrm{CO}_{2} 7 \%$. Except for the low dose I-NAME and the control group all differences between groups were statistically significant (Wilcoxon-Mann-Whitney; $\mathrm{p}<0.05$ ).

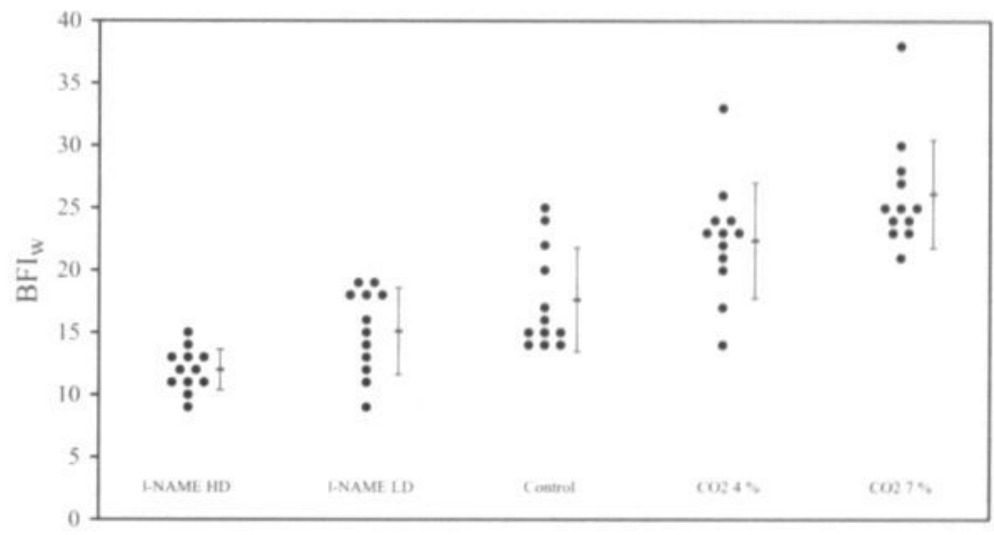

Figure 2. Scatterplot of $\mathrm{BFI}_{w}$ obtained from control animals, rats treated with i.v. injection of I-NAME at two dosages, and rats subjected to inhalation of different concentrations of $\mathrm{CO}_{2}$. Dots represent individual data. Bars indicate the mean and the $95 \% \mathrm{Cl}$. All groups are significantly different from each other except for the I-NAME (15 mg/kg) and the control group (Wilcoxon-Mann-Whitney; $\mathrm{p}<0.05$ ). The $\mathrm{BFI}_{w}$ increases dose dependently with the $\mathrm{CO}_{2}$, compatible with an increased CBF. Treatment with I-NAME at the high dose causes a significant decrease in $\mathrm{BFI}_{w}$ 


\section{Validation study}

In both the I-NAME and the control group one animal was excluded because the difference between right and left kidney flow exceeded $10 \%$. In all included tissue samples the amount of microspheres largely exceeded 400 microspheres, which is the minimally required number for an accurate MS-flow measurement (Buckberg et al., 1971).

Table 2 summarises the physiological data before the onset of the NIRS-measurement, and the brain weight obtained post mortem. Physiological variables were comparable between groups. Only $\mathrm{PaCO}_{2}$ was significantly lower in the control group than in the other groups, although all values were within the normal physiological range.

\begin{tabular}{|c|c|c|c|c|}
\hline & 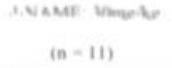 & $\begin{array}{l}\text { Cenetrol } \\
(\mathrm{n}-11)\end{array}$ & $\begin{array}{l}\cos 7 \mathrm{~s} \\
(\mathrm{n}-12)\end{array}$ & p-value \\
\hline Weight (g) & $404: 13$ & $403 \div 16$ & $401 \div 16$ & 0.7677 \\
\hline firain weight (z) & $206 \div 005$ & $205+007$ & $2.05+0.07$ & 0.8094 \\
\hline $\mathrm{PaCO},(\mathrm{mm}) / \mathrm{g})$ & $416+1.8$ & $40.1+2.5^{*}$ & $423 \times 20$ & 0.0467 \\
\hline $\mathrm{PaO}_{2}\left(\mathrm{~mm} \mathrm{H}_{\mathrm{g}}\right)$ & $103 \div 15$ & $109 \times 13$ & $113 * 15$ & 0.3060 \\
\hline $\mathrm{pH}$ & $742 \div 001$ & $7.43+0.03$ & $7.42 \div 002$ & 05563 \\
\hline
\end{tabular}

The variables related to blood flow assessment are summarised in table 3 . All variables were significantly different in the $\mathrm{CO}_{2}$ group, compatible with a significant increase in flow compared to the control group. In the I-NAME group, the BFI, $\mathrm{BFI}_{\mathrm{w}}$, and the total brain MS-flow were significantly lower compared to control conditions. No differences between left and right hemispheric MS-flow were observed. This indicates that the microspheres were homogeneously distributed in the brain. While the observed decrease in $\mathrm{BFI}$ and $\mathrm{BFI}$ in response to l-NAME administration almost equalled the increase in response to $\mathrm{CO}_{2}$ breathing, the two variables necessary for BFI calculation ( $\triangle \mathrm{t}$ and $\triangle \mathrm{ICG}$ ) changed differently in response to an increase and decrease in flow, respectively. $\Delta t$ did not respond as much to increases in flow as it did to decreases, but the difference with control conditions was significant in both cases. For $\triangle \mathrm{ICG}$ the situation was the opposite. Here the response was blunted for decreases in flow and the values obtained after l-NAME administration were not different from the control values $(\mathrm{p}>0.05)$. The $\mathrm{BFI}$ and the $\mathrm{BFI}_{w}$ did not show any blunted response neither to a decrease, nor to an increase in 
flow. A clear distinction between the different flow conditions could be made by both indices as well as by the MS-flow.

\begin{tabular}{|c|c|c|c|c|}
\hline & HNAME: 30mekg & Centrol & $\cos .75$ & p-valus \\
\hline & $(n-11)$ & $(\mathrm{s}-11)$ & $(n-12)$ & \\
\hline $\sin$ & $2100025 \cdot$ & $x \operatorname{sen} x$ & 130.615 & -6021 \\
\hline scoum & $0000+5021$ & entr + nes & 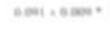 & enest \\
\hline$m$ & nest venes & sase venen & 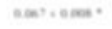 & $-4 \times \infty$ \\
\hline mol. & $136+14$ & $300+10$ & $x \times, \ldots$ & - comi \\
\hline 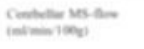 & $116 \times 23 *$ & $190 \times 4$ & $20 \times+\infty$ & theni \\
\hline Let inetims in: & $15+10$ & 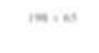 & $\mathrm{ses} \times \mathrm{su}$. & 4001 \\
\hline 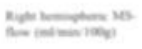 & $167 \times x$ & 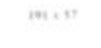 & $29+40$ & $\sin n$ \\
\hline 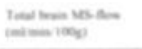 & $160 \times 4]^{*}$ & 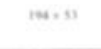 & $\mathrm{xes}, \mathrm{ne}$ & s neet \\
\hline \multicolumn{5}{|c|}{ 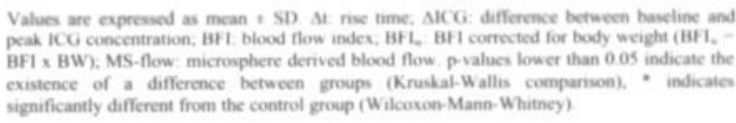 } \\
\hline
\end{tabular}

In figure 3 the linear regression (with $95 \% \mathrm{CI}$ ) and the Bland and Altman analysis from the $\mathrm{BFI}_{w}$ and the MS-flow data are shown. The regression analysis indicated that $\mathrm{BFI}_{w}$ is a significant predictor of MS-flow and resulted in the following formula: MS-flow $=62.4+$ $7.06 \mathrm{BFI}_{\mathrm{w}}(\mathrm{R}=0.6466 ; \mathrm{p}<0.0001)$. The residuals from the regression analysis showed a normal distribution, which was checked with a normal quantile plot and the Shapiro-Wilk W test. A better method to compare techniques that measure the same variable is represented in figure $3 \mathrm{~B}$. Using the regression analysis formula, the $\mathrm{BFI}_{w}$ data were transformed into MS-flow data. The difference between the original MS-flow data and those obtained by calculation were then plotted against the mean of both data. The average difference between both methods was not significantly different from zero $(0.0022 \pm 52.4 \mathrm{ml} / \mathrm{min} / 100 \mathrm{~g} ; \mathrm{p}=0.9731)$ and the individual differences were normally distributed (normal quantile plot, Shapiro-Wilk W test). 


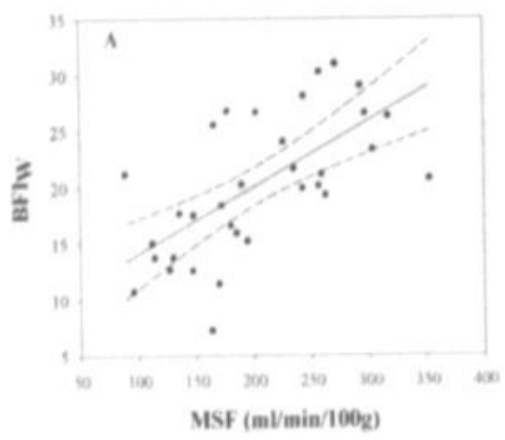

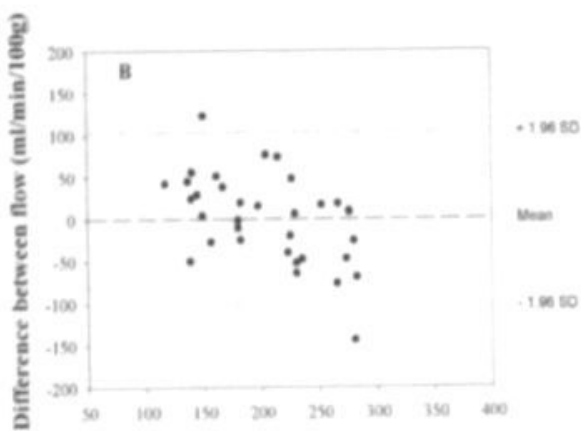

Average flow from both measurement $(\mathrm{mL} / \mathrm{min} / 100 \mathrm{~g})$

Figure 3. Comparison between the BFlw and CBF measured with microspheres (MS-flow). Figure $3 \mathrm{~A}$ contains the regression analysis (full line: regression; dashed line: $95 \% \mathrm{CI}$ ) resulting in the following formula: $\mathrm{BFlw}=8.13+0.059 \mathrm{MS}$. flow. The residuals from the regression analysis were normally distributed (normal quantile plot, Shapiro-Wilk W test). A more accurate method for comparison of two techniques that measure the same variable is presented in figure $3 \mathrm{~B}$. Using the regression formula, MS-flow $=62.4+7.06 \mathrm{BFIw}$, the BFIW data were converted into MS-flow data. The mean of the data is represented by the dashed line and the $95 \% \mathrm{Cl}$ of the data between both dotted lines are indicated on this graph. The difference between the original MS-flow data (flow) and those obtained by calculation are then plotted against the mean of both data (average flow). The differences between the measurements were normally distributed (normal quantile plot, Shapiro - Wilk W test). 


\section{Discussion}

We have previously shown that the transit of a small indocyanine green (ICG) bolus through the rat brain can be accurately monitored with NIRS and that a BFI can be calculated from the $\Delta t$ and $\triangle \mathrm{ICG}$ derived from the transit curve (De Visscher et al., 2002b). The aim of the present study was to validate the BFI for the measurement of cerebral blood flow in rats. First, we evaluated the need for a correction factor for blood volume, and the changes in BFI induced by different concentrations of I-NAME and $\mathrm{CO}_{2}$, two agents that alter the $\mathrm{CBF}$ in the opposite way. $\mathrm{CO}_{2}$ is known to increase flow in Sprague-Dawley rats (Estevez et al., 1997) due to vasodilation while I-NAME decreases flow (Macrae et al., 1993) due to vasoconstriction. Secondly, we compared the $\mathrm{BFI}$ with the $\mathrm{CBF}$ as measured with coloured microspheres in different flow conditions.

\section{ICG cerebral blood flow study}

In this study we included control rats with normal and low body weight in order to evaluate the dependence of the BFI on blood volume. As the volume of the injected ICG bolus is $5 \mu \mathrm{l}$ in all rats, differences in blood volume might lead to different ICG concentrations in situ, and thus different amplitudes of the ICG bolus transit curve ( $\triangle \mathrm{ICG}$ ). ICG dilution in itself is an appropriate method for the measurement of the blood plasma volume in humans (Haller et al., 1993). However, the clearance of ICG in rats is twice as high as in normal human volunteers (Paumgartner et al., 1970). Moreover, the amount of ICG injected by us is 20 times lower than the one used for plasma volume assessment and specially chosen for its good signal to noise ratio in combination with a rapid clearance. This is important since residual ICG may disturb the simultaneous measurement of other NIRS chromophores such as brain haemoglobin and cytochrome oxidase (De Visscher et al., 2002b). Hence, it was not possible to use the ICG dilution technique for the measurement of blood volume in the present study. As it is known that rat tissue contains $65 \mathrm{ml}$ of blood per $\mathrm{kg}$, we used the body weight to correct for differences in blood volume.

All rats used in this experiment were normal adult rats. As such we assumed that there were no differences in CBF between the two groups with different body weight. We found that the BFI was significantly higher in the rats with a lower body weight. The fact that the high BFI in the LW control group was solely due to an increase in $\triangle \mathrm{ICG}$ whereas the rise time or $\Delta \mathrm{t}$ was the same as in the control group is compatible with a dilution issue. An appropriate correction could be made by multiplying the BFI by the body weight. After correction, the differences between both groups disappeared. 
Another part of this study consisted of an extensive study of the $\mathrm{BFI}_{\mathrm{w}}$ in different $\mathrm{CBF}$ conditions induced by pharmacological interventions. The results clearly demonstrate that the $\mathrm{BFI}_{\mathrm{w}}$ method can be used to detect dose-dependent changes in $\mathrm{CBF}$.

\section{Validation study}

In our set up NIRS is applied in transmission mode. The emitting and receiving optodes have a diameter of $3 \mathrm{~mm}$ and are positioned onto respectively the right and left temporal bone of the rat. In these conditions, the light detected by the receiving optode has transversed the different regions of the entire brain (Delpy D.T., personal communication). Hence, the BFI provides a measurement of the average global CBF. The coloured microsphere technique also allows to measure global CBF (Herrijgers et al. 1996) and was chosen to validate the NIRS method. The changes in the BFI in response to hypercapnia in rats have already been described earlier (De Visscher et al., 2002b) and showed a good concordance with the results obtained by other groups with either laser Doppler flowmetry (Lee et al., 1995; Estevez and Phillis, 1997) or hydrogen clearance (von Kummer, 1984).

Total brain MS-flow was significantly different in the three groups evaluated. The left and right hemispheric MS-flows were not different in any group. This indicates that the technique and location used for microsphere injection (Nakai et al., 1990) did neither alter CBF nor compromise the induced $\mathrm{CBF}$ changes in one of the hemispheres. If the carotid artery is used no distinction between left and right hemispheric MS-flow can be made in normocapnic conditions (De Ley et al., 1985; De Visscher, unpublished data). In contrast, the absence of a response of the MS-flow to hypercapnia at the same side of carotid artery cannulation has been observed previously using either radioactive (De Ley et al., 1985) or fluorescent microspheres (De Visscher, unpublished data).

Linear regression showed that the $\mathrm{BFI}_{w}$ was a significant predictor for MS-flow. The derived formula was used to convert the BFI data to MS-flow data. The pairs of MS-flow data were then analysed with a statistical method specially designed for comparison of two methods for measuring the same variable (Bland and Altman, 1986). The fact that the mean difference between measurements equals zero indicates that the average MS-flow can be accurately calculated from the $\mathrm{BFI}_{w}$ with the aid of the linear regression formula. As the differences were normally distributed, a good prediction of MS-flow can be made for a sufficiently large group of animals over the range of flows that was covered in this study. Since the $95 \% \mathrm{Cl}$ is notable, the prediction of individual MS-flow values from the $\mathrm{BFI}_{w}$ data may be less accurate. Possible 
variability, intrinsic to the microsphere technique may also be a contributing factor in this respect.

\section{Conclusion}

We conclude that application of multi wavelength NIRS to measure the transit of an ICG bolus through the brain is a valuable method to assess global CBF. The BFI calculated from the bolus transit curve and corrected for blood volume (via body weight) is an accurate predictor of global $\mathrm{CBF}$ as measured with the microsphere technique. 


\section{References}

Bland JM, Altman DG (1986) Statistical methods for assessing agreement between two methods of clinical measurement. Lancet 1(8476): $307-310$

Brambink AM, Kopacz L, Astheimer A, Noga H, Heimann A, Kempski 0 (1999) Control of brain temperature during experimental global ischemia in rats. J. Neurosci. Meth. 92: 111-122.

Brooker LGS (1955) Some recent developments in the chemistry of photographic sensitizing dyes. Experientia Suppl. 2 . 229-257.

Buckberg GD, Luck JC, Payne DB, Hoffman JI, Archie JP, Fixier DE (1971) Some sources of error in measuring regional blood flow with radioactive microspheres. J. Appl. Physiol. 31(4): 598-604.

Burggraaf J, Schoemaker RC, Kroon JM, Cohen AF (1998) The influence of nifedipine and captopril on liver blood flow in healthy subjects. Brit. J. Clin. Pharmacol. 45: 447-451.

Cherrick GR, Stein WS, Levy CM, Davidson CS (1960) Indo-cyanine green: observations on its physical properties, plasma decay and hepatic excretion. J. Clin. Invest. 39.592-600.

Cooper CE, Cope M, Springett R, Amess PN, Penrice J, Tyszcuk L, Punwani S, Ordidge R, Wyatt J, Delpy DT. (1999) Use of mitochondrial inhibitors to demonstrate that cytochrome oxidase near-infrared spectroscopy can measure mitochondrial dysfunction noninvasively in the brain. J. Cereb. Blood Hlow Metab. 19(1): 21-38.

Cope M, Delpy DT, Wray S, Wyatt JS, Reynolds EOR (1989) A CCD spectrophotometer to quantitate the concentration of chromophores in living tissue utilising the absorption peak of water at $975 \mathrm{~nm}$. Adv. Exp. Med. Biol. 248: 33-40.

De Ley G, Nshimyumuremyi J-B, Leusen I (1985) Hemispheric blood flow in the rat after unilateral common carotid artery occlusion: evolution with time. Stroke 16(1): 69-73.

De Visscher G, Springett R, Delpy DT, Van Reempts J, Borgers M, van Rossem K (2002a) Nitric oxide does not inhibit cerebral cytochrome oxidase 'in vivo' nor in the reactive hyperaemic phase post brief anoxia in the adult rat. J. Cereb. Blood Flow Metab. 22: 515-519.

De Visscher G, van Rossem K, Van Reempts J, Borgers M, Flameng W, Reneman RS (2002b) Cerebral blood flow assessment with indocyanine green bolus transit detection by near-infrared spectroscopy in the rat. Comp. Biochem. Physiol. A 132: 87-95.

Edwards AD, Wyatt JS, Richardson C, Delpy DT, Cope M, Reynolds EOR (1988) Cotside measurement of cerebral blood flow in ill newborn infants by near-infrared spectroscopy. Lancet 2: 770-771.

Eke A, Herman P, Balla I, Ikrenyi C (1997) NIRS assessment of regional red blood cell and plasma transit by a single bolus of indocyanine green in the brain cortex. Abstract presented at the $25^{\mathrm{m}}$ annual meeting of the International Society of 0xygen Transport to Tissue 1997: www.elet2.sote.hu/eke/publications/abstracts.html

Estevez AY, Phillis JW (1997) Hypercapnia-induced increases in cerebral blood flow: roles of adenosine, nitric oxide and cortical arousal. Brain Res. 758: 1-8.

Fox IJ, Brooker LGS, Heseltine DW, Wood EH (1956) A new dye for continuous recording of dilution curves in whole blood independent of variations in blood oxygen saturation. Circ. 24: 937-938.

Fox IJ, Wood EH (1960) Indocyanine green: physical and physiologic properties. Proc. Staft Meet. Mayo Clin. 35(25): 732 744.

Gentile S, Bajema BL, Baldini G, Lunazzi G, Groothuis GMM, Tiribelli C, Meijer DKF, Sottocasa GL (1985) Measurement of the association of cholephylic organic anions with different binding proteins. Biochem. Pharmacol. 34(14): 2439-2444

Haller M, Akbulut C, Brechtelbauer H, Fett W, Briegel J, Finsterer U, Peter K (1993) Determination of plasma volume with indocyanine green in man. Life Sci. 53: 1597-1604 
Herijgers P, Leunens V, Tjandra-Maga TB, Mubagwa K, Flameng W (1996) Changes in organ pertusion after brain death in the rat and its relation to circulating catecholamines. Transplantation 62: 330-335.

Jobsis FF (1977) Noninvasive, infrared monitoring of cerebral and myocardial oxygen sufficiency and circulatory parameters. Science 198(4323): 1264-1267.

Kowallik P, Schulz R, Guth BD, Schade A, Paffhausen W, Gross R, Heusch G (1991) Measurement of regional myocardial blood flow with multiple colored microspheres. Circ. 83: 974-982.

Kuebler WM, Sckell A, Habler 0, Kleen M, Kuhnle GEH, Welte M, Messmer K, Goetz AE (1998) Noninvasive measurement of regional cerebral blood flow by near-infrared spectroscopy and indocyanine green. J. Cereb. Blood Flow Metab. 18: 445-456.

Kumlien J, Perbeck L (1986) Blood flow measurements in rabbit sinus mucosa. A comparison between fluorescein flowmetry and blood flow measurements with microspheres and $\mathrm{Rb}^{\text {" }} \mathrm{Cl}$. Acta Otolaryngol. (Stockh.) 101: 475-483.

Landsman MLJ, Kwant G, Mook GA, Zijlstra WG (1976) Light-absorbing properties, stability, and spectral stabilization of indocyanine green. J. Appl. Physiol. 40(4): 575-583.

Lee JG, Smith JJ, Hudetz AG, Hillard CJ, Bosnjak ZJ, Kampine JP (1995) Laser-doppler measurement of the effects of halothane and isoflurane on the cerebrovascular $\mathrm{CO}_{2}$ response in the rat. Anesth. Anal. 80: 696-702.

Macrae IM, Dawson DA, Norrie JD, McCulloch J (1993) Inhibition of nitric oxide synthesis: effects on cerebral blood flow and glucose utilisation in the rat. J Cereb. Blood Flow Metab. 13: 985-992.

Matcher SJ, Cooper CE (1994) Absolute quantification of deoxyhaemoglobin concentration in tissue near-infrared spectroscopy. Phys. Med. Biol. 39: 1295-1312.

Matcher SJ, Elwell CE, Cooper CE, Cope M, Delpy DT (1995) Performance comparison of several published tissue nearinfrared spectroscopy algorithms. Anal. Biochem. 227: 54-68.

Nakai M, Tamaki K, Yamamoto J, Shimouchi A, Maeda M (1990) A minimally invasive technique for multiple measurement of regional blood flow of the rat brain using radiolabeled microspheres. Brain Res. 507: 168-171.

Olsen KS, Svendsen LB, Larsen FS (1996) Validation of transcranial near-infrared spectroscopy for evaluation of cerebral blood flow autoregulation. J. Neurosurg. Anesthesiol. 8(4): 280-285.

Paumgartner G, Probst P, Kraines R, Leevy CM (1970) Kinetics of indocyanine green removal from the blood. Ann. NY Acad. Sci. 170: 134-147.

Perbeck L, Lewis DH, Thulin L, Tyden G (1985a) Correlation between fluorescein flowmetry, 133 Xenon clearance and electromagnetic flow measurement: a study in the intestine of the pig. Clin. Physiol. 5(3): 293-299.

Perbeck L, Lund F, Svensson L, Thulin L (1985b) Fluorescein flowmetry: a method for measuring relative capillary blood flow in the intestine. Clin. Physiol. 5(3): 281-292.

Prinzen FW, Glenny RW (1994) Developments in non-radioactive microsphere techniques for blood flow measurement. Cardiovasc. Res. 28: 1467-1475.

Prinzen FW, Bassingthwaighte JB (2000) Blood flow distributions by microsphere deposition methods. Cardiovasc. Res. 45: $13-21$.

Roberts I, Fallon P, Kirkham FJ, Lloyd-Thomas A, Cooper C, Maynard R, Elliot M, Edwards AD (1993) Estimation of cerebral flow with near-infrared spectroscopy and indocyanine green. Lancet 342: 1425.

Roberts IG, Fallon P, Kirkham FJ, Kirshbom PM, Cooper CE, Elliott MJ, Edwards AD (1998) Measurement of cerebral blood flow during cardiopulmonary bypass with near-infrared spectroscopy. J. Thor. Cardiovasc. Surg. 115: 94-102.

Robertson CS, Gopinath SP, Chance B (1995) A new application for near-infrared spectroscopy. detection of delayed intracranial hematomas after head injury. J. Neurotrauma 12(4): 591-600.

Ruokonen E, Takala J, Kari A, Saxén H, Mertsola J, Hansen EJ (1993) Regional blood flow and oxygen transport in septic shock. Crit. Care Med. 21(9): 1296-1303. 
Springett R, Newman J, Cope M, Delpy DT (2000) Oxygen dependency and precision of cytochrome oxidase signal from full spectral NIRS of the piglet brain. Am. J. Physiol. Heart Circ. Physiol. 279: H2202-H2209.

Tamura M, Hoshi Y, Okada F (1997) Localized near-infrared spectroscopy and functional optical imaging of brain activity. Phil. Trans. R. Soc. Lond. B 352: $737-742$.

van Rossem K, Garcia-Martinez S, De Mulder G, Van Deuren B, Engelborghs K, Van Reempts J, Borgers M (1999a) Brain oxygenation after experimental closed head injury. Adv. Exp. Med. Biol. 471: 209-215.

van Rossem K, Garcia-Martinez S, Wouters L, De Mulder G, Van Deuren B, Van Reempts J, Borgers M (1999b) Cytochrome oxidase redox state in brain is more sensitive to hypoxia after closed head injury: a near-infrared spectroscopy (NIRS) study. J. Cereb. Blood Flow Metab. 19 (Suppl 1): S391.

Villringer A, Planck J, Hock C, Schleinkofer L, Dirnagl U (1993) Near-infrared spectroscopy (NIRS): a new tool to study hemodynamic changes during activation of brain function in human adults. Neurosci. Lett. 154: 101-104.

von Kummer R (1984) Local vascular response to changes in carbon dioxide tension. Long term observations in the cat's brain by means of hydrogen clearance technique. Stroke 15(1): 108-114.

Wieland W, Wouters PF, Van Aken H, Flameng W (1993) Measurement of organ blood flow with colored microspheres: a first time-saving improvement using automated spectrophotometry. In: Computers in cardiology 1993. Los Alamos, CA. IEEE Computers Society Press, 691.

Wyatt JS, Cope M, Delpy DT, Richardson CE, Edwards AD, Wray S, Reynolds EOR (1990) Quantitation of cerebral blood volume in human infants by near-infrared spectroscopy. J. Appl. Physiol 68(3): 1086-1091. 
Chapter 6

Comparison between intracranial pressure measured in the cerebral cortex and the cerebellum of the rat

Servan Rooker, Geofrey De Visscher, Bruno Van Deuren, Marcel Borgers, Philippe Jorens, Robert S. Reneman, Koen van Rossem \& Jan Verlooy 


\section{Abstract}

In this study we evaluated the accuracy of intracranial pressure (ICP) measurement in rats by insertion of a miniature ICP probe in the parenchyma of the cerebellum. A comparison is made between the ICP values measured simultaneously in the parenchyma of the cerebral cortex and the cerebellum.

ICP was recorded in 45 Sprague-Dawley rats. In order to obtain a wide range of ICP, 15 animals were subjected to severe closed head injury $(\mathrm{CHI}), 15$ to moderate $\mathrm{CHI}$ and 15 to sham operation. ICP values ranged from 0.8 to $43.9 \mathrm{mmHg}$. After $15 \mathrm{~min}$ stabilisation the first measurement was performed, and the second measurement $25 \mathrm{~min}$ after onset to allow comparison of ICP changes between the two implantation sites. Linear regression analysis showed a highly significant correlation as well at $15 \mathrm{~min}$ : cerebellar ICP $=0.919$ cerebral ICP $+0.655\left(\mathrm{R}^{2}=0.977\right)$, as at $25 \mathrm{~min}$ cerebellar ICP $=0.931$ cerebral ICP $+0.698\left(\mathrm{R}^{2}=0.976\right)$. The differences in ICP measurement between cerebellar and cerebral site were not significantly different from zero on both time points. Bland and Altman plots showed that the difference in ICP readings between the two locations could differ maximally $5.3 \mathrm{mmHg}$. The largest differences were detected in presence of high ICP values.

We conclude that in rats the ICP measurement in the cerebellum is comparable to the ICP measurement in the cerebral cortex. The cerebellar ICP can be used as a valuable alternative in experimental set-up. 


\section{Introduction}

During the past 6 years our research group has developed a rat model of $\mathrm{CHI}$ that features several clinically relevant pathological changes, including increased ICP (Engelborghs et al., 1998; De Mulder et al.,2000), disturbed autoregulation of cerebral blood flow (Engelborghs et al., 2000), and increased sensitivity to hypoxia (Van Rossem et al., 1999). Since the introduction of ICP measurement in 1951 (Guillaume and Janny) ICP has become an essential parameter in the assessment of severe head injured patients. The therapeutic regimes are often instituted on the basis of ICP values. Measurement of intracranial pressure can be performed with various techniques based on different principles of pressure transformation. Strain gauge, piezo-resistive and fibre-optic probes are most commonly used today (Morgalla et al., 1999). In our own laboratory we reported on the results with fibreoptic ICP measurement (Verlooy et al., 1990). Currently, the gold standard for ICP measurement in human is a fluid-filled ventricular catheter. In small animals like the rat this method of ICP measurement as such is difficult. Therefore we use a miniature ICP probe that is inserted in the cerebral parenchyma. Morgalla and co-workers (1999) have tested 7 types of current ICP transducers under in vitro conditions for measurement accuracy. They conclude that most accurate probes were Haniset ${ }^{*}$, Camino $^{*}$ and the Codmann ${ }^{*}$. Measurement accuracy for the Codmann ${ }^{*}$ probe could deviate up to $5 \mathrm{mmHg}$, in the pressure group from $60 \mathrm{mmHg}$ onwards.

In previous studies we reported the use of the Codman ${ }^{*}$ micro-sensor probe to measure ICP after closed head injury in the rat (Engelborghs et al., 1997; De Mulder et al., 2000). The probe was inserted into the cortical parenchyma of the right hemisphere. Insertion of a miniature probe can induce spreading depressions of cortical activity in the entire hemisphere with concomitant alterations in cerebral blood flow (CBF), vascular responsiveness and metabolism (Verhaegen et al., 1992). When CBF and metabolism are the subject of investigation, such alterations need to be avoided. Moreover, when optical techniques such as NIRS are used to evaluate cerebral oxygenation and perfusion, the insertion of a miniature probe may cause unwanted light scattering and induce small bleedings that can interfere with the measurements. In our lab we apply NIRS to measure cerebral oxygenation (van Rossem et al., 1999a+b) and perfusion in the rat (De Visscher et al., 2002) and study pathophysiological changes after traumatic brain injury (van Rossem et al., 1999a+b). As ICP probe placement in the cerebellum does not induce spreading depressions of cortical activity, and does not interfere with light transmission through the hemispheres this site is an alternative location for ICP recording, especially when simultaneous evaluation of cerebral oxygenation, $\mathrm{CBF}$ and metabolism is envisaged. 
The aim of the present study was to evaluate if the ICP measured in the cerebellum corresponds to the hemispheric cerebral ICP, in the rat. 


\section{Materials and methods}

\section{Animal treatment and preparation}

Animal housing and treatment conditions complied with the European Directive \#86/609 for animal welfare. Forty-five male Sprague-Dawley rats (Charles River, Sulzfeld, Germany), weighing between $370 \mathrm{~g}$ and $490 \mathrm{~g}$ were used for the experiments. They were allowed free access to food and water (12/12-hour day-night cycle). The animals underwent standard anaesthesia induction over $4 \mathrm{~min}$. with $4 \%$ isoflurane in a mixture of $30 \% \mathrm{O}_{2}$ and $70 \% \mathrm{~N}_{2} \mathrm{O}$. Subsequently, rats were endotracheally intubated and anaesthesia was maintained at $2 \%$ isoflurane during surgical procedures.

In the sham and moderate $\mathrm{CHI}$ group a $2 \mathrm{~cm}$ midline incision of the scalp was made and the periosteum removed to expose the bregma. After identification of the impact place, on the bregma, the rat is transferred to the trauma device as described earlier (De Mulder et al., 2000). To induce moderate closed head injury (CHI), a $400 \mathrm{~g}$ weight was dropped from a height of $50 \mathrm{~cm}$. Shams underwent all of the above except the weight drop.

Severe head injury was induced on a similar apparatus. The differences with the moderate CHI procedure were the presence of a silicon tip on the steel cylinder and the absence of an incision in the scalp of the rat. The rats were placed on the table and impact place was determined using fixed ear bars on the table. To induce severe $\mathrm{CHI}$, the $400 \mathrm{~g}$ weight was dropped from a height of $70 \mathrm{~cm}$ (Engelborghs et al., 1998; Engelborghs et al., 2000).

After $\mathrm{CHI}$ or sham procedure the head of the rats was fixed in a stereotaxic apparatus (model DK 1962; Ultra Precise Small Animal Stereotaxic, Kopf Intstruments, Germany) and a thermistor inserted into the tip of an ear bar was used to measure the tympanic temperature, providing an accurate measurement of brain temperature (Brambink et al., 1999). A rectal temperature probe was inserted to monitor body temperature, which was controlled with a heating pad connected to a temperature control unit. The end tidal $\mathrm{CO}_{2}\left(\mathrm{EtCO}_{2}\right)$ and breathing rate were continuously monitored with an $\mathrm{EtCO}_{2}$-monitor (Capnogard, Novametrix USA). The left femoral artery was canullated to allow continuous monitoring of the mean arterial blood pressure (MABP) and heart rate (Argon Transducer, Maxxim Medical, Greece). Neck muscles were retracted and dissected until the occipital bone was exposed. In the severe $\mathrm{CHI}$ group the scalp was removed at this time point. Possible sites of bleeding were cauterised to prevent excessive blood loss. 
To measure cerebellar ICP, a burr hole of $2 \mathrm{~mm}$ was drilled into the right part of the occipital bone, $2 \mathrm{~mm}$ caudal of the cranial edge and $2 \mathrm{~mm}$ lateral from the midline, avoiding damage to the sagital sinus. The first microsensor ICP probe (ICP Neuro microsensor; diameter $1.2 \mathrm{~mm}$, length $4 \mathrm{~mm}$; Codman \& Shurtleff Inc., Randolph, MA) was attached to a micromanipulator. The tip was positioned in the sagital plane under an angle of $35^{\circ}$ relative to the horizontal plane and carefully inserted in the cerebellar parenchyma.

To measure cerebral ICP, a $2 \mathrm{~mm}$ burr hole was drilled into the right interparietal plate of the rat's skull $4 \mathrm{~mm}$ from the midline and $2 \mathrm{~mm}$ caudal to the bregma suture. The second microsensor probe attached to a micromanipulator was inserted in the cortical parenchyma with the sensor facing towards the midline. In a frontal plane, the probe was placed at a $70^{\circ}$ angle to the horizontal plane to avoid perforation of the lateral ventricle. Insertion depth of both probes was $4 \mathrm{~mm}$.

After surgical ,nręnazation and the insertion of the ICP,probes the anaesthesia was maintained at $1.5 \%$ Isoflurane. ICP was then monitored continuously during $25 \mathrm{~min}$. Before sacrification of the animals with an overdose of Nembutal $^{*}, 195 \mu \mathrm{l}$ arterial blood sample was collected for bloodgas analysis (blood gas analyser model ABL 725; Radiometer, Copenhagen, Denmark).

All data was collected with a MacLab* computer system (MacLab/8 MK3 Version 3.5, ADInstruments Australia). Fifteen and twenty five minutes after the onset of the ICP registration the mean value was calculated over a 30 second period. Statistical analysis was performed on two different time points respectively 15 and $25 \mathrm{~min}$ after onset of the ICP measurement.

Statistical computations were performed using a commercially available software package for exact statistical inference (StatXact 4.0.1 for Windows). The three groups were first compared using a Kruskal-Wallis test and when a significant difference was found $(\alpha<0.05)$ a two-sided Wilcoxon-Mann-Whitney rank-sum test was used for analysis between pairs of groups separately. Two-sided probability values of less than 0.05 were regarded as statistically significant. Bland and Altmann (1986) analysis was used to evaluate the differences between the two ICP measurement sites and linear regression graphs were made to illustrate the correlation of the two measurements. A Wilcoxon signed rank test was used to test if the differences between both methods were significantly different from zero $(\alpha<0.05)$. As a test for normality of these differences the Shapiro-Wilk W test, combined with a normal quantile plot (NQP) was used $(\alpha<0.10)$. Differences in ICP between 15 and $25 \mathrm{~min}$ are also shown in a linear regression graph. 


\section{Results}

Table 1 shows the physiological variables at the end of the ICP registration. In both moderate and severe $\mathrm{CHI}$ groups $\mathrm{pO}_{2}$ and $\mathrm{MABP}$ were significant lower than in sham treated animals. For $\mathrm{pH}, \mathrm{EtCO}_{2}$ and ear temperature only the severe $\mathrm{CHI}$ group showed significant differences from the sham group. The breathing rate in the severe $\mathrm{CHI}$ group was significantly lower than in the moderate $\mathrm{CHI}$ group.

Table 1. Physiological variables at 25 min after onset of ICP measurement

\begin{tabular}{|c|c|c|c|}
\hline & Sham & Moderate CHI & Severe CHI \\
\hline Weight (g) & $396[384,430]$ & $392[384,402]$ & $410[394,430]$ \\
\hline $\mathrm{PO}_{2}(\mathrm{mmHg})$ & $130[123,139]$ & $108[94.7,126]^{\circ}$ & $106[96.4,128]^{\circ}$ \\
\hline $\mathrm{PCO}_{2}(\mathrm{mmHg})$ & $46.4[43.3,49.0]$ & $48.4[44.4,52.5]$ & $50.6[44,0,54.5]$ \\
\hline $\mathrm{PH}$ & $7.40[7.39,7.40]$ & $7.37[7.36,7.42]$ & $7.37[7.33,7.39]^{\circ}$ \\
\hline $\mathrm{MABP}(\mathrm{mmHg})$ & $104[98,112]$ & $90[86,102]^{\circ}$ & $91[81,103]^{\circ}$ \\
\hline Heart rate (BPM) & $349[323,393]$ & $353[318,407]$ & $387[309,412]$ \\
\hline $\mathrm{EtCO}_{2}(\mathrm{mmHg})$ & $54[50,55]$ & $55[52,59]$ & $58[57,62]^{\circ}$ \\
\hline Breathing rate (BPM) & $58[55,62]$ & $62[57,65]$ & $56[49,59]^{\circ}$ \\
\hline Ear temp. $\left({ }^{\circ} \mathrm{C}\right)$ & $36.4[36.1,36.7]$ & $35.7[35.0,36.2]$ & $35.4[34.8,36.1]^{\circ}$ \\
\hline
\end{tabular}

Data are presented as median $[95 \% \mathrm{CI}]$. Except for the weight that was measured at the onset of the experiment, all variables were measured at 25 min after onset of ICP measurement. * significantly different from sham $(\alpha<0.05)^{\circ}$ significantly different from moderate $\mathrm{CHI}(\alpha<0.05)$. ( $\mathrm{PaCO}_{2}$ : arterial $\mathrm{CO}_{2}$ pressure: $\mathrm{PaO}_{2}$ : arterial $\mathrm{O}_{2}$ pressure; MABP: mean arterial blood pressure; $\mathrm{EtCO}_{2}$ : end tidal $\mathrm{CO}_{2}$ ) 
Figure I shows the data from the cerebral and cerebellar ICP measurement, at both 15 and 25 $\min$. The four graphs are comparable and show similar distributions within one group. The ICP measurements from both the moderate and severe $\mathrm{CHI}$ group show a significant increase compared to the sham group.
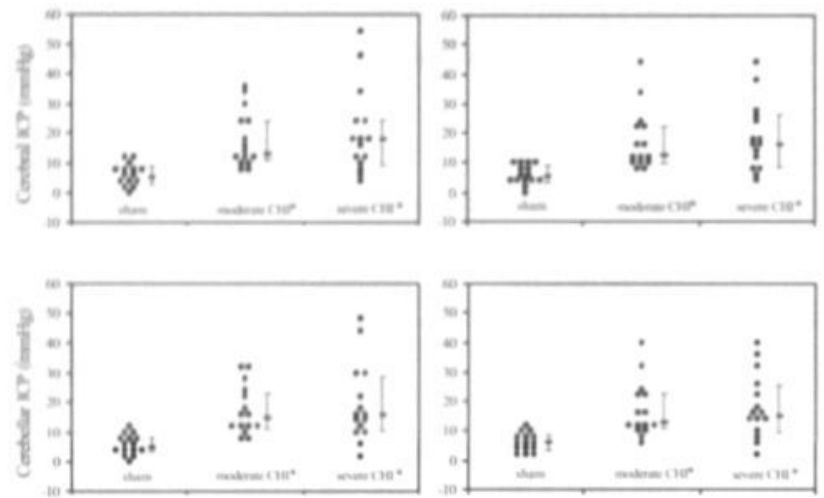

Figure 1. The four panels represent the data from the cerebral and cerebellar ICP measurement at 15 and 25 min. Each panel contains the individual data $(n=45)$ divided in their treatment groups respectively. Next to the individual data the median with the $95 \%$ confidence interval is given - significantly different from sham $(\alpha<0.05)$.

Bland and Altman analysis, from both the 15 and 25 min ICP measurement, is used to compare two methods for measuring the same variable (fig 2). The $x$-variable is an average of the two ICP measurements, because the average is a better estimate of the real value compared to both individual values. The $y$-variable is the difference between the new method and the established one, cerebellar ICP and cerebral ICP respectively. At $15 \mathrm{~min}$ there was no indication the differences were not normally distributed. At $25 \mathrm{~min}$ however both the Shapiro-Wilk W test and the NQP showed no normal distribution. At both 15 and $25 \mathrm{~min}$, the average value did not significantly differ from zero indicating that both methods of measurement are not significantly different and actually measure the same ICP.

Regression analysis from both the 15 and 25 min ICP measurements resulted in good correlation between both measurement sites (fig 2 ). As $\mathrm{x}$ variable we used the established cerebral ICP and as $y$ our novel method being the cerebellar ICP. At $15 \mathrm{~min}$. the following formula was calculated: $\mathrm{Y}=0.919 \mathrm{X}+0.655\left(\mathrm{R}^{2}=0.977\right)$. At $25 \mathrm{~min} . \mathrm{Y}=0.931 \mathrm{X}+0.698\left(\mathrm{R}^{2}=0.976\right)$. As indicated by the $\mathrm{R}^{2}$-values, regression analyses on both time points resulted in a high correlation between the two methods of ICP measurement. The slope of both regressions is somewhat lower then 1, this is in part a result of the fact that the cerebellar ICP underestimates the cerebral ICP in the high ICP measurements. When we only use the sham data (lower ICP) the slope of the regression is approximately 1 (data not shown) which is concurrent with what we stated before. 

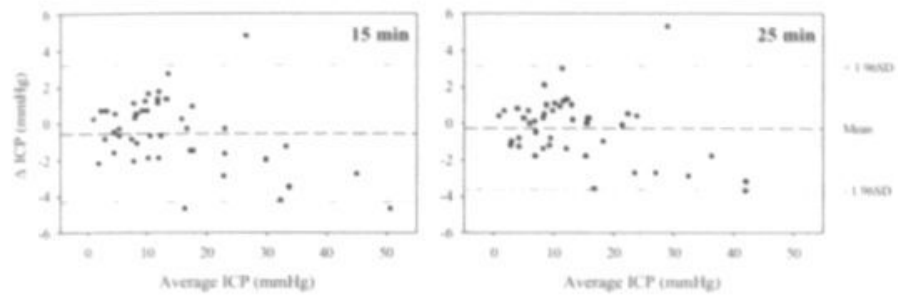

Figure 2. The upper panels are the Bland and Altman plots at 15 and 25 min showing the difference between both measurements against their mean value. The dashed line represents the mean difference and the $95 \%$ confidence interval of the data lies between the dotted lines. The lower panels are the regression analysis plots for both timepoints. The line represents the regression line and the dashed line the $95 \%$ confidence interval of the regression. Linear regressions: ICP cerebellum $15^{\circ}=0.919$ ICP cerebrum $15^{\circ}+0.655\left(R^{2}=\right.$ $0.977)$ and ICP cerebellum $25^{\circ}=$ 0.931 ICP cerebrum $25^{\prime}+0.698$ $\left(R^{2}=0.976\right)$.

Regression analysis of ICP changes in time, between $t=15 \mathrm{~min}$ and $t=25 \mathrm{~min}$, gave the following formula: $\mathrm{Y}=0.876 \mathrm{X}+0.188\left(\mathrm{R}^{2}=0.970\right.$ ) for all 45 animals (fig 3 ).

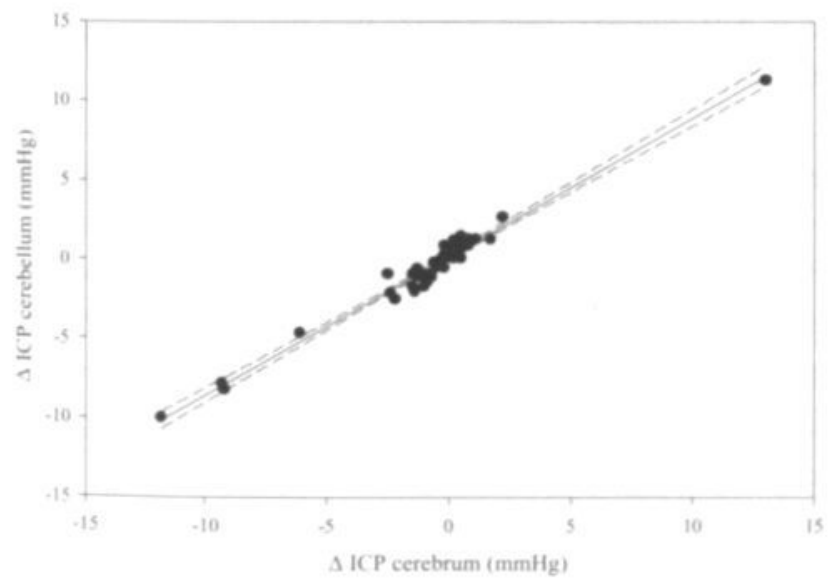

Figure 3. Changes of both cerebral and cerebellar ICP measurements in time plotted against each other. For both ICP measurements the differences $(\Delta)$ were calculated by subtracting the 15 min ICP measurement from the 25 min one. The cerebral $(X)$ and cerebellar $(Y)$ differences were then plotted against each other. The line represents the regression line and the dashed line the $95 \%$ confidence interval of the regression. Linear regression: $\triangle I C P$ cerebellum $=0.876 \Delta \mathrm{ICP}$ cerebrum + $0.188\left(R^{2}=0.970\right)$. 


\section{Discussion}

This study shows that the cerebellar ICP equals the cerebral cortex ICP, as well in normal as in pathological circumstances. Trauma was used to create a wide range of ICP values. The absolute measurement of ICP in both sites correlates extremely well. The divergence is quite small compared to the actual measurement but tends to increase with increasing ICP, because the cerebellar ICP has the tendency to slightly underestimate high ICP's. The Bland and Altman plots show that both methods of ICP measurement do actually measure the same ICP. If the novel technique measures the same ICP as the established technique it should also respond to changes in ICP in the same way. Although this experiment was not specially designed to study these responses, we looked at normally occurring ICP changes over time with both techniques and compared those. The differences at both time points are not significantly different from zero. Here we can conclude that both methods of ICP measurement behave similar when the ICP changes. The obtained slope, for time related changes of ICP, is somewhat smaller then I. This was again caused by the somewhat blunted response of the cerebellar ICP when larger changes occur. Except for one, these larger changes could only be found in the higher ICP measurements where we already marked that the cerebellar ICP measurement tends to be somewhat lower then the cerebral ICP measurement. The central cloud in figure 3 which corresponds with small changes in both ICP measurements has a slope that is approximately 1 , indicating a good response of the novel method to smaller ICP changes. This implies that the cerebellar site can also be of use to evaluate the effect of pharmacological interventions that influence ICP.

The positioning of the ICP probe in the cerebellum instead of the cerebral parenchyma has several advantages. Firstly, the cortical area remains intact, which implies that no electrophysiological, metabolic or cerebrovascular changes occur due to spreading depression of cortical activity. These changes are present hours after insertion of a probe with a diameter larger than $50 \mu \mathrm{m}$ (Verhaegen et al., 1992). The Codman probe has a diameter of $1 \mathrm{~mm}$. Secondly, there is no interference with light transmission and scattering in the cortical area when the probe is placed in the cerebellum. Thirdly, bleedings due to drilling and probe insertion can interfere with NIRS measurements. Practical, cerebellar ICP probe placement makes the NIRS optodes positioning easier as compared to the situation when the probe is stereotaxically placed in the cortex. This experimental set-up makes it possible to study simultaneously cerebral blood flow (CBF). oxygenation and ICP. This may provide very valuable information about pathophysiologic changes and the effect of pharmacological treatment of intracranial hypertension. 
To conclude; in experimental studies in rats, where insertion of a cerebral probe should be avoided, cerebellar ICP measurement is a very useful and valuable alternative to the cerebral ICP measurement. 


\section{References}

Bland JM, Altman DG (1986) Statistical methods for assessing agreement between two methods of clinical measurement Lancet 1(8476): 307-310.

Brambink AM, Kopacz L, Astheimer A, Noga H, Heimann A, Kempski 0 (1999) Control of brain temperature during experimental global ischemia in rats. J. Neurosci. Meth. $92: 111-122$.

De Mulder G, Van Rossem K, Van Reempts J, Borgers M, Verlooy J (2000) Validation of a closed head injury model for use in long-term studies. Acta Neurochir. (suppl.) 76: 409-413.

De Visscher G, van Rossem K, Van Reempts J, Borgers M, Flameng W, Reneman RS (2002) Cerebral blood flow assessment with indocyanine green bolus transit detection by near-infrared spectroscopy in the rat. Comp. Biochem Physiol. A 132: 87.95

Engelborghs K, Haseldonckx M, Van Reempts J, Van Rossem K, Wouters L, Borgers M, Verlooy J (2000) Impaired autoregulation of cerebral blood flow in an experimental model of traumatic brain injury. J. Neurotrauma. 17: 667-677

Engelborghs K, Verlooy J, Van Deuren B, Van Reempts J, Borgers M (1997) Intracranial pressure in a modified experimental model of closed head injury. Acta Neurochir. (suppl.) 70: 123-125.

Engelborghs K, Verlooy J, Van Reempts J, Van Deuren B, Van de Ven M, Borgers M (1998) Temporal changes in intracranial pressure in a modified experimental model of closed head injury. J. Neurosurg. 89: 796-806.

Guillaume J, Janny P (1951) Manometrie intra-crannienne continue. La presse medicale 59: 953-955.

Morgalla MH, Mettenleiter H, Bitzer M, Fretschner R, Grote EH (1999) ICP measurement control: laboratory test of 7 types of intracranial pressure transducers. J. Med. Engin. Technol. 23: 144-151.

van Rossem K, Garcia-Martinez S, De Mulder G, Van Deuren B, Engelborghs K, Van Reempts J, Borgers M (1999a) Brain oxygenation after experimental closed head injury. Adv. Exp. Med. Biol. 471: 209-215.

van Rossem K, Garcia-Martinez S, Wouters L, De Mulder G, Van Deuren B, Van Reempts J, Borgers M (1999b) Cytochrome oxidase redox state in brain is more sensitive to hypoxia after closed head injury. a near-infrared spectroscopy (NIRS) study. J. Cereb. Blood Flow Metab. 19 (Suppl 1): S391.

Verhaegen MJ, Todd MM, Warner DS, James B, Weeks JB (1992) The role of electrode size on the incidence of spreading depression and on cortical cerebral blood flow as measured by $\mathrm{H} 2$ clearance. J. Cereb. Blood Flow Metab. 12: 230-237.

Verlooy J, Selosse P, Van Reempts J, Haseldonckx M, Borgers M (1990) Fiberoptic intracranial pressure monitoring in rats. J. Neurosci. Meth. 31: 1-6. 
Chapter 7

Assessment of saturation with oxygen of cerebral venous blood and estimation of the cerebral metabolic rate of oxygen in rats using near infrared spectroscopy

Geofrey De Visscher, Servan Rooker, Philippe Jorens, Jan Verlooy, Marcel Borgers,

Robert S. Reneman, Willem Flameng \& Koen van Rossem 


\section{Abstract}

We evaluated the influence of pentobarbital on cerebral metabolic rate of oxygen $\left(\mathrm{CmrO}_{2}\right)$ in normal rats and rats receiving closed head injury $(\mathrm{CHI}) . \mathrm{CmrO}_{2}$ calculation was based on the use of cerebral blood oxygen saturation determined in sagital sinus blood samples $\left(\mathrm{SvO}_{2}\right)$ and haemoglobin content and cerebral blood flow (CBF) assessment by NIRS technology. Furthermore cerebral blood oxygen saturation assessed with $\mathrm{NIRS}\left(\mathrm{SmcO}_{2}\right)$ was validated using $\mathrm{SvO}_{2}$ in sagital sinus blood as a standard.

In normal rats pentobarbital administration reduced cerebral oxygen metabolism and blood flow (corrected for body weight) to about $2 / 3$ of its original value ( $p<0.05$ ). CHI by itself resulted in a reduction of $\mathrm{CBF}$, but not consistently in subsequent series. Supplementary, pentobarbital administration did not cause further decrease in $\mathrm{CBF}$ and oxygen metabolism. Correlation analysis of $\mathrm{SmcO}_{2}$ and $\mathrm{SvO}_{2}$ revealed a loss of correlation when partial venous oxygen pressure $\left(\mathrm{PvO}_{2}\right)$ decreased below $50 \mathrm{mmHg}$. Using this cut-of point two subgroups were obtained: one with good correlation $(\mathrm{R}=0.74)$ between $\mathrm{SmcO}_{2}$ and $\mathrm{SvO}_{2}$ and one without $(\mathrm{R}=0.04)$. The latter contained a significant higher portion of $\mathrm{CHI}$ animal $(67 \%$ vs. $33 \% ; \mathrm{p}=0.0013)$, but no differential distribution of the pentobarbital treated rats was observed. Uni- and multivariate analysis of haemodynamic and blood data revealed that, besides $\mathrm{CHI}$, haemodynamic instability in terms of low arterial pressure predicted loss of correlation between $\mathrm{SmcO}_{2}$ and $\mathrm{SvO}_{2}$.

It is concluded that pentobarbital inhibits cerebral oxygen metabolism in rats but not after $\mathrm{CHI}$. Furthermore determination of $\mathrm{CmrO}_{2}$ exclusively, with the exception of the arterial blood oxygen saturation, from NIRS derived parameters remains questionable mainly in rats after $\mathrm{CHI}$ 


\section{Introduction}

Jöbsis (1977) was the first to make use of the relative transparency of brain tissue to the wavelengths of light ranging from 700 to $1000 \mathrm{~nm}$ to measure tissue oxygenation and circulatory parameters non-invasively. Since then this technique, known as near-infrared spectroscopy (NIRS), has been further developed for use in both experimental and clinical conditions to monitor oxygenation of blood and tissue. Related applications in brain include the detection of intracranial haematomas after head injury (Robertson et al., 1995), functional imaging in adults (Villringer et al., 1993; Tamura et al., 1997), quantitation of cerebral blood volume in infants (Wyatt et al., 1990) and measurement of mitochondrial dysfunction via the cytochrome oxidase signal (Cooper et al., 1999).

Furthermore, NIRS became an important tool in the study of cerebral blood flow (CBF) in experimental animals (Goddard-Finegold et al., 1998; Soul et al., 2000) and infant and adult humans (Edwards et al., 1988; Olsen et al., 1996; Meek et al.,1998; Tyszczuk et al., 1998). Not only physiological changes in cerebral blood flow (CBF) but also the effect of pharmacological interventions in the rat can be determined by this technique (De Visscher et al., 2002a+b; De Visscher et al., submitted).

In our laboratory, NIRS has been used to investigate brain oxygenation after closed head injury in an experimental rat model (van Rossem et al., 1999a+b) and during transient anoxia (De Visscher et al., 2002b), using a multi wavelength NIRS system developed at the University College London (Cope et al., 1989; Matcher et al., 1995). In transmission mode, this system allows to monitor the oxygenation of the whole rat brain. We also have shown that the transit of a small bolus of indocyanine green (ICG) through the brain can be accurately monitored with NIRS in rats (De Visscher et al., 2002a).

The ultimate goal of the NIRS technology however is to assess cerebral oxygen consumption, in order to identify the pathophysiological mechanism of altered brain oxygen consumption. Achieving this measurement would yield a complete overview of the brains oxygen housekeeping, with $\mathrm{CBF}$, cerebral blood oxygenation, cellular oxygenation and oxygen metabolism.

The study of cerebral oxygen consumption is based on the simultaneous measurement of CBF and the arterio-venous difference of oxygen content on the brain. Currently we are able to assess CBF using a blood flow index of which the properties have already been studied extensively (De Visscher et al., 2002a; De Visscher et al., submitted). Arterial blood sampling is a fairly straightforward procedure, so in order to obtain all the data required for $\mathrm{CmrO}_{2}$ calculation we 
need to measure the cerebral venous saturation. This can be achieved either via sagital sinus cannulation or possibly via NIRS monitoring of the cerebral blood saturation with oxygen. The importance of $\mathrm{CmrO}_{2}$ monitoring in stroke (Yonas and Pindzola, 1994; Heiss et al., 1998) and neurotrauma patients (Enevoldsen, 1986; Muizelaar and Schroder, 1994) is well known and $\mathrm{CmrO}_{2}$ assessment is an important clinical tool to predict outcome, establish therapeutic strategies and follow the progress of the patients. It is therefore imperative to obtain these measurements in animal models dealing with stroke and neurotrauma, such as the closed head injury extensively studied in our lab (Engelborghs et al., 1997 and 2000; De Mulder et al., 2000).

The first aim of the present study is to show that cerebral oxygen consumption can be measured in small experimental using NIRS. Therefore we determined $\mathrm{CmrO}_{2}$ under baseline conditions and after the administration of pentobarbital, a known inhibitor of cerebral oxygen metabolism (Hyder et al., 2000; Linde et al., 1999; Albrecht et al., 1985) and as such often used in the treatment of neurotrauma patients (Lee et al., 1994).

The second aim of this study is to assess the stability of a known model of closed head injury $(\mathrm{CHI})$ in terms of changes in cerebral oxygen metabolism and the reactivity of $\mathrm{CmrO}_{2}$ to pentobarbital treatment.

The final goal of the study is to validate $\mathrm{O}_{2}$ saturation of haemoglobin in the cerebrum $\left(\mathrm{SmcO}_{2}\right)$ determined indirectly by NIRS instead of directly from sagital sinus blood sampling. When NIRS determined $\mathrm{SmcO}_{2}$ correlates with measurement of $\mathrm{SvO}_{2}$ in the sagital sinus blood the measurement of cerebral oxygen consumption can be safely performed by NIRS, avoiding complex sagital sinus cannulation and blood sampling. 


\section{Materials and methods}

\section{Animal treatment and preparation}

Animal housing and treatment conditions complied with the European Union directive \# 86/609 on animal welfare. Twenty four male Sprague-Dawley rats (Charles River, Sulzfeld, Germany) weighing $380-430 \mathrm{~g}$ were used. They were allowed free access to food and water (12/12-hour day-night cycle) underwent standard anaesthesia induction over 4 min with $4 \%$ isoflurane in a mixture of $30 \% \mathrm{O}_{2}$ and $70 \% \mathrm{~N}_{2} \mathrm{O}$. Subsequently rats were endotracheally intubated and anaesthesia was maintained at $2 \%$ isoflurane during surgical procedures. The rats were randomly assigned to one of the four treatment groups: control, closed head injury (CHI), pentobarbital treated and $\mathrm{CHI}$ with pentobarbital treatment ( $\mathrm{n}=6$ in each group). The control and pentobarbital group did not receive $\mathrm{CHI}$ and as such they are the same until pentobarbital administration. In both the $\mathrm{CHI}$ and $\mathrm{CHI}$ with pentobarbital group the trauma was induced before the NIR spectroscopy. Both groups are equal before pentobarbital administration. The $\mathrm{CHI}$ and non $\mathrm{CHI}$ groups differ from the start of the NIRS measurements because the first two are normal rats and the last two are neurotrauma rats.

All rats received a $2 \mathrm{~cm}$ midline incision of the scalp and the periosteum was removed to expose the bregma. After identification of the impact place, on the bregma, the rat was transferred to the trauma device as described earlier (De Mulder et al., 2000). To induce moderate closed head injury (CHI) a $400 \mathrm{~g}$ weight was dropped on the skull from a height of $50 \mathrm{~cm}$. Sham and pentobarbital treated animals underwent all of the above except the weight drop. Rats with skull fractures or major intracranial bleedings were excluded at this point.

After the $\mathrm{CHI}$ procedure the animal was placed on a rectal temperature controlled heating pad. For ICG bolus injection, necessary for blood flow assessment, the right external jugular vein was cannulated with a silicon tipped PE50 catheter prefilled with albumin bound ICG solution. Both femoral arteries were cannulated with PE50 catheters. The left femoral artery cannula was used for continuous arterial pressure monitoring/registration and the right femoral artery cannula for blood sampling. The femoral vein was cannulated with a PE50 catheter that was used for pentobarbital (Nembutal, Sanofi, Brussels, Belgium) administration.

The rats were fixed in a stereotaxic apparatus (Model 900, David Kopf, Tujunga, CA, USA). A thermistor inserted into the tip of an ear bar was used to measure the tympanic temperature, providing an accurate measurement of brain temperature (Brambink et al., 1999). A rectal 
thermistor probe was inserted to monitor body temperature, which was controlled with a heating pad connected to a homemade temperature control unit. The end tidal $\mathrm{CO}_{2}\left(\mathrm{EtCO}_{2}\right)$ and breathing rate were continuously monitored with an $\mathrm{EtCO}_{2}$-monitor (Capnogard, Novametrix, Wallingford, CT, USA).

The parietal and temporal bones were exposed by removing the scalp, periosteum and parts of the temporal muscles. Sites of possible bleeding were cauterised and the temporal bones were covered with cyano-acrylate glue (Loctite 404, Loctite Corporation, Newington, CT, USA). A small burr hole not penetrating the skull was made at the site of the sagital sinus. A 23 gauge needle was used to open the burr hole and to puncture the upper wall of the sagital sinus. Immediately after the withdrawal of the needle a PE10 catheter with a $1.5 \mathrm{~cm}$ PE 50 cuff was inserted into the sagital sinus. A few drops of $2 \%$ (in saline) low melting point agarose (SeaPlaque, FMC BioProducts, Rockland, ME, USA) were applied at the site of entrance in order to avoid bleeding and catheter movement. This cannula was used for cerebral venous blood sampling required for accurate measurement of the cerebral oxygen consumption.

Emitting and receiving optical fibres $(3 \mathrm{~mm}$ diameter) were placed onto the right and left temporal bones, respectively (frontal pole of the fibres at the level of the bregma, angle of $\pm 10^{\circ}$ relative to both the coronal and sagittal plane). To prevent blood entering the space between the skull and the optical fibre, optical gel (Optical Gel code 0608, R.P. Cargille Laboratories Inc., Cedar Grove, New Jersey, USA) was used to fill in this space and provide a good optical coupling. The remainder of the skull was covered with black clay (Modelling clay No 8401 , Eberhard Faber GmbH, Neumarkt, Germany).

The isoflurane concentration was then switched to $1.5 \%$ and this level was maintained till the end of the experiment. The surgical procedure was finished within the hour and a 10 min stabilisation period was applied before the start of the measurements. A first arterial blood sample was taken $10 \mathrm{~min}$ after the start of the measurements followed by the first ICG bolus injection at $12.5 \mathrm{~min}$. The first venous blood sample was taken immediately thereafter. At $15 \mathrm{~min}$ the animals either received sham or pentobarbital infusion. The rats from the pentobarbital group were first infused with $5 \mathrm{mg} / \mathrm{kg} / \mathrm{min}$ for $2 \mathrm{~min}$ after which a ten times lower dose was infused for the remainder of the experiment. The second arterial blood sample was taken $27 \mathrm{~min}$ after the onset of the measurements and was followed by the second ICG bolus injection at $30 \mathrm{~min}$. Here again, the second venous blood sample was taken immediately after the ICG injection. The animals were killed by terminal anoxia, a necessity for NIRS. 


\section{NIRS equipment}

The NIRS system and algorithms, all developed at the University College London (Cope et al., 1989; Matcher et al., 1995), have been described previously (Springett et al., 2000). NIR spectra were collected contiguously with a period of $100 \mathrm{~ms}$ and hundred spectra were averaged to give a time resolution of 10 seconds. Absolute changes in the concentration of oxyhaemoglobin $\left(\left[\mathrm{HbO}_{2}\right]\right)$, deoxyhaemoglobin $([\mathrm{Hb}])$ and oxidised $\mathrm{Cu}_{\mathrm{A}}\left(\left[\mathrm{Cu}_{\mathrm{A}}\right]\right)$ were calculated from the change in attenuation between 780 and $900 \mathrm{~nm}$ (Cope et al., 1989; Matcher et al., 1995) and normalised to the baseline optical pathlength measured from the $840 \mathrm{~nm}$ water feature using $2^{\text {nd }}$ differential analysis (Matcher and Cooper, 1994). Assuming $85 \%$ water content the absolute concentration of $\mathrm{Hb}$ was obtained from $2^{\text {nd }}$ differential analysis and normalised to the pathlength obtained from the $740 \mathrm{~nm}$ water feature. The absolute $[\mathrm{Hb}]$ and absolute changes in $\left[\mathrm{HbO}_{2}\right]$ and $\left[\mathrm{Cu}_{\mathrm{A}}\right]$ were monitored on-line. Absolute $\left[\mathrm{HbO}_{2}\right]$ was back-calculated taking the value after terminal anoxia as zero. Total haemoglobin $([\mathrm{HbT}])$ was calculated as the sum of $\left[\mathrm{HbO}_{2}\right]$ and $[\mathrm{Hb}]$. and mean cerebral saturation of haemoglobin with oxygen $\left(\mathrm{SmcO}_{2}\right)$ by the following formula: $\left(\left[\mathrm{HbO}_{2}\right] /[\mathrm{HbT}]\right) \times 100$. ICG has an absorption peak at $805 \mathrm{~nm}$ (Landsman et al., 1976) and can be measured by the same set up as the ICG absorption spectrum is included in the algorithm. During ICG bolus transit detection for CBF measurement the sampling frequency was switched from $0.1 \mathrm{~Hz}$ to $10 \mathrm{~Hz}$ (De Visscher et al., 2002a; De Visscher et al., submitted).

A $1 \mathrm{ml} / \mathrm{mg} \mathrm{ICG} \mathrm{(IR-125,} \mathrm{laser} \mathrm{grade;} \mathrm{Acros,} \mathrm{Geel,} \mathrm{Belgium)} \mathrm{solution} \mathrm{was} \mathrm{used} \mathrm{in} \mathrm{these} \mathrm{studies.}$ Five percent bovine serum albumin (BSA fraction V; Sigma, Bornem, Belgium) was added to this solution to bind the ICG. The solution was then sterilised by filtration with a $0.22 \mu \mathrm{m}$ filter unit. If BSA is added, ICG will not bind to the endothelium of the vascular wall and a clear passage of the bolus can be detected. The ICG solution is also stable when BSA is added, otherwise selfaggregation of the dye may occur (Cherrick et al., 1960; Gentile et al., 1985).

\section{Data analysis}

For all continuously monitored data the mean value of two 3 min periods of time starting at 7 and $22 \mathrm{~min}$ after the onset of the NIRS measurement were calculated as pre- and posttreatment values, respectively. Data obtained by this method are the physiological and brain oxygenation data. The blood gas data were obtained by arterial and sagital sinus blood sample both at pre- and posttreatment. 


\section{Blood flow index calculation}

AICG was calculated from the ICG bolus transit curve by subtraction of the baseline value, taken immediately before injection (mean value of 20 measurements) from the peak value after injection. The rise time $(\Delta t)$ was measured as the time between the first value where the ICG signal deviates from the baseline and the peak value. A blood flow index (BFI) was then calculated by dividing $\Delta$ ICG by $\Delta t$ (Kuebler et al., 1998; De Visscher et al., 2002a). The index is then corrected $\left(\mathrm{BFI}_{w}\right.$ ) for individual differences in blood volume by multiplying the BFI with the bodyweight ( $\mathrm{BFI}_{w}$; De Visscher et al., submitted). The $\mathrm{BFI}_{\mathrm{w}}$ is used to asses the total cerebral blood flow in the rat. Since the blood volume is linearly proportional to the body weight, the latter can be used as a valid correction factor. The $\mathrm{BFI}_{\mathrm{w}}$ data were then converted to calculated $\mathrm{CBF}\left(\mathrm{CBF}_{c}\right)$ data using the formula: $\mathrm{CBF}_{\epsilon}=62.4+7.06 \times \mathrm{BFI}_{w}$ (De Visscher et al., submitted)

\section{$\operatorname{avDO}_{2}, \mathrm{CmrO}_{2}$ and $\mathrm{CmrO}_{2}$ calculation}

The arterio-venous $\mathrm{O}_{2}$ content difference was calculated from the arterial and venous oxygen saturation combined with the average haemoglobin concentration obtained from the same blood samples according to the following formula:

$$
\mathrm{avDO}_{2}=1.34 \times[\mathrm{Hb}]_{\text {blood }} \times\left(\mathrm{SaO}_{2}-\mathrm{SvO}_{2}\right)
$$

Both $\mathrm{ICmrO}_{2}$ and $\mathrm{CmrO}_{2}$ were calculated from the arterio-venous $\mathrm{O}_{2}$ content difference and both flow variables according to the following formulas based on the Fick equation:

$$
\begin{aligned}
& \mathrm{ICmrO}_{2}=\mathrm{avDO}_{2} \times \mathrm{BFI}_{\mathrm{w}} \\
& \mathrm{CmrO}_{2}=\mathrm{avDO}_{2} \times \mathrm{CBF}_{\mathrm{c}}
\end{aligned}
$$

\section{Statistical analysis}

All the results are expressed as medians and $95 \%$ confidence intervals $(\mathrm{CI})$.

A two-sided Wilcoxon-Mann-Whitney rank-sum test was used for analysis between groups separately. Two-sided probability values of less than 0.05 were regarded as statistically significant. Within group analysis was performed with the Wilcoxon signed ranks test $(\mathrm{p}<0.05)$. The same 
test was used to evaluate if differences between subsequent measurements differed from zero. Bland and Altman analysis (1986) was used for comparing venous oxygen saturation $\left(\mathrm{SvO}_{2}\right)$ and oxygen saturation of the haemoglobin in the cerebrum $\left(\mathrm{SmcO}_{2}\right)$, two blood oxygenation variables measured by different technologies. Cook's distance (Cook's D) was used to identify deviating data which influenced the linear regression. Proportions of control and neurotrauma animals in both subgroups were compared using Fisher's exact test. 


\section{Results}

Table 1 shows the summary of the general physiological data from the four groups obtaine before and after pentobarbital or sham treatment. Except for the mean arterial blood pressur (MABP) of the pentobarbital treated $\mathrm{CHI}$ group, no differences in baseline were detecte relative to the control group. All baseline variables were within physiological range. In bot the control and $\mathrm{CHI}$ group the variables remained stable. Although a significant differenc between the rectal temperature before and after pentobarbital administration was observed, bi the differences were very small and both measurements were well within physiological rang Pentobarbital administration resulted in a decrease in breathing rate which was statisticall significant in the pentobarbital treated $\mathrm{CHI}$ group. In the pentobarbital group one unusually hig breathing rate was recorded in one animal both before and after pentobarbital administration Next to the suppression of the breathing pentobarbital also induced a concurrent increase in en tidal $\mathrm{CO}_{2}$, that was significant in both groups. No additional differences between pretreatment and posttreatment values were found in both pentobarbital treated groups.

The basic NIRS variables and oxygen saturation of the haemoglobin in the cerebrum from the four groups measured before and after pentobarbital or sham treatment, when performed, are shown in table 2. Comparing the baseline values of the three groups to those of the control group resulted in a significant increase of the oxyhaemoglobin concentration of the pentobarbital group. Whereas, all variables remained stable in the control, $\mathrm{CHI}$ and pentobarbital treated $\mathrm{CHI}$ group, some differences between pre- and posttreatment could be observed in the pentobarbital treated group. Concurrent significant decreases in $\left[\mathrm{HbO}_{2}\right],[\mathrm{HbT}]$ and $\mathrm{SmcO}_{2}$ were observed. Although $\mathrm{SmcO}_{2}$ decreased, a significant increase in oxidised cytochrome oxidase could be observed.

Table 3 contains the data obtained from both arterial and venous blood sampling for the four groups. Except for the lower venous oxygen saturation in both $\mathrm{CHI}$-groups and a lower venous $\mathrm{O}_{2}$ pressure as compared to the control, no differences in baseline values were detected. In the control group a significant increase in $\mathrm{PaO}_{2}$ and a concurrent significant $\mathrm{SaO}_{2}$ increase were found. The $\mathrm{CHI}$ group also showed a significant $\mathrm{PaO}_{2}$ increase. Significant decreases in $\mathrm{PvO}_{2}$ and $\mathrm{pHa}$ combined with an increase in $\mathrm{PaCO}_{2}$ could be observed in the pentobarbital group. The only significant difference in the pentobarbital treated $\mathrm{CHI}$ group was the venous $\mathrm{pH}$. 
Table 1: Body weight and physiological data derived from the continuous monitoring of four groups of six rats

\begin{tabular}{|c|c|c|c|c|c|c|c|c|}
\hline & \multicolumn{2}{|c|}{ Control group } & \multicolumn{2}{|c|}{ CHI group } & \multicolumn{2}{|c|}{ Pentobarbital group } & \multicolumn{2}{|c|}{ CHI + pentobarbital group } \\
\hline & Pretreatment & Posittreatment & Pretreatment & Posttreatment & Pretreatment & Posttreatment & Pretreatment & Posttreatment \\
\hline Weight (g) & $396[383,409]$ & & $394[388,402]$ & & $400[388,416]$ & & $390[386,430]$ & \\
\hline HR (BPM) & $343[291,405]$ & $360[286,398]$ & $353[299.433]$ & $338[300,448]$ & $355[300,423]$ & $355[291,415]$ & $329[319,409]$ & $344[324,414]$ \\
\hline $\mathrm{MABP}(\mathrm{mmHg})$ & $94.0[88.9 .115]$ & $94.9[88.8,114]$ & $86.3[78.5,101]$ & $86.9[67.3,97.1]$ & $92.1[91.3,111]$ & $102[94,6,112]$ & $77.0[69.5,97.0]:$ & $78.1[67.6,96.0]$ \\
\hline Tree $\left({ }^{\circ} \mathrm{C}\right)$ & $37.1[36.9 .37 .5]$ & $37.1[36.9,37.2]$ & $37.2[37,1,37.2]$ & $37.2[36.9,37.2]$ & $37.2[37.0,37.3]$ & $37.2[37.2,37.3]$ & $37.2[37.1,37.2]$ & $37.2[37.2,37.2]+$ \\
\hline Tear $\left({ }^{\circ} \mathrm{C}\right)$ & $35.0[34.7,35.4]$ & $35.0[34.6,35.3]$ & $34.6[34,1,35.7]$ & $34.4[33.9,35.3]$ & $35.1[34,7,35.3]$ & $35.2[34.8,35.7]$ & $35.0[34.5,35.3]$ & $35.1[34.6,35.3]$ \\
\hline $\mathrm{EtCO}_{2}(\mathrm{mmHg})$ & $46.2[43,2,51,1]$ & $47.1[41.2,51.7]$ & $44.6[38.6,53.1]$ & $42.5[38.2,52.5]$ & $43.5[40.6,50.2]$ & $47.7[43.9 .54 .9]^{+}$ & $42.4[38,7,50.0]$ & $45.4[42.0,53.1]^{+}$ \\
\hline $\mathrm{BrR}$ (BPM) & $70.3[60.1 .89 .1]$ & $67.3[58.4,88.8]$ & $69.6[61.5,124]$ & $69.1[63.5 .72 .3]$ & $77.7[64.6 .127]$ & $64.7[57.9,130]$ & $72.9[68.1 .84 .5]$ & $65.7[62.1 .74 .8]+$ \\
\hline
\end{tabular}

Values are expressed as median [95\% Cl]. CHI: closed head injury; HR: heart rate; MABP: mean arterial blood pressure; Trec: rectal temperature; Tear: tympanic temperature; $\mathrm{EtCO}_{2}$ : end tidal $\mathrm{CO}_{2}: \mathrm{BrR}$ : breathing rate. Pre and Posttreatment data were calculated as the mean value of a 3 min time window starting respectively 7 and 22 min after the onset of the measurements. + : significant difference from pre treatment within the same group. $\ddagger$ : significant difference from control Pretreatment.

Table 2: Brain oxygenation data derived from the continuous NIRS monitoring of four groups of six rats

\begin{tabular}{|c|c|c|c|c|c|c|c|c|}
\hline & \multicolumn{2}{|c|}{ Control group } & \multicolumn{2}{|c|}{$\mathrm{CHI}$ group } & \multicolumn{2}{|c|}{ Pentobarbital group } & \multicolumn{2}{|c|}{ CHI + pentebarbital group } \\
\hline & Pretreatment & Posttreatment & Pretreatment & Posttreatment & Pretreatment & Posttreatment & Pretreatment & Posttreatment \\
\hline$[\mathrm{HbO} 2](\mu \mathrm{M})$ & $85.3[751.105]$ & $86.4[81,1,103]$ & $76,3[00.2 .84 .8]$ & $73.6[61.6 .86 .2]$ & $104.7[95.2 .119]:$ & $85:[70,3,93,7]+$ & $76.21492,1101$ & $63.5[58.6 .96 .6]$ \\
\hline$[\mathrm{Hb}](\mu \mathrm{M})$ & $240[19,7,317]$ & $218(19,4,321)$ & $38.7[19.4,46.0]$ & $347[20,4,45.0]$ & $235[18.4,26.7]$ & $27.5[213,30.2]$ & $39.2[4.42,58.6]$ & $40.1[15.2,47,4]$ \\
\hline$[\mathrm{HbT}](\mu \mathrm{M})$ & $112(05,4,136)$ & $111[103,130\}$ & $110[88.7 .126]$ & $112\{820,125\}$ & $126[120,145]$ & $111[105,124\}+$ & $112\{909,142\}$ & $104[96.4,128]$ \\
\hline$\left[\mathrm{Cu}_{\mathrm{J}}\right](\mu \mathrm{M})$ & $0.1440082 .0 .378\}$ & $0.258[0 \times 4,0465]$ & $-0.004[-0.256,0,310\}$ & $0.270\{-0.315 .0 .872\}$ & $0.027[-0.038 .0 .161]$ & $1,4[0.767 .192]$ & $0.103[-0.151,0.5 \times 2]$ & $0.398[-0.133 .279]$ \\
\hline Smco: $(\%)$ & $7 \times 2 \mid 72+814]$ & $207[716.841]$ & $068[56-7.782]$ & $09,1[007,756]$ & $82,3[793,849]$ & $75,774.81090$ & $649[456,95.1]$ & $60 \times[55,3,4,2]$ \\
\hline
\end{tabular}

Values are expressed as median [95\% Cl] . CHI: closed head injury: [HbO2]: oxyhaemoglobin concentration: [Hb]: deoxyhaemoglobin concentration; [HbT]: total haemoglobin concentration: $[\mathrm{Cu}]$; changes in oxidised cytochrome oxidase: $\mathrm{SmcO}_{2} ;$ oxygen saturation of the haemoglobin in the cerebrum. Pre and Posttreatment data were calculated as the mean value of a 3 min time window starting respectively 7 and 22 min after the onset of the measurements. 4 : significant difference from pre treatment within the same group. $\$$ : significant difference from control Pretreatment. 
Table 3: Blood gas analysis data from the pre- and posttreatment arterial and venous samples from four groups of six rats

\begin{tabular}{|c|c|c|c|c|c|c|c|c|}
\hline & \multicolumn{2}{|c|}{ Control group } & \multicolumn{2}{|c|}{ CHI group } & \multicolumn{2}{|c|}{ Pentobarbital zroup } & \multicolumn{2}{|c|}{ CHI + pentebarbital group } \\
\hline & Pretreatment & Posttreatment & Pretreatment & Posttreatment & Pretreatment & Pontreatment & Pretreatment & Posttreatment \\
\hline $\mathrm{PaCO}_{2}(\mathrm{mmHg})$ & $43.0[395,46,1]$ & $433[361,496]$ & $46[38.4,4 \times 3]$ & $432\{[390,491\}$ & $23[40.2 .475]$ & $62 \mid 415.5301 \%$ & $44,41,2.476]$ & $478[41.2004]$ \\
\hline $\mathrm{PvCO}_{2}\left(\mathrm{mmH}_{\mathrm{g}}\right)$ & $45.9\{4 \mid 2,500\}$ & $45.5[359.46 .6]$ & $4 \times 4[390,52.6]$ & $45.4\left[\begin{array}{lll}33 & 1.53 & 1\end{array}\right]$ & $46,4[43,1,48.6]$ & $4.4|4| 7,40.5\}$ & $402\{4 \mid, 4,450\}$ & $45.2(4.4,46)^{4}$ \\
\hline $\mathrm{PaO}_{2}(\mathrm{mmHg})$ & $120[104,143\}$ & $132[117,148)^{+}$ & 112 [80.9.138] & $120\{87.2 .141\}^{+}$ & $132[106,140]$ & $1291100.136\}$ & $\$ 0 \mid 83,1,128\}$ & 110 [58.4. 138]" \\
\hline $\mathrm{PrO}_{2}(\mathrm{mmHg})$ & $60.4[561.672]$ & $61.4[52.4,710]$ & $53 . \mid(40.9 .791\}$ & $496[420,55,1]$ & $59.2[57.0,62.6]$ & $55.0[54.5,61.5]^{*}$ & $48.6(377,56.5):$ & $46.4[4.4,55.4]$ \\
\hline $\mathrm{pHa}$ & $7407\{7362,7,429]$ & $7404[7,374,7,430]$ & $7389[7.351,7415]$ & $7380[7.339 .7 .416]$ & $7412[7384,7.425]$ & $737857328,7.2004$ & $7.376[7.307 .7 .207$ & $7.352[7.330,7381]$ \\
\hline $\mathrm{pHv}$ & $7400[7,343,7,25]$ & $7386[7370.7 .422]$ & $7.374[7.319 .7,408]$ & $7378[7,325,7439]$ & $7.400[7.378,7.429]$ & $7306[7360,7413]$ & 34x, 7.258 & $7.345[7.201 .73899+$ \\
\hline $\mathrm{SaO}_{2}(\%)$ & $95 \times[9.4,97.7]$ & $964195,4,9811$ & $950[89 \times, 97.0]$ & $95.8[91.5 .96 .8]$ & $96.8[95,4,97,4]$ & $0.5[4,1.971]$ & $931[90.6 .26 .2]$ & $940[91.297 .1]$ \\
\hline $\mathrm{SvO}_{2}(\%)$ & $77.1172 .5 .85 .6]$ & $81.2[66,7,838]$ & $72.8[51] .759]:$ & $72.2\left[\begin{array}{lll}53 & 3.75 .8\end{array}\right]$ & $80.4[779.84 .4]$ & $76.0[7,2,703]$ & $600[58,3,76,4)$ & $645[50.1 .754]$ \\
\hline
\end{tabular}

Values are expressed as median $[95 \% \mathrm{Cl}]$. CHI: closed head injury: $\mathrm{PaCO}_{2}$ : arterial $\mathrm{CO}_{2}$ pressure; $\mathrm{PvCO}_{2}$ : venous $\mathrm{CO}_{2}$ pressure; $\mathrm{PaO}$ : arterial $\mathrm{O}_{2}$ pressure: $\mathrm{Pu}_{2}$;enous $\mathrm{O}$ pressure; $\mathrm{pHa}$ arterial $\mathrm{pH}$ : $\mathrm{pHv}$; venous $\mathrm{pH}: \mathrm{SaO}_{2}$ : arterial oxygen saturation; $\mathrm{SvO}_{2}$; sinus sagitalis venous oxygen saturation. + : significant difference from pre treatment within the same group. $\$$ : significant difference from control Pretreatment.

Table 4: Cerebral blood flow, arterio-venous $\mathrm{O}_{2}$ content difference and $\mathrm{CmrO}^{2}$ ( $\mathrm{n}=6$ in each group)

\begin{tabular}{|c|c|c|c|c|c|c|c|c|}
\hline & \multicolumn{2}{|c|}{ Control group } & \multicolumn{2}{|c|}{ CHI group } & \multicolumn{2}{|c|}{ Pentobarbital group } & \multicolumn{2}{|c|}{ CHI + pentebarbital group } \\
\hline & Pretreatment & Posttreatment & Pretreatment & Posttreatment & Pretreatment & Posttreatment & Pretreatment & Posttreatment \\
\hline $\mathrm{BFI}_{2}$ & $18.5[12.4,24.0]$ & $19.1[14.1 .24 .6]$ & $12.6[7.69,22.2]$ & $11.8[9.38,20.8]$ & $21.2[18.8,30.1]$ & $140[11.2,20.4]+$ & $12.3[6.77 .16 .018$ & $10.7[5.46,16.5]$ \\
\hline $\mathrm{CBF}_{c}(\mathrm{ml} / \mathrm{g} / \mathrm{min})$ & $193[150,232]$ & $197[162.236]$ & $152[117,219]$ & $145[129,209]$ & $212[195,275]$ & $161[141,207]+$ & $149[110,175\}:$ & $138[101,179]$ \\
\hline $\mathrm{avDO}_{3}(\mathrm{ml} / \mathrm{dl})$ & $4.00[2.69,4.72]$ & $3.46[2.46,5.65]$ & $4.56[3,68,7.99]$ & $4.79[3.59,7.81]$ & $3.34[2.65,4.14]$ & $3.92[3.36,4.63]$ & $4.58[3.70,7.55]$ & $5.57[4.26,7.92]$ \\
\hline $\mathrm{ICmrO}_{2}$ & $62.5[49.7,89.5]$ & $61.4[51.4,87.3]$ & $59.7[41.8,81.5]$ & $66.2[46.7 .81 .7]$ & $76.1[57.4,104]$ & $515[41,3,85,6]^{+}$ & $59.9[29.9,75.5]$ & $65.2[34.4 .91 .5]$ \\
\hline $\mathrm{CmrO}_{2}(\mathrm{ml} / \mathrm{g} / \mathrm{min})$ & $6.43[6.02,927]$ & $6.63[5.16,9.69]$ & $7.50[6.25,9.32]$ & $7.39[6.14,10.5]$ & $7.62[5.71,9.57]$ & $6.13[5.17,8.65]$ & $7.59[4.42,8.96]$ & $7.83[5.21,11.4]$ \\
\hline
\end{tabular}

Values are expressed as median $[95 \% \mathrm{CI}]$. CHI: closed head injury; $\mathrm{BFI}_{\mathrm{w}}$ : weight corrected blood flow index; $\mathrm{CBF}_{4}$ : cerebral blood flow from conversion of BFI: avDO, arterio-venous $\mathrm{O}_{2}$ content difference: $\mathrm{ICmrO}_{2}: \mathrm{CmrO}_{2}$ index: $\mathrm{CmrO}_{2}$ : metabolic rate of oxygen. + ; significant difference from pre treatment within the same group. \$: significant difference from control Pretreatment. 
Blood flow data, avDO, and metabolic rate of oxygen data for all groups are summarised in table 4. Baseline $\mathrm{BFI}_{\mathrm{w}}$ and $\mathrm{CBF}_{\mathrm{c}}$ data from the pentobarbital treated $\mathrm{CHI}$ group were significantly different from the control. No other differences in baseline as compared to the control were observed. Significant decreases in both blood flow variables and the ICmrO2 occur after pentobarbital administration in normal rats.

Figure 1 shows the correlation and Bland and Altman analyses of the $\mathrm{SvO}_{2}$ and the $\mathrm{SmcO}_{2}$ in the complete data set and two subgroups. The complete data set, as shown in panels A and B, showed that the regression was markedly influenced by some data in the lower region of the $\mathrm{SvO}_{2}$. This was confirmed with the Cook's D analysis. In this region a disagreement between $\mathrm{SvO}_{2}$ and $\mathrm{SmcO}_{2}$ is notable. Since the difference is not significantly different from zero $(\mathrm{p}=0.6805)$, Bland and Altman analysis showed that on average both methods are measuring the same value. This method also revealed discrepancies between both measurements, thus causing large confidence intervals. This gives rise to a low accuracy of the prediction. We then looked at the data and saw that the animals could be separated into two subgroups: one of animals with both $\mathrm{PvO}_{2}$ measurements above and the others with at least one under $50 \mathrm{mmHg}$. Both subgroups were reanalysed using linear regression and Bland and Altman analysis. The data from the animals with both $\mathrm{PvO}_{2}$ measurements exceeding $50 \mathrm{mmHg}$ are shown in panels $\mathrm{C}$ and $\mathrm{D}$. The regression analysis resulted in a better correlation, with a slope not significantly different from 1 (slope $[95 \% \mathrm{CI}]=0.88[0.58,1.18]$ ). Here again, the Bland and Altman analysis showed that both measurements are measuring the same value, since the difference between both did not significantly differ from zero $(\mathrm{p}=0.7550)$. In addition, the confidence interval became smaller thus indicating a good agreement of individual measurements. Panel $\mathrm{E}$ and $\mathrm{F}$ show the regression and Bland and Altman analysis from the data obtained from animals where at least one $\mathrm{PvO}_{2}$ measurement was under $50 \mathrm{mmHg}$, respectively. In this subgroup no correlation between both measurements could be found. Here again, the differences between both measurements did not significantly differ from zero $(\mathrm{p}=\mathbf{0 . 8 6 0 3})$. The very broad confidence interval clearly indicates that individual agreement between both variables can be extensive.

The upper part of the fifth table shows the frequency analysis of $\mathrm{CHI}$ versus non $\mathrm{CHI}$ and pentobarbital versus non pentobarbital after the animals were reassigned to two subgroups according the above describes $\mathrm{PvO}_{2}$ requirements. This analysis clearly shows that the $\mathrm{CHI}$ group is significantly more represented in the group where $\mathrm{PvO}_{2}$ is lower than $50 \mathrm{mmHg}$, thus indicating a differential population spreading of $\mathrm{CHI}$ and non $\mathrm{CHI}$ over the $\mathrm{PvO}_{2}$ criteria. When comparing the frequencies from the pentobarbital and non pentobarbital animals no such difference could be found 

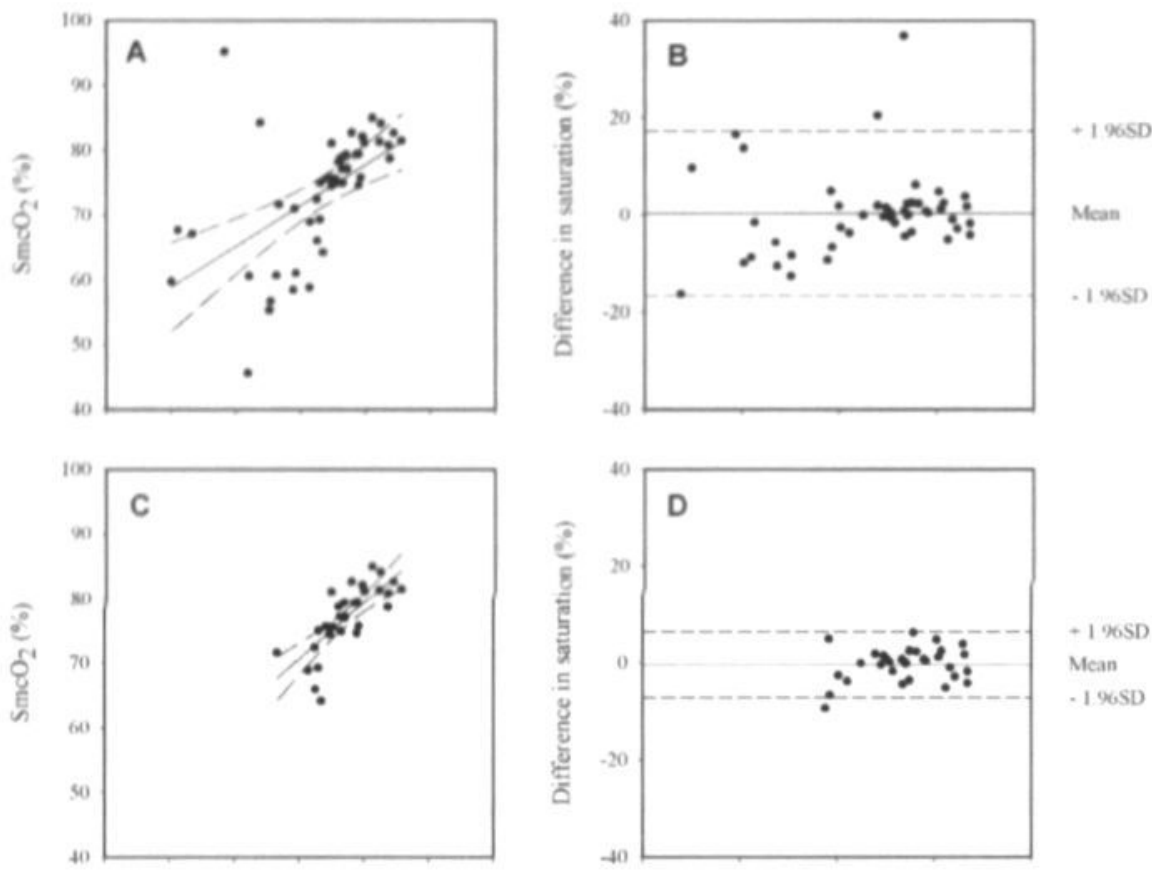

$+1 \% 65$

Mean

$.196 \mathrm{SD}$
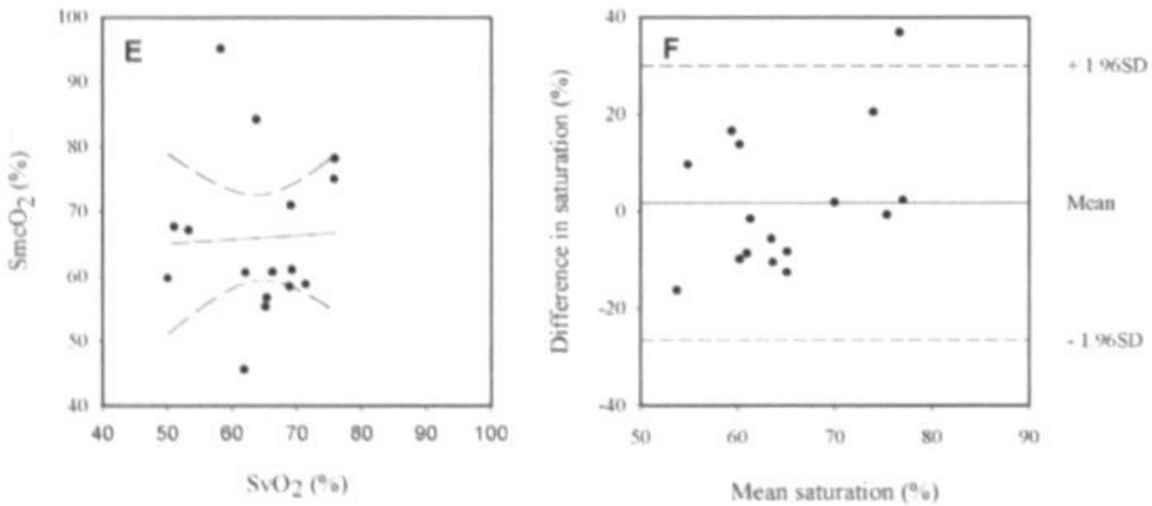

Figure 1. Comparison between oxygen saturation of the venous blood $\left(\mathrm{SvO}_{2}\right)$ derived from a sagital sinus blood sample and the NIRS measured oxygen saturation of the haemoglobin in the cerebrum $\left(\mathrm{Smc}_{2}\right)$. Panels $\mathrm{A}$ and $\mathrm{B}$ show the complete data analysed by linear regression (full line; dashed line: $95 \% \mathrm{Cl}$ ) and Bland and Altman analysis, respectively. Linear regression: $\mathrm{SmcO}_{2}=0.63 \times \mathrm{SvO}_{2}+27.27(\mathrm{R}=0.55)$. Panels $\mathrm{C}$ and $\mathrm{D}$ show the linear regression and Bland and Altman analysis of the data from the animals with all $\mathrm{PvO}_{2}$, measures above $50 \mathrm{mmHg}$. respectively. Linear regression: $\mathrm{Smc}_{2}=$ $0.88 \times$ Sv0 $+8.81(R=0.74)$. Panels $E$ and $F$ show the linear regression and Bland and Altman analysis of the data from the animals with at least one Pv0, measures under $50 \mathrm{mmHg}$, respectively. Linear regression: $\mathrm{SmcO}=0.06 \times \mathrm{Sv0}+61.31$ $(R=0.04)$. 
The lower part of table five contains the summary of the univariate analysis from the pretreatment data after the animals were reassigned to two subgroups according the above describes $\mathrm{PvO}_{2}$ requirements. The table clearly shows that $16(62 \%)$ out of 26 variables differed significantly. From the variables that showed significant differences we chose a subgroup of variables that could be easily assessed at the start of an experiment. This would allow us to establish a usable exclusion criterion when an accurate assessment of the $\mathrm{SmcO}_{2}$ is required. The chosen variables were then analysed with a multiple regression analysis. This analysis showed that $\mathrm{pHa}, \mathrm{pHv}$, $\mathrm{SaO}_{2}, \mathrm{SvO}_{2},[\mathrm{HbT}]_{\mathrm{av}}$ and $\mathrm{MABP}$ are significant linear predictors for the assignment into one of both groups. Considering these five variables the least overlap into the measurements from both groups can be seen in the MABP (individual graphs not shown).

\begin{tabular}{|c|c|c|c|}
\hline Subereups & $\mathrm{MO}_{1}<\mathrm{se}$ & $\mathrm{PuO}_{2}>50$ & p-value \\
\hline Non CHI rats & 0 & 12 & \multirow{2}{*}{0.0013} \\
\hline CHI rat & 8 & 4 & \\
\hline No pentobarbital & 3 & 9 & \multirow[t]{2}{*}{0.4735} \\
\hline Pentobartival & 5 & 7 & \\
\hline Weight (e) & $390[386,401]$ & 398 [388, 408] & 0.1663 \\
\hline HR (BPM) & $329[319.368]$ & $356[339,389]$ & 00745 \\
\hline MABP $\left(m m H_{y}\right)^{*}$ & $78.6[72.9 .84 .1]$ & $94.8[91.7,100.1]$ & -00001 \\
\hline $\operatorname{Trec}(\gamma)$ & $37.2\{37.1 .372\}$ & $37.2\{37,1,37.2\}$ & 06451 \\
\hline $\operatorname{Tear}\left({ }^{\circ} \mathrm{C}\right)^{*}$ & $346[345,352]$ & $35.2[34 \times, 35.2]$ & 0.0052 \\
\hline $\mathrm{ExCO}_{2}\left(\mathrm{~mm} \mathrm{H}_{2}\right)$ & $44.1(40.0,500)$ & $45.8[43.9,48.4]$ & 0.2031 \\
\hline BrR (BPM) & $68.2[65.7,74.8]$ & $71.2[637,76.2]$ & 05035 \\
\hline [HbO:] ( $\mu \mathrm{M})$ & $66.7[60.2 .81 .2]$ & $87.4[83.2,96.6]$ & 40001 \\
\hline$[\mathrm{Hb}](\mu \mathrm{M})$ & $40.2[20,4,46,0]$ & $26.9[22 \times 30.2]$ & 00060 \\
\hline$[\mathrm{HbT}](\mathrm{aM})$ & $1061[96,4,1145]$ & $114.4\{1005,124.2\}$ & 00016 \\
\hline$[\mathrm{Cu}](\mu \mathrm{M})$ & $0.295[0.020,0.674]$ & $0.142[-0.029,0.290]$ & 0.1535 \\
\hline $\mathrm{SmcO}_{2}(\mathrm{~S})$ & $60 \times[55.4,750]$ & $77.1[75.0 .80 .8]$ & 0.0003 \\
\hline $\mathrm{PaCO}_{2}(\mathrm{mmH})$ & $43 \times[41,2,48,4]$ & $43.5[42.3,45.5]$ & 0.7993 \\
\hline $\mathrm{PVCO}_{2}\left(\mathrm{mmH}_{\mathrm{g}}\right)$ & $476[43 \times, 509]$ & $463[440,46.8]$ & 01751 \\
\hline $\mathrm{PaO}_{3}\left(\mathrm{~mm} \mathrm{H}_{\mathrm{g}}\right)^{*}$ & $98.4[5 \times 6,12 k 09]$ & $1250\{1170,13\} 0\}$ & 00018 \\
\hline $\mathrm{POO}_{3}\left(\mathrm{mmH}_{\mathrm{g}}\right)^{*}$ & $45.7[42.4,47.5]$ & $56 \times[55,4,60.6]$ & -00001 \\
\hline $\mathrm{pHa}^{*}$ & $737|734,739|$ & $7.40[7.38,7.42]$ & 00007 \\
\hline pHt. & $735[7,32,7391$ & $7.39[7.38,7.40]$ & 00065 \\
\hline $\mathrm{SaO}_{7}(\mathrm{~S})^{*}$ & $93.1[915,96.2]$ & $961[95,4,966]$ & 00004 \\
\hline $\mathrm{SvO}_{2}(\mathrm{~S}) \cdot$ & $653[58.6,693]$ & $771[74 \times, 793]$ & -00001 \\
\hline BFL, & $9.97[7.93,13.93]$ & $17.68[14 \quad 10.20 .44]$ & .00001 \\
\hline $\mathrm{CBF},(\mathrm{ml} / \mathrm{g} \min )$ & $133[118,161]$ & $\ln 7[162,207\}$ & -00001 \\
\hline $\mathrm{NDO}$; (mlstif) & $535[426.755]$ & $400[3,47,433]$ & 0.0001 \\
\hline $1 \mathrm{Cm}_{\mathrm{O}} \mathrm{O}$ & $601[4] \times 75.5]$ & $636[574,7\} \times 1]$ & 0.2539 \\
\hline $\mathrm{CmrO},(\mathrm{mi} / \mathrm{g} \min )$ & $7 \times 7[636,896]$ & $6.93\{6.26,7.91\}$ & 0.1954 \\
\hline$(\mathrm{Hb}]_{L}$, ig dil) & $14.4\{130.15 .2\}$ & $156[15,2,160]$ & 0.0001 \\
\hline
\end{tabular}

Yalues are capteaned as median $[95$ S CI CHI closed head insory, HR. heart rate; MABP mess antenal blood presuure. Tres metal iemperature. Tear tympanic temperature. FaCO, esd bdal $C O$

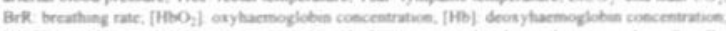
$[\mathrm{HbT}]$ total hacmoglobin concentratioe. $[\mathrm{Cu}$. $]$ changes in oxidised cylochrome oxidase, SmeO

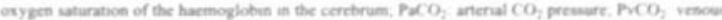

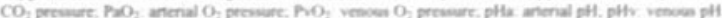

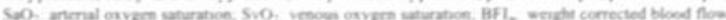
inder, $\mathrm{CBF}$; cetebral blood flow from coeversion of $\mathrm{BFI}_{2} . \mathrm{wDO}_{2}$ arneriovenows $\mathrm{O}_{2}$ coetent

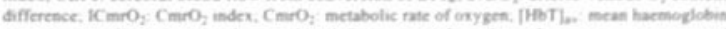

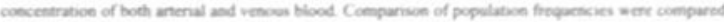

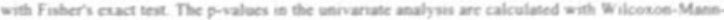

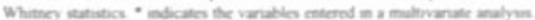




\section{Discussion}

We have previously used NIRS to study cerebral oxygenation after closed head injury (van Rossem et al., $1999 \mathrm{a}+\mathrm{b}$ ), influences of NO inhibition on cytochrome oxidase (De Visscher et al., 2002b) and cerebral blood flow (De Visscher et al., 2002a; De Visscher et al., submitted). Although the NIRS technique has been extensively developed for its use in small experimental animals some questions remained to be solved. The first question we addressed in the present study was the possibility of $\mathrm{CmrO}_{2}$ assessment making use of an arterial and venous blood sample combined with the blood flow indexed $\left(\mathrm{BFI}_{w}\right)$ described earlier (De Visscher et al., 2002a; De Visscher et al., submitted). We studied the $\mathrm{CmrO}_{2}$ assessment in control and neurotrauma rats and in both we also looked at the influence of pentobarbital administration, a known inhibitor of oxygen metabolism (Hyder et al., 2000; Linde et al., 1999; Albrecht et al., 1985). The second question we studied was the agreement between the saturation of venous blood with oxygen $\left(\mathrm{SvO}_{2}\right)$ and the oxygen saturation of the haemoglobin in the cerebrum $\left(\mathrm{SmcO}_{2}\right)$.

One of the models used was oxygen metabolism suppression by barbiturates such as pentobarbital. As compared to the controls pentobarbital administration in normal rats resulted in respiratory suppression with a lower breathing rate and a significantly higher end tidal $\mathrm{CO}_{2}$ and $\mathrm{PaCO}_{2}$. The absence of a significant difference in breathing rate in the pentobarbital group is most probably caused by the extreme values measured in 1 rat. The breathing suppression effect of pentobarbital in normal (Wilson et al., 1993; Wixson et al., 1987) and decerebrated rats (Sapru and Krieger, 1979) has already been described by other groups. Pentobarbital administration also influenced the NIRS variables in the pentobarbital group. The decreased oxygen demand resulted in an increase in the concentration of oxidised $\mathrm{Cu}_{\mathrm{A}}$ with a concurrent $\mathrm{SmcO}_{2}$ decrease, mainly caused by a decrease in the concentration of oxidised haemoglobin. This clearly indicates that the oxygen metabolism is decreased by the administered pentobarbital but that the oxygen supply is still sufficient. Furthermore pentobarbital reduced the cerebral blood flow to approximately $2 / 3$ of the initial value. In a comparable set up where the pentobarbital was given additionally to a baseline anaesthetic Hyder and co-workers (2000) found a reduction to $66 \%$ of the initial CBF after pentobarbital administration. Although a decrease in $\mathrm{ICmrO}_{2}$ could be seen in the same group this could not be translated into a difference in $\mathrm{CmrO}_{2}$ probably due to the problem of individual $\mathrm{CBF}_{c}$ calculation from the blood flow index, which we already described previously (De Visscher et al., submitted).

Another somewhat more variable approach towards an altered cerebral oxygen metabolism is the induction of neurotrauma, a model extensively studied in our lab (Engelborghs et al., 1997 and 2000; De Mulder et al., 2000). Although the rats received a moderate neurotrauma this 
only resulted in 1 significant difference, but looking more closely at the data we see that some variables are deviating from their control values. Most probably the $\mathrm{CHI}$ group contains animals that have received the insult but only suffer minor or no damage due to the very strict exclusion criteria applied by us. This might result in a larger variability in the $\mathrm{CHI}$ group as compared to the controls. The used exclusion criteria do not allow fractures or intracranial bleedings, but they are visually detected and thus bleedings at the base of the skull or in the brain can not be detected.

A final group consisted of $\mathrm{CHI}$ animals receiving pentobarbital before the second measurements. Although somewhat more significant differences with control could be found at the baseline measurement as compared to the $\mathrm{CHI}$ group, they show almost identical numerical values for their variables. After neurotrauma we found that pentobarbital still induced a respiratory suppression, but no longer did it influence NIRS, oxygen metabolism and already altered cerebral blood flow parameters. This is an indication that under the pathological conditions we induced with our neurotrauma model, cerebral haemodynamics are already disturbed in such a way that the lack reactivity with respect to the direct or indirect effects of pentobarbital.

In general, no differences in arterio-venous oxygen concentration were found, the observed $\mathrm{ICmrO}_{2}$ decrease was thus mainly caused by the decreased cerebral blood flow.

Different theories on what NIRS is actually measuring exist. The most common theory states that NIRS is measuring a mixture of arterial and venous blood (Watzman et al., 2000). We were interested in comparing the NIRS measured $\mathrm{SmcO}_{2}$ with the venous blood sample obtained $\mathrm{SvO}_{2}$ to see whether the $\mathrm{SmcO}_{2}$ represented venous blood or showed a deviation. If this deviation would be an overestimation this would indicate that the $\mathrm{SmcO}_{2}$ was not only venous but also contained an arterial component. In a first approach a correlation could be found and it also showed that both techniques were actually measuring the same value, but on an individual basis large deviations could be observed.

After redistributing the rats according to the $\mathrm{PvO}_{2}$ classes we looked at the actual distribution of $\mathrm{CHI}$ versus non $\mathrm{CHI}$ and pentobarbital versus non pentobarbital rats. With this analysis we clearly showed that pentobarbital treatment did not result in a differential distribution as compared to the controls, whereas $\mathrm{CHI}$ resulted in an increased amount of animals in the $\mathrm{PvO}_{2}$ lower then $50 \mathrm{mmHg}$ group. Considering this result and what has been described in the previous paragraph we conclude that $\mathrm{SvO}_{2}$ can not be estimated with the NIRS derived $\mathrm{SmcO}_{2}$ in most of the neurotrauma rats. Therefore, the only valid methodology for obtaining an accurate $\mathrm{SvO}_{2}$ in neurotrauma rats in venous blood sampling from the sagital sinus. In respect to this method we 
need to mention that obtaining a good sagital sinus cannulation in neurotrauma rats is difficult. The fact that some animals that received $\mathrm{CHI}$ are still in the group with a $\mathrm{PvO}_{2}$ larger then $50 \mathrm{mmHg}$, together with all the control, is probably caused the larger variability in this group. In reality a lower proportion of these almost normal $\mathrm{CHI}$ animals should be obtained but the increases proportion can be caused by the exclusion criteria. These criteria might lead to the exclusion of animals with the most damage and bleeding, thus only retaining the least damaged rats for the study of which some might not even be damaged.

Assuming that we need to measure the $\mathrm{SvO}_{2}$ by estimating it with the NIRS measures $\mathrm{SmcO}_{2}$ * we can refine our exclusion criteria. Redistribution of the measured variables according to the $\mathrm{PvO}_{2}$ classes allowed defining important differences between both groups. In a first approach we screened for differences using a univariate analysis. From the found differences some were selected to be used in a multivariate analysis. In our selection we included variables that could be measured early in the experiment such as variables obtained from a blood gas analysis, arterial blood pressure monitoring and the tympanic thermistor. Parameters derived from NIRS were excluded because they can only be obtained when the animals is fully prepared. Finally six variables were retained, being: $\mathrm{pHa}, \mathrm{pHv}, \mathrm{SaO}_{2}, \mathrm{SvO}_{2},[\mathrm{HbT}]_{\mathrm{av}}$ and $\mathrm{MABP}$. The most usable from these would be MABP where animals below $85 \mathrm{mmHg}$ could be excluded. When all included animals fulfil these requirements the $\mathrm{SvO}_{2}$ can be accurately estimated by the $\mathrm{SmcO}_{2}$, thus $\mathrm{avDO}_{2}$ could be calculated by the following formula:

$$
\mathrm{avDO}_{2}=1.34 \times[\mathrm{Hb}]_{\text {blood }} \times\left(\mathrm{SaO}_{2}-\mathrm{SmcO}_{2}\right)
$$

This would avoid the somewhat complex sagital sinus cannulation and blood sampling.

In conclusion we can state that the measurement of $\mathrm{CmrO}_{2}$ using a blood flow index and the arterio-venous difference in oxygen content can be performed in small experimental animals under normal and either pharmacological or pathophysiological changed conditions. Secondly, in the closed head injury model the correlation between the NIRS determined $\mathrm{SmcO}_{2}$ and sagital sinus blood $\mathrm{SvO}_{2}$ does no longer hold. Finally, under normal conditions the correlation is enabling us to replace $\mathrm{SvO}_{2}$ by the NIRS derived $\mathrm{SmcO}_{2}$ thus allowing $\mathrm{CmrO}_{2}$ calculation without sagital sinus blood sampling. 


\section{References}

Albrecht RF, Cook J, Hoffman WE, Larscheid P, Miletich DJ, Naughton N (1985) The interaction between benzodiazepine antagonists and barbiturate-induced cerebrovascular and cerebral metabolic depression. Neuropharmacol. 24(10): 957 . 963.

Bland JM, Altman DG (1986) Statistical methods for assessing agreement between two methods of clinical measurement. Lancet 1(8476): 307-310.

Brambink AM, Kopacz L, Astheimer A, Noga H, Heimann A., Kempski 0 (1999) Control of brain temperature during experimental global ischemia in rats. J. Neurosci. Meth. 92: 111-122.

Cherrick GR, Stein WS, Levy CM, Davidson CS (1960) Indo-cyanine green: observations on its physical properties, plasma decay and hepatic excretion. J. Clin. Invest. 39: 592-600.

Cooper CE, Cope M, Springett R, Amess PN, Penrice J, Tyszcuk L, Punwani S, Ordidge R, Wyatt J, Delpy DT (1999) Use of mitochondrial inhibitors to demonstrate that cytochrome oxidase near-infrared spectroscopy can measure mitochondrial dysfunction noninvasively in the brain. J. Cereb. Blood Flow Metab. 19(1): 27-38.

Cope M, Delpy DT, Wray S, Wyatt JS, Reynolds EOR (1989) A CCD spectrophotometer to quantitate the concentration of chromophores in living tissue utilising the absorption peak of water at $975 \mathrm{~nm}$. Adv. Exp. Med. Biol. 248: 33-40

De Mulder G., van Rossem K., Van Reempts J., Borgers M., Verlooy J (2000) Validation of a closed head injury model for use in long-term studie. Acta neurochir. (suppl.) 76: 409-413.

De Visscher G, van Rossem K, Van Reempts J, Borgers M, Flameng W, Reneman RS (2002a) Cerebral blood flow assessment with indocyanine green bolus transit detection by near-infrared spectroscopy in the rat. Comp. Biochem. Physiol. A 132(1): 87-95.

De Visscher G, Springett R, Delpy DT, Van Reempts J, Borgers M, van Rossem K (2002b) Nitric oxide does not inhibit cerebral cytochrome oxidase 'in vivo' nor in the reactive hyperaemic phase post brief anoxia in the adult rat. J. Cereb. Blood Flow Metab. 22(5): 515-519.

De Visscher G, Leunens V, Borgers M, Reneman RS, Flameng W, van Rossem K. Validation of CBF assessment by means of indocyanine green bolus transit detection with NIRS: a comparison with coloured microsphere flowmetry, submitted.

Edwards AD, Wyatt JS, Richardson C, Delpy DT, Cope M, Reynolds EOR (1988) Cotside measurement of cerebral blood flow in ill newborn infants by near-infrared spectroscopy. Lancet 2: 770-771.

Enevoldsen E (1986) CBF in head injury. Acta Neurochir. Suppl. (Wien) 36: 133-136.

Engelborghs K, Verlooy J, Van Deuren B, Van Reempts J, Borgers M (1997) Intracranial pressure in a modified experimental model of closed head injury. Acta Neurochir. suppl. 70: 123-125.

Engelborghs K, Haseldonckx M, Van Reempts J, van Rossem K, Wouters L, Borgers M, Verlooy J (2000) Impaired autoregulation of cerebral blood flow in an experimental model of traumatic brain injury. J. Neurotrauma 17(8): 667-677.

Gentile S, Bajema BL, Baldini G, Lunazzi G, Groothuis GMM, Tiribelli C, Meijer DKF, Sottocasa GL (1985) Measurement of the association of cholephylic organic anions with different binding proteins. Biochem. Pharmacol. 34(14): 2439-2444.

Goddard-Finegold J, Louis PT, Rodriguez DL, David Y, Contant CF, Rolfe P (1998) Correlation of near infrared spectroscopy cerebral blood flow estimations and microsphere quantitations in newborn piglets. Biol. Neonate. 74(5): 376-384.

Heiss WD, Graf R, Grond M, Rudolf J (1998) Quantitative neuroimaging for the evaluation of the effect of stroke treatment. Cerebrovasc. Dis. 8 Suppl. 2: 23-29.

Hyder F, Kennan RP, Kida I, Mason GF, Behar KL, Rothman D (2000) Dependence of oxygen delivery on blood flow in rat brain: a 7 tesla nuclear magnetic resonance study. J. Cereb. Blood Flow Metab. 20(3): 485-498.

Jobsis FF (1977) Noninvasive, infrared monitoring of cerebral and myocardial oxygen sufficiency and circulatory parameters. Science 198(4323): 1264-1267. 
Kuebler WM, Sckell A, Habler 0, Kleen M, Kuhnle GEH, Welte M, Messmer K, Goetz AE (1998) Noninvasive measurement of regional cerebral blood flow by near-infrared spectroscopy and indocyanine green. J. Cereb. Blood Flow Metab. 18 : 445-456.

Landsman MLJ, Kwant G, Mook GA, Zijlstra WG (1976) Light-absorbing properties, stability, and spectral stabilization of indocyanine green. J. Appl. Physiol. 40(4): 575-583.

Lee MW, Deppe SA, Sipperly ME, Barrette RR, Thompson DR (1994) The efficacy of barbiturate coma in the management of uncontrolled intracranial hypertension following neurosurgical trauma. J. Neurotrauma 11(3): 325-31.

Linde R, Schmalbruch IK, Paulson 0B, Madsen PL (1999) The Kety-Schmidt technique for repeated measurements of global cerebral blood flow and metabolism in the conscious rat. Acta Physiol. Scand. 165(4): 395-401.

Matcher SJ, Cooper CE (1994) Absolute quantification of deoxyhaemoglobin concentration in tissue near-infrared spectroscopy. Phys. Med. Biol. 39: 1295-1312.

Matcher SJ, Elwell CE, Cooper CE, Cope M, Delpy DT (1995) Performance comparison of several published tissue nearinfrared spectroscopy algorithms. Anal. Biochem. 227: 54-68.

Meek JH, Tyszczuk L. Elwell CE, Wyatt JS (1998) Cerebral blood flow increases over the first three days of life in extremely preterm neonates. Arch. Dis. Child Fetal. Neonatal. Ed. 78(1): F33-37.

Muizelaar JP, Schroder ML (1994) Overview of monitoring of cerebral blood flow and metabolism after severe head injury. Can. J. Neurol. Sci. 21(2): S6-11.

OIsen KS, Svendsen LB, Larsen FS (1996) Validation of transcranial near-infrared spectroscopy for evaluation of cerebral blood flow autoregulation. J. Neurosurg. Anesthesiol. 8(4): 280-285.

Robertson CS, Gopinath SP, Chance B (1995) A new application for near-infrared spectroscopy: detection of delayed intracranial hematomas after head injury. J. Neurotrauma 12 (4): 591-600.

Sapru HN, Krieger AJ (1979) Cardiovascular and respiratory effects of some anesthetics in the decerebrate rat. Eur. J. Pharmacol. 53(2): 151-158.

Soul JS, Taylor GA, Wypii D, Duplessis AJ, Volpe JJ (2000) Noninvasive detection of changes in cerebral blood flow by near-infrared spectroscopy in a piglet model of hydrocephalus. Pediatr. Res. 48(4): 445-449.

Springett R, Newman J, Cope M, Delpy DT (2000) Oxygen dependency and precision of cytochrome oxidase signal from full spectral NIRS of the piglet brain. Am. J. Physiol. Heart Circ. Physiol. 279: H2202-H2209.

Tamura M, Hoshi Y, Okada F (1997) Localized near-infrared spectroscopy and functional optical imaging of brain activity. Phil. Trans. R. Soc. Lond. B 352: 737-742.

Tyszczuk L, Meek J, Elwell C, Wyatt JS (1998) Cerebral blood flow is independent of mean arterial blood pressure in preterm infants undergoing intensive care. Pediatrics 102(2 Pt 1): 337-341.

van Rossem K, Garcia-Martinez S, De Mulder G, Van Deuren B, Engelborghs K, Van Reempts J, Borgers M (1999a) Brain oxygenation after experimental closed head injury. Adv. Exp. Med. Biol. 471: 209-215.

van Rossem K, Garcia-Martinez S, Wouters L, De Mulder G, Van Deuren B, Van Reempts J, Borgers M (1999b) Cytochrome oxidase redox state in brain is more sensitive to hypoxia after closed head injury: a near-infrared spectroscopy (NIRS) study. J. Cereb. Blood Flow Metab. 19 (Suppl 1): S391.

Villringer A, Planck J, Hock C, Schleinkofer L, Dirnagl U. Near-infrared spectroscopy (NIRS): a new tool to study hemodynamic changes during activation of brain function in human adults. Neurosci. Lett. 1993; 154: 101-104

Watzman HM, Kurth CD, Montenegro LM, Rome J, Steven JM, Nicolson SC (2000) Arterial and venous contributions to near-infrared cerebral oximetry. Anesthesiol. 93(4): 947-953.

Wilson RP, Zagon IS, Larach DR, Lang CM (1993) Cardiovascular and respiratory effects of tiletamine-zolazepam. Pharmacol. Biochem. Behav. 44(1): 1-8. 
Wixson SK, White WJ, Hughes HC Jr, Lang CM, Marshall WK (1987) The effects of pentobarbital, fentanyl-droperidol, ketamine-xylazine and ketamine-diazepam on arterial blood $\mathrm{pH}$, blood gases, mean arterial blood pressure and heart rate in adult male rats. Lab. Anim. Sci. 37(6): 736-742.

Wyatt JS, Cope M, Delpy DT, Richardson CE, Edwards AD, Wray S, Reynolds EOR (1990) Quantitation of cerebral blood volume in human infants by near-infrared spectroscopy. J. Appl. Physiol. 68(3): 1086-1091.

Yonas H, Pindzola RR (1994) Physiological determination of cerebrovascular reserves and its use in clinical management. Cerebrovasc. Brain Metab. Rev. 6(4): 325-340. 
Chapter 8

Discussion and future prospects 


\section{Contributions to NIRS}

\section{State of the art NIRS}

State of the art NIRS has been widely used both in human and experimental animal studies and applications (for review: Owen-Reece et al., 1999). Different variables such as the basic NIRS variable, being oxyhaemoglobin, deoxyhaemoglobin and cytochrome oxidase redox state, or various derivatives, such as quantifying the cerebral haemodynamics (Elwell et al., 1994) have already been studied. In the first study (Chapter 2) we used the state of the art NIRS equipment to study cytochrome oxidase inhibition by nitric oxide in vivo, if any. I-NAME, a non specific of nitric oxide synthase (Hobbs and Gibson, 1990; Rees et al., 1990) was intravenously infused (30 $\mathrm{mg} / \mathrm{kg}$ ) which resulted in a marked increase in MABP consistent with other published reports (Buchanan and Phillis, 1993; Prado et al., 1993). Also the NIRS variables showed changes consistent with the previously described cerebral blood flow (CBF) decrease (for review: ladecola et al., 1994). The decrease in both the concentration of oxyhaemoglobin and cerebral blood oxygen saturation can be attributed to the vasoconstriction and concurrent CBF decrease, respectively. The I-NAME administration did not alter the redox state of cytochrome oxidase, thus indicating the absence of cytochrome oxidase inhibition by NO under physiological conditions. A 70 s period of anoxia was used to study the NIRS variables and effects of nitric oxide synthase inhibition in non-physiologic conditions In general we could conclude that in adult rats nitric oxide synthase inhibition by $\mathrm{l}-\mathrm{NAME}$ does not alter the vascular responses nor the partial reduction of cytochrome oxidase during and after a $70 \mathrm{~s}$ period of anoxia. This indicates that $\mathrm{NO}$ is not a major determinant of the observed alterations in these conditions (De Visscher et al., 2002a). This study contained two assumptions which were based on published studies. The first was the decrease caused by the vasoconstrictory effect and consequent CBF decrease caused by l-NAME (for review: ladecola et al., 1994). The second assumption states that the cerebral metabolic rate of oxygen is not altered by I-NAME administration under normal physiologic conditions (Horvath et al., 1994). Although these were well-founded assumptions the actual data could not be obtained with the state of the NIRS equipment in the rat.

\section{Introducing ICG blood flow assessment in the rat}

We adapted a dye dilution method for CBF assessment in pigs previously described by Kuebler and co-workers (1998) for its use in small animals (Chapter 3). The method described is based on the detection of the transit of a single indocyanine green (ICG) bolus with NIRS. From this 
bolus transit curve two variables can be obtained namely the rise time and the amplitude of the ICG concentration deflection. We adopted this approach but used a slightly different rise time measurement. Kuebler et al. (1998) took the time between 10 and $90 \%$ of the peak value, whereas we measured the time from the onset to the peak of the deflection. This can be done accurately in our setting as application of a high sampling speed provides a clear onset and peak of the transit curve. First we established the use of a dose of ICG which yielded a good signal to noise ratio with only very small and short-lasting disturbances of the other NIRS parameters. In a second approach this ICG-derived blood flow index (BFI) was tested for the detection of hypercapnia increased CBF and repeatability (De Visscher et al, 2002b). Significant increases in BFI ranging from 16 to $98 \%$ were found during hypercapnia. Using $7.5 \% \mathrm{CO}_{2}$ breathing, Estevez and Phillis (1997) found a similar range of rCBF increase (20 to $100 \%$ ) in rats with Laser-Doppler probes. In order to evaluate the BFI response to hypercapnia in a semi-quantitative way, we calculated its percentual increase per $\mathrm{mmHg}$ increase in $\mathrm{EtCO}_{2}$. This increase was reproducible. The values obtained at the three subsequent $\mathrm{CO}_{2}$ responses are in concordance with those found in cat and rat by other authors (von Kummer, 1984; Lee et al., 1995) suggesting that the measurement of relative $\mathrm{CBF}$ changes by our method is accurate. From this we could conclude that this method of $\mathrm{CBF}$ assessment can be used to perform repetitive qualitative measurements of $\mathrm{CBF}$ and also to measure changes in blood flow in a semi-quantitative way (De Visscher et al, 2002b).

\section{Combining cerebral blood flow measurement with histological examination}

The developed method of CBF assessment described above needed further validation by comparing it with an established method of flow measurement. Since our method of CBF assessment is a whole brain BFI we needed to compare it with another method allowing measurement of the global CBF. Although different methods exist, most of them were not readily available. The method chosen, microsphere blood flow measurement (MS-flow) was a method already extensively used in one of the laboratories involved (Herijgers et al., 1996). Before using this technique for the validation of the above described BFI, we developed the MSflow technique in to a method allowing both $\mathrm{CBF}$ measurement and histological examination. This allowed the evaluation of the microsphere distribution and route of microsphere injection prior to its use as a validation comparison. This technique consisted of the injection of two subsequent injections of a different colour of fluorescent microspheres into the left ventricle of a rat heart. Others (Nakai et al., 1990) have shown that for CBF measurement the optimal route of left ventricle cannulation went via the right brachial artery, with which we concur. After both injections the animal was transcardially perfused with paraformaldehyde for fixation of the brain. The number of both colours of microspheres was counted on contiguous brain sections. 
The brain volume was obtained by image analysis. One of the problems encountered with this technique was loss of microspheres in the filtration of the reference samples, which yielded overestimated $\mathrm{CBF}$ values. This was later solved by three subsequent filtrations of the same reference sample, resulting in a $>97 \%$ yield of microspheres. The number of microspheres in the reference sample was obtained by counting the microspheres on the three filters. Finally the MS-flow was challenged by using a hypercapnia induced CBF increase. After the MS-flow measurement the sections could then be stained and histologically examined. The final technique can be very useful tool in correlating the flow in certain brain regions with the residual flow during a specific insult, here hypercapnia but possibly also stroke or neurotrauma. The method by itself is not causing disturbances in the cerebral blood flow. This is clearly shown by the absence of differences between both the hemispheric flow, in hypercapnic and normocapnic conditions, and the first and second flow measurement in the control animals. Furthermore, we clearly showed that the same and adjacent material could be used for histological examination after multiple flow measurement. (Chapter 4)

\section{Validation of the ICG derived blood flow index}

Having achieved and examined a rat preparation yielding a good microsphere distribution without $\mathrm{CBF}$ disturbances, we could return to the validation of the BFI. The first part assessed the influence of different blood volumes on the BFI. Since the blood volume is linearly related to the body weight, groups of animals with different bodyweight were used. Using regular and low body weight rats a clear increase in BFI could be seen in the lighter animals. From hereon the body weight corrected $\mathrm{BFI}$ or $\mathrm{BFI}_{w}$ that did not show this increase was used. The behaviour of the $\mathrm{BFI}_{w}$ was studied in different flow conditions, all except the controls obtained by either $\mathrm{CO}_{2}$ breathing or l-NAME administration. With this we clearly demonstrate that the $\mathrm{BFI}_{w}$ method of $\mathrm{CBF}$ assessment can be used to detect dose-dependent changes in $\mathrm{CBF}$. From this part the highest dose of both $\mathrm{CO}_{2}$ and I-NAME together with the control were chosen for the final validation. Since no histological examination was necessary we made use of coloured microspheres. Both tissue and reference samples were digested and filtered for microsphere retrieval. From hereon the dye extraction method first described by Kowallik and co-workers in 1991 was used. The MS-flows of these groups were clearly different with low, normal and high flows in the I-NAME, control and $\mathrm{CO}_{2}$ group, respectively. For the comparison of both measurements the analysis described by Bland and Altman (1986) was used. This method is specially designed for comparison of two methods measuring the same variable. One problem with this approach is the one measurement yields an absolute value, while the other is an index. A linear regression formula was used for the conversion of the index to its absolute value, thus 
enabling Bland and Altman analysis. The mean difference between measurements equals zero indicating that the average MS-flow can be accurately calculated from the $\mathrm{BFI}_{\mathrm{w}}$ with the aid of the linear regression formula. As the differences were normally distributed, a good prediction of MS-flow can be made for a sufficiently large group of animals over the range of flows that was covered in this study. Since the $95 \% \mathrm{Cl}$ is notable the prediction of individual MS-flow values from the $\mathrm{BFI}_{w}$ data may be less accurate. Possible variability, intrinsic to the microsphere technique may also be a contributing factor in this respect. In general we can conclude that application of multi wavelength NIRS to measure the transit of an ICG bolus through the brain is a valuable method to assess global $\mathrm{CBF}$. The BFI calculated from the bolus transit curve and corrected for blood volume (via body weight) is an accurate predictor of global CBF as measured with the microsphere technique (Chapter 5). Ultimately when the arterial ICG function can be determined an absolute flow measurement can be obtained with multiwavelength NIRS.

\section{Cerebellar ICP measurement: an alternative for cerebral ICP measurement}

A next variable, intracranial pressure or ICP, was studied because it is one of the variables which is predictive in the outcome of neurotrauma. Extensive research in this field has already been performed by our lab (Engelborghs et al., 1997, De Mulder et al., 2000). Combining this technique with NIRS monitoring of perfusion and brain oxygenation would enable a more extensive study of our closed head injury model and its possible use in pharmaceutical research. As stated before NIRS requires a bleeding free preparation, thus insertion of the ICP probe in the cerebrum is very unlikely to give acceptable results in the NIRS monitoring. In order to obtain a different site of ICP monitoring the correlation between the cerebral and cerebellar ICP was studied. Therefore, both measurements were performed simultaneously in each rat. The range of ICP was enlarged by including both control and neurotrauma rats. The closed head injury was obtained by dropping a weight $(400 \mathrm{~g}$ ) from $50 \mathrm{~cm}$ or $70 \mathrm{~cm}$ height onto the rats head, thus obtaining moderate or severe neurotrauma, respectively. Here again, Bland and Altman analysis was used to compare both sites of ICP measurement. This analysis showed that the ICP measured at both sites is actually the same. If the novel technique measures the same ICP as the established technique it should also respond to changes in ICP in the same way. Although this experiment was not specially designed to study these responses, we looked at normally occurring ICP changes over time with both techniques and compared those. This lead to the conclusion that both methods of ICP measurement behave in a similar way when ICP changes occur. To conclude; in experimental studies in rats, where insertion of a cerebral probe should be avoided, cerebellar ICP measurement is a very useful and valuable alternative to the cerebral ICP measurement (Chapter 6). 


\section{Cerebral metabolic rate of oxygen in the rat}

For the final variable necessary to obtain a total view on the cerebral oxygen house-holding we needed to enable calculation of the cerebral metabolic rate of oxygen. Since we had previously validated a measure of $\mathrm{CBF}$ the only supplementary requirement was to obtain a blood sample from the venous outflow of the brain. Different routes of venous blood sampling were available (Ito et al., 1995; Cooper et al., 1998) but the final route we used was sampling from the sagital sinus. As was the case for ICP measurement the cannulation of the sagital sinus needed to be bleeding free in order to allow NIRS. An easy and bleeding free rat preparation was achieved that allowed simultaneous NIRS monitoring and venous blood sampling from the brain. This preparation and the $\mathrm{CmrO}_{2}$ calculated from the arterio-venous difference in oxygen concentration and the BFI was then studied in control, neurotrauma, pentobarbital (Nembutal) treated and neurotrauma with pentobarbital treatment rats. Pentobarbital induced respiratory suppression. a previously described effect of this barbiturate (Wixson et al., 1987; Wilson et al., 1993), in both pentobarbital (Nembutal) treated and neurotrauma with pentobarbital treatment animals. Pentobarbital showed marked decreases in cerebral blood flow and $1 \mathrm{CmrO}_{2}\left(\mathrm{CmrO}_{2}\right.$ calculated with the $\mathrm{BFI}_{w}$ as a cerebral blood flow measure) concurrent with the findings of Hyder and coworkers (2000). The neurotrauma animals only show a significant difference from the control for its venous blood oxygen saturation $\left(\mathrm{SvO}_{2}\right)$, although other differences were eminent they were confounded by two factors. The first one is the increased variability in the closed head injury (CHI) model and the second one the exclusion criteria that probably resulted in an over-selection of animals with only minor or no damage. The fact that pentobarbital administration after $\mathrm{CHI}$ did not cause additional decreases in cerebral blood flow and oxygen metabolism is indicative for disturbed haemodynamics and vascular reactivity in the $\mathrm{CHI}$ animals.

The correlation analysis between venous blood oxygen saturation $\left(\mathrm{SvO}_{2}\right)$ and the NIRS derived cerebral blood oxygen saturation $\left(\mathrm{SmcO}_{2}\right)$ resulted in a redistribution of the animals into two subgroups. The first group were rats with both partial oxygen pressure in the venous blood $\left(\mathrm{PvO}_{2}\right)$ measurements above $50 \mathrm{mmHg}$ and the second contained rats at least $1 \mathrm{PvO}_{2}$ measurement below this criteria. In the first group we found an excellent correlation between $\mathrm{SvO}_{2}$ and $\mathrm{SmcO}_{2}$, thus enabling an accurate $\mathrm{CmrO}_{2}$ measurement without invasive sagital sinus blood sampling. In the other group no such correlation was found. Therefore it is necessary to obtain a venous blood sample for $\mathrm{CmrO}_{2}$ measurement in these animals. We also showed that the latter group only contained $\mathrm{CHI}$ animals and that they were significantly more represented within this group as compared to non $\mathrm{CHI}$ animals. Finally we looked for additional differences between the groups confirming that they were different. From all variables tested $62 \%$ were significantly different. Selecting for variables measured at the onset of the experiment 9 were entered in a multivariate 
analysis of which 6 were retained. The most usable because of distinctive power was MABP, where a $85 \mathrm{mmHg}$ boundary could be used to devide between groups (Chapter 7). 


\section{Applications and future prospects}

The current developments contributed to the study of cerebral oxygen house-holding measure with NIRS. State of the art NIRS allowed studying certain aspects such as blood and cellula oxygenation in rats. We supplemented the technique in the assessment of certain important clinici variables, namely cerebral blood flow, metabolic rate of oxygen metabolism and intracrania pressure. The final application would be to combine all previously described techniques int one experiment were all variables could yield a complete insight into the cerebral oxygenation perfusion and metabolism in the rat. A first experiment which would combine these technique has already been planned and partially performed. This experiment includes monitoring of th standard NIRS variables, namely the concentrations of oxyhaemoglobin, deoxyhaemoglobil and cytochrome oxidase, combined with ICG flow assessment, ICP-monitoring and venou blood sampling for $\mathrm{CmrO}_{2}$, calculation. The experiment also includes a comparison between the standárd 'treatment tor neurotrauma as well as neurotrauma itself. Besides the sham and $\mathrm{CHI}$ groups, four treatment groups were included. Both mannitol and Nembutal were used as standard clinical treatment. Another group comprised of animals receiving $100 \%$ oxygen as breathing gas was included as a surrogate for treatment with hyperventilation, a widely used therapeutic strategy (Ghajar et al., 1995; Meyer et al., 1999). The last group we included was I-NAME treatment that served as a positive control because of its known effects on the NIRS variables, ICP and MABP. In general we can state that it is possible to measure all variables at the same time in one animal, but that closed head injury often resulted in the inability to cannulate the sagital sinus in the rat.

Finally, in doing these and forthcoming experiments a lot of knowledge and information concerning the oxygen supply and metabolism of both normal brain and cerebral pathology in rat was and can be obtained. This is interesting in basic research were the unravelling of mechanisms involved in pathology are concerned as well as in the more applied science of pharmaceutical research. Secondarily, since the latter has a higher turn over the fact that a less expensive experimental animal is used compared with the previous use of pigs (Kuebler et al., 1998), piglets (Springett et al., 2000), cats (Ferrari et al., 1995) or calf (Pringle et al., 1998) is also contributing to the usability of this technique. As a general conclusion we can state that within this thesis we have achieved to contribute to the application and validation of near infrared spectroscopy in general and more specifically in the rat. 


\section{References}

Bland JM, Altman DG (1986) Statistical methods for assessing agreement between two methods of clinical measurement. Lancet 1(8476) 307-310.

Buchanan JE, Phillis JW (1993) The role of nitric oxide in the regulation of cerebral blood flow. Brain. Res. 610: 248-255.

Cooper CE, Delpy DT, Nemoto EM (1998) The relationship of oxygen delivery to absolute haemoglobin oxygenation and mitochondrial cytochrome oxidase redox state in the adult brain: a near-infrared spectroscopy study. Biochem. J. 332(Pt 3) 627-632.

De Mulder G, van Rossem K, Van Reempts J, Borgers M, Verlooy J (2000) Validation of a closed head injury model for use in longterm studies. Acta Neuroch. Suppl. 76: 409-413.

De Visscher G, Springett R, Delpy DT, Van Reempts J, Borgers M, van Rossem K (2002a) Nitric oxide does not inhibit cerebral cytochrome oxidase 'in vivo' nor in the reactive hyperaemic phase post brief anoxia in the adult rat. J. Cereb. Blood Flow Metab. 22(5): 515-519.

De Visscher G, van Rossem K, Van Reempts J, Borgers M, Flameng W, Reneman RS (2002b) Cerebral blood flow assessment with indocyanine green bolus transit detection by near-infrared spectroscopy in the rat. Comp. Biochem. Physiol. A 132(1): 87-95.

Elwell CE, Cope M, Edward AD, Wyatt JS, Delpy DT, Reynolds EOR (1994) Quantification of adult cerebral hemodynamics by near infrared spectroscopy. J. Appl. Physiol. 77(6): 2753-2760.

Engelborghs K, Verlooy J, Van Deuren B, Van Reempts J, Borgers M (1997) Intracranial pressure in a modified experimental model of closed head injury. Acta Neurochir. suppl. 70: 123-125.

Estevez AY, Phillis JW (1997) Hypercapnia-induced increases in cerebral blood flow: roles of adenosine, nitric oxide and cortical arousal. Brain Res. 758: 1-8.

Ferrari M, Williams MA, Wilson DA, Thakor NV, Traystman RJ, Hanley DF (1995) Cat brain cytochrome-c oxidase redox changes indiced by hypoxia after blood-fluorocarbon exchange transfusion. Am. J. Physiol. 269: 417-424

Ghajar J, Hariri RJ, Narayan RK, lacono LA, Firlik K (1995) Patterson R.H. Survey of critical care management of comatose, head-injured patients in the United States. Crit. Care Med. 23(3): 560-567.

Herijgers P, Leunens V, Tjandra-Maga TB, Mubagwa K, Flameng W (1996) Changes in organ perfusion after brain death in the rat and its relation to circulating catecholamines. Transplantation 62: 330-335.

Hobbs AJ, Gibson A (1990) L-NG-nitro-arginine and its methyl ester are potent inhibitors of non-adrenergic, noncholinergic transmission in the rat anococcygeus. Brit. J. Pharmacol. 100(4): 749-52.

Horvath I, Sandor NT, Ruttner Z, McLaughlin AC (1994) Role of nitric oxide in regulating cerebrocortical oxygen consumption and blood flow during hypercapnia. J. Cereb. Blood Flow Metab. 14(3): 503-509.

Hyder F, Kennan RP, Kida I, Mason GF, Behar KL, Rothman D (2000) Dependence of oxygen delivery on blood flow in rat brain: a 7 tesla nuclear magnetic resonance study. J. Cereb. Blood Flow Metab. 20(3): 485-498.

ladecola C, Pelligrino DA, Moskowitz MA, Lassen NA (1994) Nitric oxide synthase inhibition and cerebrovascular regulation. J. Cereb. Blood Flow Metabol. 14: 175-192.

Ito H, Koyama M, Goto R, Kawashima R, Ono S, Atsumi H, Ishii K, Fukuda H (1995) Cerebral blood flow measurement with iodine-123-IMP SPECT, calibrated standard input function and venous blood sampling. J. Nucl. Med. 36(12): 2339-2342.

Kowallik P, Schulz R, Guth BD, Schade A, Paffhausen W, Gross R, Heusch G (1991) Measurement of regional myocardial blood flow with multiple colored microspheres. Circ. 83(3): 974-982.

Kuebler WM, Sckell A, Habler O, Kleen M, Kuhnle GEH, Welte M, Messmer K, Goetz AE (1998) Noninvasive measurement of regional cerebral blood flow by near-infrared spectroscopy and indocyanine green. J. Cereb. Blood Flow Metabol. 18: $445-456$ 
Lee JG, Smith JJ, Hudetz AG, Hillard CJ, Bosnjak ZJ, Kampine JP (1995) Laser-doppler measurement of the effects of halothane and isoflurane on the cerebrovascular CO2 response in the rat. Anesth. Analges. 80: 696-702.

Meyer P, Legros C (1999) Orliaguet G. Critical care management of neurotrauma in children: new trends and perspectives Childs Nerv. Syst. $15(11-12):$ 732-739.

Nakai M, Tamaki K, Yamamoto J, Shimouchi A, Maeda M (1990) A minimally invasive technique for multiple measurement of regional blood flow of the rat brain using radiolabeled microspheres. Brain Res. 507: 168-171.

Owen-Reece H, Smith M, Elwell CE, Goldstone JC (1999) Near infrared spectroscopy. Brit. J. Anaesth. 82(3): 418-426.

Prado R, Watson BD, Wester P (1993) Effects of nitric oxide synthase inhibition on cerebral blood flow following bilateral carotid artery occlusion and recirculation. J. Cereb. Blood Flow Metabol. 13: 720-723.

Pringle J, Uystepruyst C, Art T, Lekeux P (1998) Continuous and non-invasive study of brain oxygenation in the calf by near infrared spectroscopy. Res. Vet. Sci. 65: 239-244.

Rees DD, Palmer RMJ, Schulz R, Hodson HR, Moncada S (1990) Characterization of three inhibitors of endothelial nitric oxide synthase in vitro and in vivo. Brit. J. Pharmacol. 101: 746-752.

Springett R, Wylezinska M, Cady EB, Cope M, Delpy DT (2000) 0xygen dependency of cerebral oxidative phosphorylation in newborn piglets. J. Cereb. Blood Flow Metab. 20: 280-289.

von Kummer $A$ (1984) Local vascular response to changes in carbon dioxide tension. Long term observations in the cat's brain by means of hydrogen clearance technique. Stroke 15(1): 108-114.

Wilson RP, Zagon IS, Larach DR, Lang CM (1993) Cardiovascular and respiratory effects of tiletamine-zolazepam. Pharmacol. Biochem. Behav. 44(1): 1-8.

Wixson SK, White WJ, Hughes HC, Lang CM, Marshall WK (1987) The effects of pentobarbital, fentanyl-droperidol, ketamine-xylazine and ketamine-diazepam on arterial blood $\mathrm{pH}$, blood gases, mean arterial blood pressure and heart rate in adult male rats. Lab. Anim. Sci. 37(6): 736-742. 
Summary 
As an introduction (chapter 1) we describe the general physical background of near infrared spectroscopy (NIRS) as well as an extensive description of our NIRS-system. Starting from the most basic form of spectrophotometry, as described by the Beer-Lambert law, the developments of the current in vivo NIRS are presented. Two basic mechanism involved in the decrease in light intensity measured by a detector are absorption and scattering. The first occurring when light is absorbed by a molecule in the solution and the second occurring at boundaries where two media with a differential diffraction coefficient meet. The somewhat more complex scattering phenomenon causes both loss of light due to photon deflection out of the detectors range and lengthening of the pathway, thus increasing the measured volume. The fully described multi wavelength NIRS-system we use assumes that the loss of light is on average the same and accounts for the lengthening in pathlength by assessing the absorption of water in the area of the spectrum of interest. This system allows assessment of the concentrations of oxy-, deoxy- and total haemoglobin, changes in the concentration of oxidised cytochrome oxidase and finally the detection of a tracer compound, indocyanine green. In general this thesis is comprised of studies set up to develop and validate the use of NIRS in small experimental animals combined with assessment of other clinically relevant parameters. Regarding the latter we mainly focused on the difficulties encountered in assessing simultaneously NIRS-parameters on the one hand and intracranial pressure and cerebral oxygen metabolism on the other. NIRS measurements, after all, may be disturbed due to the insertion of a pressure probe or a sagital sinus sampling catheter.

Furthermore, we describe a modified microsphere technique for blood flow assessment. In short, the microsphere technique is based on the injection of labelled microsphere into the heart after which they get dispersed through the body and embolise microvessels. The microspheres in the tissue of interest are then counted and compared to the microspheres obtained in an artificial organ, the flow of which is known. In a later stage this technique was used for the validation of the $\mathrm{CBF}$ assessment as performed with NIRS.

In a first study in the rat (chapter 2) we investigated the changes in the NIRS-variables following a pharmacological intervention and a pathophysiological event, enabling detailed evaluation of the NIRS-system as available at that time-point. Administration of the nitric oxide (NO) synthase inhibitor I-NAME showed that some of the measured NIRS variables were altered by this intervention. More specific I-NAME increased the mean arterial blood pressure and decreased the saturation of the cerebral blood, most probably both caused by arterial vasoconstriction. Since this intervention did not alter the redox state of cytochrome oxidase, we could not conclude whether NO does inhibit cytochrome oxidase in vivo, since certain mechanisms of NO-production do only occur after a prolonged post-insult period. 
As a pathological event, anoxia of the brain of the rat resulted in major changes in the measured NIRS-variables. During anoxia clear decreases in cytochrome oxidase and oxyhaemoglobin and increases in deoxyhaemoglobin and total haemoglobin were observed. It was concluded that the NIRS-technique can measure both minor and major differences, but certain shortcomings were also apparent after this study. The most important were the inability to assess cerebral blood flow $(\mathrm{CBF})$ and the cerebral metabolic rate of oxygen $\left(\mathrm{CmrO}_{2}\right)$ in small experimental animals.

Therefore, we devised a method to assess CBF by means of NIRS in small experimental animals (chapter 3). A NIRS-detectable compound, indocyanine green (ICG), was used as an intravascular tracer, yielding bolus transit curves. From these we could calculate a blood flow index (BFI). Initially, we established the use of an ICG-bolus yielding a good signal to noise ratio and causing only minor interference with the basic NIRS variables. Behaviour of NIRSdetermined BFI was assessed in animals, subjected to a series of normocapnic (normal blood $\mathrm{CO}_{2}$ concentration) and hypercapnic (increased blood $\mathrm{CO}_{2}$ concentration) $\mathrm{CBF}$ conditions. The results were in agreement with those obtained by other groups using similar conditions but alternative CBF measurements. We concluded that the NIRS-method can be used for repetitive and qualitative CBF assessment. This method however still needed validation.

In the search for validation of the BFI as determined with ICG, the following study was designed (chapter 4). It had a double aim. The first one was to evaluate the potential of the microsphere technique for CBF measurement in small experimental animals and consequently its use as reference technique. The second was to develop a microsphere technique enabling the assessment of CBF combined with histological examination of the brain. Microspheres were injected using an already published method of cannulation and counted in situ after brainsectioning. Calibration of the flow, using an adequate reference sample, remained problematic. We could show that three subsequent filtrations yielded an adequate estimate of microspheres in the reference sample. The distribution of microspheres in the brain was found to be homogenous. We again estimated flow under normocapnic and hypercapnic conditions and observed significant flow increases during hypercapnia. Finally, this technique was used in a model of incomplete ischemia and we demonstrated that this method of CBF assessment could be combined with histological evaluation of brain lesions.

Having shown that we could use the microsphere technique for CBF assessment in small experimental animals, we proceeded to the following study where we validated the determination of $\mathrm{BFI}$ by comparing to $\mathrm{CBF}$ as measured with the microsphere technique (chapter $\mathbf{5}$ ). In a first approach we evaluated the effect of the animals' body weight on the BFI, which lead to a weight corrected $\mathrm{BFI}$ calculation $\left(\mathrm{BFI}_{\mathrm{w}}\right)$. Additionally we studied the effect of both I-NAME 
and hypercapnia on $\mathrm{BFI}_{w}$, which clearly showed a dose dependent decrease and increase of flow, respectively. Finally we compared the $\mathrm{BFI}_{w}$ to the microsphere $\mathrm{CBF}$ assessment after quasisimultaneous injection of ICG and microspheres, we found that $\mathrm{BFI}_{\mathrm{w}}$ is an accurate predictor of global CBF.

Having a method of CBF assessment by means of NIRS at hand, we proceeded to another technical problem, being the simultaneous assessment of the NIRS variables and determination of intracranial pressure (chapter 6). In this respect we compared the ICP measured in the cerebrum and in the cerebellum. The advantage of cerebellar ICP is that insertion of the pressure transducer into this part of the brain does not interfere with the NIRS measurement in the cerebrum. A range of ICP values was obtained by subjecting rats to closed head injury ( $\mathrm{CHI}$ ), a proven model for increased ICP. Measuring ICP at both sites simultaneously revealed no differences in ICP-values and when changes, although generally small, occurred, both measurement changed accordingly. From these findings we concluded that the cerebellar site was a good alternative allowing the estimation of cerebral ICP simultaneously with the assessment of NIRS variables.

In the final study (chapter 7) the measurement of cerebral metabolic rate of oxygen $\left(\mathrm{CmrO}_{2}\right)$ by assessing sagital sinus blood saturation $\left(\mathrm{SvO}_{2}\right)$ and cerebral blood oxygen saturation $\left(\mathrm{SmcO}_{2}\right)$ by means of NIRS was evaluated. Using two models, pentobarbital administration and CHI, we found that in normal and pentobarbital treated animals $\mathrm{CmrO}_{2}$ could be assessed by means of the NIRS variable: $\mathrm{SmcO}_{2}$. This, however, was not the case in the majority of the CHIanimals, which still required sagital sinus blood sampling. Analysis of other indicative baseline parameters revealed predictive criteria for the requirement of sagital sinus cannulation in $\mathrm{CmrO}_{2}$ assessment.

In conclusion, in this thesis we have further developed and complemented NIRS-applications for their use in small experimental animals. In the final state NIRS will enable simultaneous monitoring of the concentrations of oxy-, deoxy- and total haemoglobin and changes in the concentration of oxidised cytochrome oxidase with either $\mathrm{CBF}, \mathrm{ICP}, \mathrm{CmrO}$, or any combination required for the study of pathophysiologal conditions or pharmacological intervention in small experimental animals. The final application is currently under study. 
Samenvatting 
Ter inleiding (Hoofdstuk 1) van deze thesis volgt allereerst een beschrijving van de fysische achtergrond van 'near infrared spectroscopy' (NIRS) gevolgd door een uitgebreide omschrijving van het door ons gebruikte NIRS-systeem. Als vertrekpunt van de huidige vorm van in vivo NIRS hebben we gebruik gemaakt van de meest eenvoudige vorm van spectrofotometrie, zoals deze beschreven wordt door de Beer-Lambert wet. Spectrofotometrie is gebaseerd op het meten van het verschil in intensiteit van licht voor en na dat het door een oplossing die een licht absorberende stof bevat is gegaan. Het verschil kan echter veroorzaakt worden door twee fysische verschijnsels namelijk absorptie en verstrooiing. Het eerste gebeurt als een foton of lichtdeeltje opgenomen wordt bij botsing met een molecule in de oplossing. Het tweede gebeurt als licht overgaat van het ene naar het ander medium dat elk van beide een andere diffractie coëfficiënt hebben. De licht verstrooiing is een complex fenomeen dat enerzijds resulteert in het verlies van licht door het afbuigen van het licht uit het detectiegebied en anderzijds resulteert in een verlenging van de afgelegde afstand van het licht. Dit laatste wil dan ook zeggen dat er een toename is van het gemeten volume. Het door ons gebruikte NIRS-systeem veronderstelt dat het gemiddeld verlies van licht constant is en berekent het verlengen van de afgelegde afstand aan de hand van lichtabsorptie van water in het 'near infrared' gebied. Dit systeem laat toe om de concentraties van oxy-, deoxy- en totaal hemoglobine te berekenen. Verder is het mogelijk om veranderingen in de concentratie van geoxideerd cytochroom oxidase, de finale electron-acceptor in de mitochondriale elektrontransport keten, te berekenen. Tevens kan ook de concentratie van indocyanine-groen, in deze context gebruikt om de cerebrale doorbloeding te meten, gedetecteerd worden. In het algemeen bevat deze thesis studies die bijdrage aan de ontwikkeling en validatie van het gebruik van NIRS in kleine experimentele dieren en het gebruik van NIRS in combinatie met het meten van andere klinisch relevante parameters. Wat deze parameters betreft hebben we ons voornamelijk toegelegd op de problemen die de simultane observatie van NIRS-parameters enerzijds en van de intracraniële druk en cerebraal zuurstof metabolisme anderzijds verhinderden, namelijk het inbrengen van respectievelijk een drukprobe en een sagitale sinus katheter.

Verder beschrijven we een aangepast microsphere techniek voor het meten van de hersendoorbloeding. In het kort is deze techniek gebaseerd op het injecteren van kleine sferen in de bloedstroom. Deze worden dan afhankelijk van de doorbloeding verdeeld over de het lichaam waar ze vast komen te zitten in kleine bloedvaten. Het aantal sferen in het weefsel van interesse is dan vergeleken met het aantal verkregen tijdens een bloedafname met constante en gekende afnamesnelheid. Op deze wijze kan de doorbloeding van het desbetreffende weefsel berekend worden. In een later stadium hebben we een variant van deze techniek gebruikt om de NIRSmethode voor het meten van de cerebrale doorbloeding te valideren. 
In de eerste studie (Hoofdstuk 2) in ratten hebben we de veranderingen van de NIRSveranderlijken na een farmacologische interventie en een pathofysiologisch insult bestudeerd. Dit liet ons tevens toe om een gedetailleerde evaluatie te maken van het NIRS-systeem bij de aanvang van deze thesis. Het toedienen van I-NAME een remmer van stikstof monoxide (NO) synthase resulteerde in het veranderen van sommige NIRS-variabelen. Stikstof monoxide (NO) synthase is een enzym dat instaat voor de productie van NO, onder meer een regulator van de arteriële tonus. Meer specifiek veroorzaakt I-NAME een stijging van de gemiddelde arteriële bloeddruk and desaturatie van het cerebrale bloed. Beide zijn het gevolg van vasoconstrictie van de cerebrale arteriën. Ten gevolge van het feit dat L-NAME geen veranderingen veroorzaakte in de redox-status van cytochroom oxidase konden we niet concluderen dat NO cytochroom oxidase inhibeert in vivo, want bepaalde mechanismen van $\mathrm{NO}$-productie treden pas veel later op na een insult.

Het door ons gebruikte pathologische insult, namelijk een korte anoxia of zuurstofgebrek van de rattenhersenen, resulteerde in ingrijpende veranderingen in de NIRS-variabelen. Deze anoxia veroorzaakte een duidelijke afname van de geoxideerde vorm van cytochroom oxidase alsook een afname van de hoeveelheid oxyhemoglobine. Anderzijds resulteerde het ook in een toename van deoxyhemoglobine en de totale hoeveelheid hemoglobine. Uit dit alles concludeerden we dat de NIRS-techniek toelaat om zowel kleine als grote verschillen te detecteren, maar de studie toonde ook een aantal gebreken of onvolmaaktheden van deze techniek aan. De belangrijkste waren dat het onmogelijk was om de hersendoorbloeding en het cerebrale zuurstofmetabolisme te meten in kleine experimentele dieren.

Daarom begonnen we met het ontwikkelen van een methode voor het meten van de hersendoorbloeding in kleine experimentele dieren, meer bepaald de rat (Hoofdstuk 3). Hiervoor gebruikten we indocyanine groen, een stof na inspuiting gelimiteerd tot het intravasculaire compartiment. Deze stof kan na aanpassing van het NIRS-systeem gedetecteerd worden en we verkrijgen dan bolus transit curven waaruit we een doorbloedingindex kunnen berekenen. Aanvankelijk hebben we nagegaan welke hoeveelheid indocyanine groen resulteert in een goede signaal/achtergrond verhouding gecombineerd met enkel kleine verstoringen van de ander NIRSvariabelen. Verder hebben we gekeken hoe de doorbloedingindex zich gedraagt bij normale en verhoogde hersendoorbloeding. Hiertoe werden metingen verricht bij normocapnische (normale $\mathrm{CO}_{2}$ concentratie in het bloed) en hypercapnische (verhoogde $\mathrm{CO}_{2}$ concentratie in het bloed) doorbloedingcondities. De gevonden resultaten waren in overeenstemming met die van andere groepen die de hersendoorbloeding gemeten hebben met andere technieken, maar onder dezelfde condities. Hieruit besloten we dat deze NIRS-methode gebruikt kan worden voor herhaaldelijke 
en kwalitatieve cerebrale doorbloedingmetingen. Wat echter nog vereist was om deze techniek te kunne gebruiken was een validatie.

Om de hierboven beschreven techniek te valideren hebben nog eerst een andere techniek bestudeerd en ontwikkeld (Hoofdstuk 4). Het doel van deze studie was dan ook dubbel, ten eerste de evaluatie van de microsfeer techniek voor het meten van hersendoorbloeding in kleine experimentele dieren en als dusdanig ook het gebruik ervan als referentie techniek. Ten tweede wilden we tegelijkertijd ook een techniek ontwikkelen die toelaat om zowel de hersendoorbloeding als microscopisch de hersenstructuur te bestuderen. De injectie van de microsferen gebeurde op een reeds door anderen gepubliceerde manier. De sferen werden echter geteld in situ op hersencoupes, als dusdanig kunnen deze dan nog gebruikt worden voor analyse van de hersenstructuur. Doch de calibratie, aan de hand van het referentiestaal, van de hersendoorbloeding bleef problematisch, maar uiteindelijk bleek dat na drie filtraties er genoeg microsferen werden terug gewonnen om de werkelijke doorbloedingwaarde te benaderen. Verder vonden we ook dat de microsfeerverdeling in de hersenen vrij homogeen was. Zoals in de vorige studie werd er terug gekeken naar normale en hypercapnisch verhoogde hersendoorbloeding. Ook hier vonden we een ingrijpende toename in de hersendoorbloeding tijdens hypercapnie. Uiteindelijk hebben we deze techniek ook gebruikt in een incompleet ischemiemodel, dit wil zeggen in een model van verminderde doorbloeding. In dit model toonden we aan dat het meten van de cerebrale doorbloeding ook gecombineerd kon worden met de histologische evaluatie van de hersenschade.

Nu we aangetoond hadden dat de microsfeertechniek konden gebruiken voor het bepalen van de hersendoorbloeding in kleine proefdieren, hebben we een studie opgezet ter validatie van de reeds eerder beschreven doorbloedingindex (Hoofdstuk 5). Hiertoe hebben we de beide beschreven technieken met elkaar vergeleken. Eerst hebben we het effect van het lichaamsgewicht op de doorbloedingindex bestudeerd. Dit leidde tot het uitvoeren van een gewichtscorrectie op de doorbloedingindex. Verder bestudeerden we het effect van zowel l-NAME als hypercapnie op de gecorrigeerde doorbloedingindex, wat resulteerde in een respectievelijke dosis afhankelijke afname en toename van de hersendoorbloeding. De uiteindelijke validatie bestond uit het quasi simultaan injecteren van zowel de ICG-bolus als de microsferen. Hieruit konden we concluderen dat de gecorrigeerde doorbloedingindex een accurate voorspeller is van de hersendoorbloeding zoals deze gemeten wordt met de microsfeertechniek.

Nu we een techniek hadden om de hersendoorbloeding te meten door middel van het NIRSsysteem, gingen we verder met het oplossen van het volgende technische probleem, namelijk het tegelijkertijd meten van de NIRS-variabelen en het bepalen van de intracraniële druk 
(ICP: Hoofdstuk 6). Hiertoe vergeleken we de ICP gemeten in het cerebrum met deze gemeten in het cerebellum. Het voordeel van het meten van de intracraniële druk in het cerebellum is dat het inbrengen van de drukprobe in dit deel van de hersenen niet interfereert met de NIRSmetingen in het cerebrum. Door de ratten te onderwerpen aan 'closed head injury', een bewezen model van verhoogde intracraniële druk, werd een groter bereik van ICP-waarden bekomen. De intracraniële drukken gemeten op beide plaatsen toonden geen verschillen. Verder vonden we dat bij drukveranderingen de druk op beide plaatsen op dezelfde wijze verandert. Uit deze gegevens konden we concluderen dat het meten van de intracraniële druk in het cerebellum een goed alternatief is dat toelaat om de intracraniële druk te meten simultaan met de NIRS-variabelen.

In laatste studie (Hoofdstuk 7) evalueerden wij het bepalen van het cerebrale zuurstofmetabolisme aan de hand van de saturatie van een sagitale sinus bloedstaal en de zuurstofsaturatie van het cerebrale bloed gemeten met het NIRS systeem. Hiertoe gebruikten we twee modellen, namelijk het toedienen van pentobarbital en 'closed head injury'. We vonden dat zowel in de normale ratten als in de ratten die pentobarbital kregen het cerebrale zuurstofmetabolisme berekend kon worden aan de hand van de NIRS-variabele: zuurstofsaturatie van cerebrale bloed. Doch in de trauma-ratten vonden we dat dit voor het merendeel van de dieren niet mogelijk was, zodat het nog steeds noodzakelijk is om hier een bloedstaal te nemen uit de sagitale sinus. Verdere analyse van de gemeten variabelen toonde aan dat er andere eenvoudig te bepalen parameters waren die predictief waren voor het al dan niet noodzakelijk zijn van een sagitaal bloedstaal.

Ter conclusie van deze thesis kunnen we zeggen dat wij de NIRS-techniek verder ontwikkeld en aangevuld hebben voor het gebruik in kleine proefdieren. Uiteindelijk laat NIRS ons nu toe om in kleine proefdieren de oxy-, deoxy- and total hemoglobine concentraties en veranderingen in de concentratie van geoxideerd cytochroom oxidase simultaan te meten met de hersendoorbloeding, de intracraniële druk, het cerebrale zuurstofmetabolisme of een combinatie van deze variabelen en parameters. Deze laatste toepassing is momenteel dan ook onder evaluatie. 


\section{Dankwoord}


Allereerst wil ik mijn beide promotoren bedanken. Prof. Dr. Marcel Borgers heeft mij de kans geboden om binnen dit boeiende onderzoeksterrein een thesis uit te bouwen en om binnen Janssen Research Foundation ervaring op te doen met pharmaceutische industrie. Prof. Dr. Robert S. Reneman zijn immer critische aanwijzingen zowel tijdens mijn onderzoek als het opstellen van de manuscripten waren zeer zeker welkom. Het was altijd een verassing om te zien vanuit welke uithoek van de wereld de correcties naar mij gefaxt werden.

Als co-promoter en begeleider vanuit de Janssen Research Foundation wil ik Dr. Koen A. van Rossem, bedanken voor zijn inzet. Het waren steeds interessante gesprekken en discussies die we voerden en die mijns inziens veel bijgedragen hebben tot de ontwikkeling van het project en de thesis. Hij stelde steeds de meest exotische dierenpreparaties voor die dan uiteindelijk ook nog bleken te werken. Dit heeft veel bijgedragen tot ontwikkeling van mijn handigheid met dierpreparaties en 'problem-solving', en tot het opvangen van mijn totaal gebrek aan geduld.

Voor mijn stage in het 'Department of Medical Physics and Bioengineering' aan het University College London wil ik allereerst Prof. Dr. David T. Delpy bedanken voor de introductie in het NIRS onderzoeksdomein. Ook Dr. Roger Springett en zijn echtgenote Dr. Yasuko Sakata dank ik voor de fijne en toch wel productieve samenwerking.

Tevens dank ik Prof. Dr. Willem Flameng voor de interesse en de samenwerking op het gebied van de microsferen techniek.

Prof. Dr. Fred De Clerck wens ik te bedanken voor het overnemen van het project en de support op het einde toen de afdeling Life Sciences ontmanteld werd ten gevolge van herstructureringen binnen JRF.

Wie ik zeker niet mag vergeten zijn Dr. Gert De Mulder en zijn opvolger Dr. Servan Rooker. Beide zijn in opleiding als neurochirurg en deden voltijds onderzoek in verband met hersentrauma. Gert wil ik voornamelijk bedanken voor het bijbrengen van het diermodel en de problematiek van neurotrauma. Servan dank ik voor de fijne samenwerking ook tijdens de weekends, die hoofdzakelijk dienden om gigantisch veel data te genereren in zo weinig mogelijk tijd.

Verder wil ik ook de nogal licht ontvlambare Marc Haseldonckx en de immer relativerende Bruno Van Deuren bedanken voor het bijbrengen van de chirurgische technieken die ik dagelijks nodig had om dit project tot een goed einde te brengen. Wat betreft het snijden van hersencoupes en het aanleren hiervan ben ik zeker dank verschuldigd aan Mies van de Ven. 
Fred Thoné bedank ik voor het tellen van de microsferen en het snijden van de fijne coupes, nodig voor de evaluatie van de hersencellen.

Met alle anderen: An, Andre, Christopher, David, Edwin, Eddy, Els, Gerrit, Greet DK, Henk, Ilse, Jo, Jos, Lambert, Luc, Marie-Jeanne, Peter B, Peter VO, Rene, Roger, Tina,... was het prettig samenwerken, waarvoor mijn dank.

Veerle Leunens van het Centrum voor Experimentele Heelkunde en Anaesthesiologie, dank ik voor de analyse van het tweede microsfeer experiment.

Ook mijn familie wil ik bedanken voor de steun en interesse. Mijn zus Géraldine dank ik bijzonder voor het extra werk dat ze mij bezorgde met de statistische analyse ter voorbereiding van haar thesis maar ik wens haar alvast succes in December. Mijn ouders en grootouders dien ik te danken voor het geduld dat ze moesten opbrengen om mij nog eens te zien, maar er is beterschap op komst.

'Last but not least' dank ik mijn echtgenote, Ine, en dochter, Nérée. Ik weet dat ik te veel met het project en deze thesis ben bezig geweest en dat ik Nérée, onze 9 maanden oude dochter nogal aan Ine heb overgelaten. Dit schijnt het onvermijdelijke lot van de wederhelft van thesisschrijvers te zijn. Bedankt voor het begrip en ook hier voorspelt de toekomst beterschap. Verder dien ik je ook nog te bedanken voor de grafische voorbereiding van deze thesis. Zo krijgt het oog ook wat. 


\section{Curriculum vitae}


De Visscher Geofrey werd geboren op 18 maart 1972 te Dendermonde. Het diploma van tet Secundair Onderwijs werd behaald aan het Koninklijk Atheneum III te Gent in 1990. Na een initiatie in de produktonwikkeling aan het Henry Van de Velde Instituut te Antwerpen ging hij in 1993 Biologie studeren aan de Vrije Universiteit van Brussel. Het diploma in de Humane Biologie werd in 1997 behaald met grote onderscheiding. Ook aan de VUB genoot hij vervolgens een IWT-overbruggingsbeurs van 3 maand en werd toen aangesteld als wetenschappelijk medewerker.

In 1999 werd hij aangesteld als Assistent in Opleiding in de vakgroep Moleculaire Celbiologie aan de Universiteit Maastricht op een door Janssen Research Foundation gefinancierd project onder de leiding van Prof. Dr. Marcel Borgers en Prof. Dr. Robert S. Reneman.

Sinds December 2001 is hij tewerkgesteld aan het Centrum voor Experimentele Heelkunde en Anaesthiologie onder leiding van Prof. Dr. Willem Flameng aan de Katholieke Universiteit Leuven. 


\section{List of publications}

\section{Abstracts}

De Visscher G., Szente M., Kirsch-Volders M. Genetic effects in neocortical cells of rats transplacentally exposed to mercury compounds. Mutation Research / Fundamental and Molecular Mechanisms of Mutagenesis 379(1), S129, 1997

\section{Articles}

Szász A., Barna A., Szupera Z., De Visscher G., Galbács Z., Kirsch-Volders M., Szente M. Chronic low-dose maternal exposure to methylmercury enhances epileptogenicity in developing rats. International Journal of Developmental Neuroscience 1S7(7), 733-742, 1999.

De Boeck M., Touil N., De Visscher G., Vande P.A., Kirsch-Volders M. Validation and implementation of an internal standard in comet assay analysis. Mutation Research 469, 181$187,2000$.

De Visscher G., van Rossem K., Van Reempts J., Borgers M., Flameng W., Reneman R.S. Cerebral blood flow assessment with indocyanine-green bolus transit detection by near infrared spectroscopy in the rat., Comparative Biochemistry and physiology 132(1), 87-95, 2002.

De Visscher G., Springett R., van Rossem K., Delpy D.T., Van Reempts J., Borgers M. Nitric oxide does not inhibit cerebral cytochrome oxidase in-vivo nor in the reactive hyperaemic phase post brief anoxia in the adult rat. Journal of cerebral blood flow and metabolism 22(5), 515-519, 2002.

De Visscher G., Leunens V., Borgers M., Reneman R.S., Flameng W., van Rossem K. Validation of $\mathrm{CBF}$ assessment by indocyanine green bolus transit detection with NIRS: a comparison with coloured microsphere flowmetry. (submitted)

De Visscher G., Haseldonckx M, Flameng W., Borgers M., Reneman R.S., van Rossem K. Fluorescent microsphere regional cerebral blood flow measurement in normal and hypercapnic rats. (in preparation) 
Servan Rooker, Geofrey De Visscher, Bruno Van Deuren, Marcel Borgers, Philippe Jorers, Robert S. Reneman, Koen van Rossem, Jan Verlooy. Comparison between intracranial pressure measured in the cerebral cortex and the cerebellum of the rat. (submitted)

Geofrey De Visscher, Servan Rooker, Philippe Jorens, Jan Verlooy, Marcel Borgers, Robert S.Reneman, Willem Flameng, Koen van Rossem. Assessment of saturation with oxygen of cerebral venous blood and estimation of the cerebral metabolic rate of oxygen in rats using near infrared spectroscopy. (in preparation) 
